


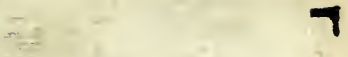

से

E

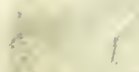

10

$1-$

is

e

r

5

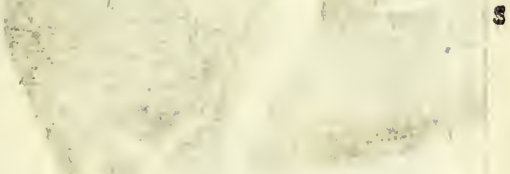




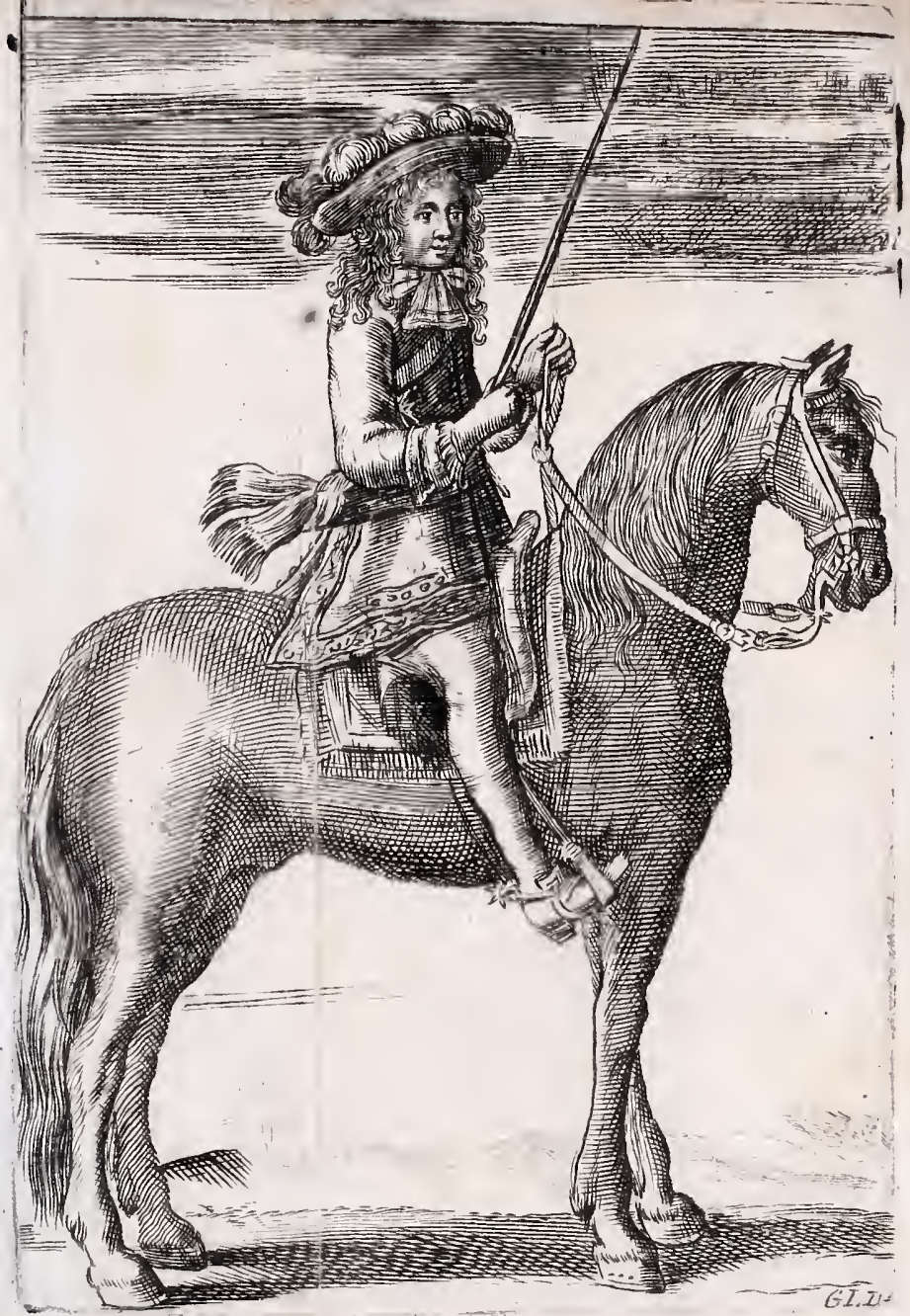




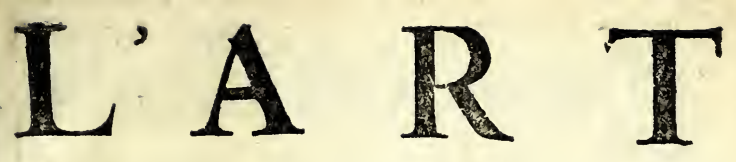

\section{E MONTER}

A

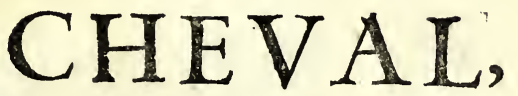

POUR ELEVER L A NOBLESSE dans les plus beaux Airs du Manege.

Enfeignée \& pratiquée par les Illuttres \& Fameux Ecuyers de France, tant pour les Voltes, Caprioles, Courbettes, Paffades, Sauts de terre à terre, Courfes de Bagues; que pour tout ce que le Cavalier doit fçavoir pour fe rendre habile homme de Cheval.

Avec les Figures neceffaires, \& les Remedes pour guerir les Maladies des Chevaux. Par $M^{r}$ DEL C AM PE, Ecryer du Roy: NOUVELLE EDITION.

\section{Coser)}

A PARIS,

Chez NICOLAS LE GRAS, aut troifiéme Pillier de la Grand' Salle du Palaie, à $l ' L$ couronnée.

M. DC. XCI. Avec Privilege din Rog. 



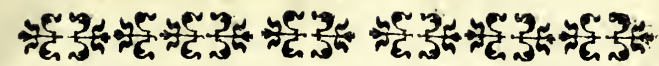

\section{T A B L E}

\section{DES C H A PITRE $S$.}

Vel doit estre l'Ecuyer, pag. 3 Les qualitez an bel bomme de cheval,

De la pofture du bel homme de Cheval, 7 $\mathrm{Ce}$ que doit f̧avoir le bon Cavalier tonchant l'ordre of le gouverniment d'une belle Ecurie,

Les chofes effentielles qui fe doivent pratiquer fans contredit dans l' Art de monter a Cheval,

20

De la difpofition que doit avoir celuy gui veut embrafer l'Art de monter à Cbeval,

Ce qu'il faut que fyache le Cavalier toschant tout l'équipage of harrois de for Cheval,

Ce que c'eft que Manege,

Ce que c'eft que volte,

Ce que c'eft que Carriere,

Ce que c'eft gue Paffades.

Du bean Cibeval,

Connoiffance certaine de l'áge duCheval, depuis Sa naifjance jusques à la fin de $\int$ so vie, 


\section{TABLE DES CHAP.}

L'Eguipage neceffaire à un Manege, 53 Des Emboucheures des Chevaux,

Le moyen de connoiftre le naturel des Chevasix,

63

Iescbofes qu'il faut abfolument que $\int \zeta_{\zeta} a-$ che le bon Cavalier,

70

Les chaftimens of les aydes que l'on donne anx Chevaux, of leur difference, 74

Pour connoiftre fi un Cheval eft dreffé, 75 Ce qu'il faut qu' un Cavalier $\int c_{\text {gache }}$ pour $\int_{e}$ dire bon bomme de Cheval,

$\boldsymbol{L}$ e moyen de drefferles Chevanx, Des Pafjades de la main à la main, 110

Des Piroiiettes,

II2.

Le moyen de mettre un Cheval Jur les Voltes,

Pour achever un Cheval, II 4 Le nom de tous les Airs \& Maneges relevez, $13 \mathrm{I}$

De la Courfe de Bagme, Pour mettre \& commencer un Cheval à Capriolles,

De l'Air des Balotades, I59 Les Parties du Cheval les plus neceffaires de fgavoir au bon Cavalier, $\quad$ I86. Les endroits oil viennent ordinairement.les manx \& fuxions aux Chevanx, 189.

Fin de la premiere Partie. 

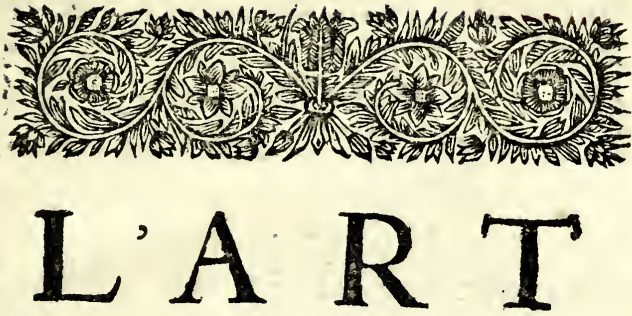

DE MONTER

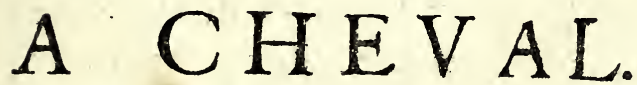

ou il est démontré par la belle metho. de, les moyens de fe pouvoir rendre bon homme de Cheval.

Chapitre Premier.

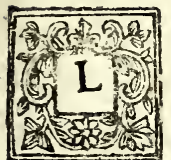

ORs que lon choifit un Maiftre de queique Arr ou Science qu'il profefle, on le doit juger capable de fon métier, \& avoir entiere creance en fa capacité : autrement il feroit impollible de rien apprendre. C'eft une regle qui 
doit refter pour conftante, \& ou il n'y a aucune exception: Il faut que le Maifte commande, \& que l'Ecolier obéiffe, \& qu'il pofe pour bafe infaillible \& principe affuré, que fon Maiftre fçait beaucoup plus que luy ce qui luy elt propre, \& pour ce feulement qu'il eit Maiftre, qui fuppofe fçavant. Lorfque les Ecoliers des Grecs avoient quelque difpute entr'eux, elle étciit terminée, lorfque l'un d'iceux pouvoit dire avec verité, le Maiftre l'a dit.

Tant il eft vray que nous devons avec docilité $\&$ refpect porrer creance $\&$ certaine affurance à ce que nos Maiftes nous enfeignent.

Lors donc que vous aurez faic élection du Maifte tel que jel'ay marqué , croyez-le abfolument, fi vous avez deffein de proficer en quelque Art, Science ou exercice que ce Loit. 


\section{cherat.}

\section{Chapitre İ́.}

\section{Quel doit être l'E:uyer.}

Et Art le plus excellent de ceux que l'on nomme liberaux, eft fi beau, fi noble \& fi attaché à la vertu, \& donne tant de pliafir aux Rois, aux Princes, Seigneurs \& Gentils-hommes, \& en un mot à tous les honneftes gens, qu'il feroit à fouhaicter que celuy qui le profoffe fùr d'extraction Noble, pour deux raifons. La premiere eft que fi Nuble fuppofe vertu, il feroit à défirer que l'Ecuyer für né Gincil-homme, afin qu'il fú plus vertueux. La feconde eft que cet exercice étant principalement pratiqué par quantité de perfonnes de condition relevée, il feroit beaucoup plus à p:opos que ce fút un Gentil.homme qui profelfat cet exercice, que non 
pas un homme de baffe naiffance, afin que les Ecoliers euffent nonfeulement plas de creance en un homme de condition, qu'en un de la lie du peuple, afin qu'ils luy obéiffent auffi avec plus de plaifir \& de refpect. Mais dautant que cela n'eft pas abfolument neceffaire, \& qu'en cas de befoin on peut apprendre de qui que ce foit, jen'infifteray pas davantage fur cette difference.

Mais je diray hardiment qu'il eft abfolument neceffaire que celuy qui enfeigne cet exercice foit fage, modefe, prudent, civil , \& bien éloigné d'être alcier, fuperbe ou glorieux, il doit être complaifant \& affible envers toutes fortes de perfonnes, $\&$ principalement à l'endroir des honneftes gens. 


\section{Chapitre III.}

Les qualitez requifes an bel or bon homme de cheral.

TL ne fuffit pas que celuy qui fait L profeflion d'cnfeigner ce noble exercice, foit doué des qualicez que jay marquées au Chapitre précedent, il faut qu'il en poffede beaucoup d'autres, fans lefquelles il luy feroit impollible de faire profiter fes Ecolicrs،

Il faut de neceffité qu'il fçache bien fon métier, c'eft-à-dire qu'il foit bon homme de cheval, tant de fa perfonne, que pour bien fçavoir la methode d'enfeigner fes Ecoliers: car le Droit \& l'experience nous apprend, que perfonne ne peut donner ce gu'il n'apas.

Il faur donc quill le fçache parfaitement; outre cela il eft neceffaire qu'il pollede cette facilité de

$$
\text { A iij }
$$


s'exprimer, qui s'appelle Railonnement, a fin que fes Ecoliers puilfent l'entendre, \& concevoir ce qu'ils doivent fçavoir, eftant tresvray que pour bien faire quelque chofe, il faut premierement $f_{\text {ça- }}$ voir ce que l'on veur faire, \& pour le bien faire il le faut entendre, $8 z$ c'elt ce qui ne fe peut, s'il n'a affez de fcience \& de raifonnement pour faire concevoir à fon Ecolier ce qu'il defire de luy. En outre, il doit être tres-patient: car s'il eft colere, il rend l'Ecolier timide, \& luy ôte le juggement, ee quil'empêche d'agir avec un fens raflis: $\&$ il arrive bien encore un aurre defordre, lorfque Ie Maifte, l'Ecolier \& le Cheval par leur impatience fe rendent incapables de raifon. Il fauc encore qu'il mon. tre également à fes Ecoliers, fans en favorifer l'un plus que l'autre, leur témoignant à tous la même affection, \& le femblable foin, afin de n'exciter aucune jaloufie parmy eur. 


\section{ChAPITRE IV.}

\section{De la Pofture du bel homme. de Cheval.}

N remarque trois chofes ne. ceflaires à la parfaice polture du bel homme de cheval.

Premierement, il doit être tresferme: Secondement, il doit être tres-vigoureux; En troifiéme lieu, il doit être tres-bien planté dans la felle, ou felon ce que difent quelques-uns, bien affis \& bien placé dans la felle: \& lors que le cheval fera en état de manier, il le doit conduire fans changer de polture, fans branler ou balancer le corps, ny de la main, ny les jambes, ny fans faire aucune mauvaife action ou grimace, lesépau. les également avancées, la tête haute $\&$ droite, la ceinture tant foit peu en avant, le corps enarA iiij 
riere, les jambes fermes \& bien tenduës, ny trop proches, ny trop éloignées du cheval, point de contrainte en aucune de fes attions, les Aydes auth delicares que prêtes, la main douce \& ferme., \& qui ne foit pas trop avancée vers les oreilies du cheval, mais bien ficuée, affez proche le pommeau de la felle, le poing de la bride droit, la contenance grave $\&$ hardie : car on dit ordinairement que le Cavalicr doit paroître un peu glorieux à cheval, \& fort humble 2 pied.

Encore qu'il ne poffedât toutes ces perfections, il ne refteroit d'être bon homme de cheval, combien qu'il feroit à fouhaiter qu'il les eút toutés au degré que je viens de décrire : Car il y a difference entre être bel homme de cheval, ou être bon homme de cheval; comme il y a aufli difference d'être bon homme de cheval, ou de bien fçavoir l'Art d'emboucher les 


\section{ì Cheval.}

chevaux: la difference de ce dernier paroît aufie, en ce que celuy qui les fçair bien emboucher, n'eft quelquefois pas capable de les dreffer ; \& celuy qui les fçait bien dreffer, n'eft quelquefois pas capable de bien enfeigner $\&$ donner leçon avec un jugement net $\&$ entier, \& facilité à fe bien exprimer $\&$ fuire entendre: mais s'il feren. controit un homme qui poffedât toutes ces perfections que je viens de dire, il fe pourroit avec raifon \& juftice nommer le Cavalier par. fait.

Chapitre V.

Ce que doit fgavoir le bon Cavalier, touchant l'ordre of le gouvernement d'une belle Ecurie.

TEs Rois, les Princes, les grands Seigneurs; $\&$ en un mot tous ceux en general qui ont une gran- 
de Ecurie, foit de chevaux entiers de manege, ou courreurs de chaffe, \& particulierement les Ecuyers tenans Academie de monter à cheval, doivent avoir un homme deftiné pour prendre le foin de leur Ecurie, profeflion qui n'eft pas peu penible, $8 z$ il eft neceflaire que celuy qui a befoin d'un tel homme, en fçache auffi faire le choix, eftant tres-vray que celuy qui en. treprend cette charge, doit être aufi vigilant quaffidu, \& qui faffe voir la verité, qui nous enfeigne, que l'ail du Maiffre engraijfe le Cheral.

C'eft-à-dire qu'il doit rarement quitter l'Ecurie, ayant toûjours les yeux ouverts \& la main levée pour bien faire travailler les Palfreniers, \& les tenir en leur devoir.

Il faut en outre qu'il entende en quelque façon les maladies dés Chevaux, du moins les plus ordinaires, afin que fon foin $\&$ vigi- 
lance y faffe fon devoir, ou qu'il y faffe promptement remedier par un bon Maréchal: il eft auffi befoin que cette même perfonne faffe connoître le nom $\&$ les infirnitez de chacun de fes Chevaux aux Palfreniers, afin que s'il y en avoit de dangereux du pied ou de la dent, que l'on ne les forte jamais de l'Ecurie fans fe bien précau tionner, \& lors que l'on les voudra panfer de la main, ou les faire ferrer, que l'on les attache fort court, que l'on leur fafle mettre le gros licol de corde, crainte de defordre.

Il ne doit pas auffi manquer de faire lever tous les jours les pieds de chacun de fes chevaux, \& voir de prés s'ils fone bien ferrez \& en érat de travailler : en un mot qu'il les vifite de telle forte, que le fer ne leur incommode point les pieds, foir pour être mal ferrez ou vieux ferrez, fi le fer ne déborde point, s'il ne leur ferre ou preffe pas 
trop les talons, s'il ne foule point $l_{2}$ folle, fi les rivez ne leur bleffent point lecôré des jambes, ou s'ils ne fe couppent, foir par lafircude, par le rravail, ou par quelque autre accident, comme aufi par la faute du Maréchal.

Les chevaux doivent être ferrez de neuf, ou du moins relevez tous les mois, \& avoir grand foin de leur faire bien parer le pied, \& leur tenir le talon bien ouvert.

Ceux qui ont trop de pied ou de corne, ne doivent être ferrez hors le befoin qu'en vieille Lune, ce qui s'appelle en décours : \& ceux qui one peu de pied ou mauvais pied, on les doit faire ferrer les trois ou quatre jours de la nourvelle Lune.

Il faut connoître les chevaux qui ont le pied fec ou aride, foit nacurellement ou par accident, à caufe du pavé fur lequel ils repofent, \& qu'ils fortent rarement de l'Ecurie, ou bien à caufe de leur 


\section{à Cherval.}

propre temperament. Tous ceux aufquels vous connoîtrez ce deffaut, il ne faudra manquer de leur faire feanter les pieds avec la feante de vache,deux jours devant que vous ayez deflein de les faireferrer, \& pour une plus cercaine precaution \& excellent ordre, vous ferez toûjours tenir à tels chevaux de leur fiente fous leurs pieds, \& qu'elle foit arroufée d'eau \& de vi. naigre : au contraire à ceux qui auront le pied tendre \& la corne molle, vous ferez fondre poix navalle $\&$ fuif de mouton portion égale, scleur en ferez fondre dans le pied, \& en oindre auffi coute la couronne, \& aux uns \& aux autres vous leur ferez frotrer les pieds de l'onguent appellé du bon pied: mais vous n'en graifferez que de l'épaiffeur d'un travers de doigt $\&$ au deffous du poil; en outre il faut $\int_{\text {ça voir }}$ que tout auffi-toft que le Cheval aura travaillé, foit au manége ou ailleurs, \& qu'il fera échauffé juf 
ques à la fueur, il faudra auffi-toft que l'on aura mis pied à terre, le faire conduire en fa place, \& luy faire mettre de la paille fraîche fous luy, puis fans le débrider, le faire deffeller au plutoft, \& luy faire bien avaller l'eau avec le coûteau de chaleur, puis le faut tres-bien faire effuyer $\&$ frotter avec de bonne paille fraîche le long des reins, fous le ventre, le long de l'encolleure, entre les jambes, foit devant, \& derriere, luy bien frotter la tête avec l'épouffette, puis vous luy remetrez la felle avec une couverture entrele poil \& ladite felle, puis vous luy ferez bien frotter les jambes, \& le laifferez bridé jufques à cequ'il foir bien fec: enfin vous luy ferez ôter la felle \& la bride, \& luy ferez donner deux ou trois coups d'étrille pour luy démêler le poil, \& abatre la poufficre, puis vous luy dennerez du foin, \&z une heure aprés vous le ferez boire, \& luy 


\section{à Cheval.}

donnerez l'avoine quelque temps aprés.

Il elt auffi de befoin de fçavoir bien faire penfer les chevaux de la main, ce qui fe doit faire en cette maniere. Vous ferez mettre vos chevaux au filet ou malticadour, puis vousles ferez tourner du cô. ré des pilliers, où vous aurez $\mathrm{fa}$ cilité de les faire étriller à vôtre plaifir : \& ainfi mâchant leur frain par l'action que leur donne l'étrille, ils fe purgeront le cerveau, \& auront la bouche fraîche \& é. cumante; aprés l'étrille, le bouchon de paille doir auffi faire fon office, tant au corps comme aux jambes, puis la broffe doit auffi être employée pour bien tirer la pouffiere, aprés vous prendrez l'épouffette pour leur adoucir le poil, puis en dernier lieu vous moüillerez bien vôtre main, \& frottez bien le cheval à poil \& à contre poil, afin de leur rendre tout-àfait uny \& luifant, puis aprés vous 
prendrez un bon peigne, une groffe éponge \& un feau d'eau fraîche, \& vous leur ferez beaucoup peigner les crains \& la queuë aux gros chevaux \& roufins, vous aurez le foin aprés les avoir bien fait peigner, de leur faire beaucoup moüiller la tête \&z l'encoleurej, cela les décharge fort \&a leur conferve la vûę : Il faut auffi a voir grand foin de faire bien bouchonner les $\mathrm{j}$ mbes des chevaux avec des bouchons de paille, crainte qu'il ne leut vienne quelque galle ou crevaffe, tant aux jambes, qu'aux pafturons, comme on ne doit pas auffi manquer de leur bien laver $8 x$ baffiner les jambes, couc autant de fois quils les auront falles. Vous ne ferez pas auffi negligent de leur faire regarder dans la bouche de temps en temps, pour voir s'ils one la bouche é chauffée, les barres bleffées, les dents ou fur dents de loup, les barbillons ou le lampas, \& en ce 


\section{à Cheval.}

cas y faire remedier, puis leur faire laver la bouche avec du verjus blanc, de porreaux \& ail pilé, yous prendrez auffi garde que le mors, la gourmetre ou les crochers ne leur bleffe la bouche, le palais ny les barres, non plus que la gourimetre ny les crochets, foir à la fous barbe; ny le long des lévres; que fi cela arrivoit, il y faut remedier $\& z$ faire embourer la gourmette \& les crochets.

Pour la nourriture du cheval, elle doit être de feize livres de bon foin, une bonne botte de paille de froment, \& cinq bons picotins d'avoine: aux chevaux dégoûtez, vous lear donnerez du fon moüillé au lieu d'avoine: il leur faur bonne litiere de paille fraîche, chacun leur place feparée de pilliers avec des barres entre deux, \& chacun deux bonnes longes. crainte qu'ils ne fe bleflent.

Si le cheval a la bouche échauffée, ille faudra faire feigner dans la 
18

bouche à la troifiéme barre dupalais, qu'il faigne abondamment, comme auffi fept ou huit coups de flamme fur le haut de la queuë, puis l'ayant ramené de l'eau, luy donner du fon de froment, puis unie heure aprés luy faire laver la bouche avec verjus, $\mathrm{fel} \& \mathrm{ail}$ pilé, \& continuer jufqu'à ce qu'il boive \& mange à fon ordinaire. L'Ecurie doit être tenuë toujours tres-netre, fans qu'il y entre jamais de poulailles, pourceaux, ny autres Beftes fales, crainte du farcin. On tient pour affuré que le Bouc eft tres-neceflaire dans une Ecurie, on dit qu'il chaffe le mauvais air, \& tient les chevaus en fanté. Le foin doit être bien fecoüé, afin qu'il n'y refte aucune poufficre qui puiffe faire touffer les chevaux: l'avoine doit auffietre tres-nette \&c bien criblée, pour Ja même raifon.

Si tu defires que tes chevaux inelteant toujours en bon état, 


\section{à Cheval.}

quils paroiffent beaux \& bien luifans, il les faudra renir bien couverts tout le jour, \& leur donner bonne litiere de paille fraîche toure la nuit, \& qu'ils ne manquent à être panfez de la main deux fois le jour, comme j'ay cy-devant enfeigné, \& de plus, tu les fcras tenir au filet ou mafticadour deux heures le matin , \& deux heures de relevée.

Il faut avoir grand foin des felles \& des brides des chevaux; pour les brides, il les faudra faire la. ver, c'eft-à-dire le mors tout autane de fois qu'il fortira de la bouche du cheval.

Pour les felles, tout aufi-toft que le cheval aura travaillé jufques à la fueur, il faudra avoir le foin de les faire metrre au Soleil, ou en quelque autre lieu où elles puiffent feicher, puis les faire battre \& bien démêler la boure des panneaux, afin que le cheval ne puilic être incommodé, ny blef 
fé fous la Selle.

En un mot, il faudia prendre gard de fi prés à cour le harnois, qu'il n'en puiffe être incommodé en quelque maniere que ce. forr.

Il ef encore neceffaire de voir bien exactement fi les chevaux fe fiottent ou mordent en quelque endroit que ce foit, qui eft figne d'érhaufiement, demangeaifon, \& chaleur de fang: lors que cela arrivera, on les fera promptement faigner la veine du col, \& on réiterera la faignée, fi l'ardeur ne cefle.

\section{CHAPITRE VI.}

Les chofes effenticlles qui fe doiven praiguer faiss contredit dans l'Art de monter à cheval.

TT IEN quil foit vray de dire, Igu'il n'y a point de reglecer: 


\section{à Cheval.}

taine dans l'art de monter à cheval, à caufe de la varieté, malice $\&$ inquietude que l'on remarque, non-feulement tous les jours \& toutes les heures que l'on travaille, ou que l'on fait travailler des chevaux, mais generalement parlant, à tous les momens que t'on les recherche \& que l'on leur demande quelque chofe de jufte, \& qu'il eft abfolument neceffaire que le bon Cavalier \& Ecuyer fçache changer felon fa fcience \& experience, aufi fouvent de methode que fon cheval luy refilte en changeant d'humeur.

Il y a pourtant des chofes effentielles \& generales qui doivent abfolument être pratiquées, fans qu'elles puiffent fouffrir aucun changement, ce que j'ay bien voulu marquer en ce lieu \& en faire unchapitre, que jeftime autant ou plus neceffaire, que nul autre qui foit inferé dans ce petit cuvre, ce qui me faic confeiller à l'Ecolier diligent, de le metre non-feu- 
lement en pratique, mais de l'e. tudier fi bien, quil le puiffe apprendre par coeur.

Premierement, quand on aura deffein de conduire un cheval en quelque endroir que ce foit, il ne faut jamais avancer ny porter la main vers les oreilles du cheval, non plus que le bras : mais il faue fimplement baiffer la main, approcher les deux gras des cuiffes, $\&$ avoir le corps un peu en arriere,

Il faut toujours partir ou pouffer un cheval droit , \& l'arrêter droit: il ne faut jamais avoir la tête baffe, ny le cul hors de la felle.

Si le cheval a la bouche delicare ou tendre, il le faudra toujours conduire en avant, \& luy donner beaucoup d'efpace ou de terrain.

Si au contraire il a la bouche forte, ille faudra conduire étroit, $8 z$ le bien foûtenir.

Si le cheval porté au vent be. gaye, ou bat à la main, il faudra 


\section{à Cheral.}

avoir le poignet \& la main tres ferme, affez proche du pommeau de la felle, le corps en arriere, \& les angles rant foit peu en haut.

Si au contraire il portoit bas, \&z s'armât, il faudra avoir la main gaillarde, vacillante $\&$ un peu avancée vers la tête du cheval. Quand vous aurez deffein de tourner un cheval, ou le changer de main, foic à droit comme à gauche, il luy faudra toujours donner du terrain ou de l'efpace, pour le moins fa longueur, en le condui. fant en avant, \& $\mathrm{le}$ bien arrondif. fant.

Si un cheval fe veut précipiter en avane, il le faudra faire reculer, s'il veut reculer de luy-même, ille faudra chaffer en avane : fi portane un cheval d'un talon fur l'aurre, il y a repugnance $\&$ n'y veuille pas obérr, nele preffez point \& ne le châriez pas pour cette faute; mais éloignez letalon, conduife z-le en avant, puis approchez de rechof le même 
talon, \& continuez ainfi par pla. fieurs fois fans l'impatienter, \& il obéira dans peu de jours.

Lors que vous aurez deffein de mettre un cheval entre les pilliers, foir pour luy faire lever le devant, ou pour connoîrre fa legereté ou fa force, ne faites jamais monter perfonne deffus que vous ne foyez tres-affuré de fa bonne volonté : crainte que fe voyant contraint $\&$ fujet, il ne fit quelque defordre, \& bleffât celuy qui feroit deffus.

Mais pour luy bien apprendre parlabelle methode, faites-le mettre entre lefdits pilliers fellé \& $\&$ bridé, poltez-vous derriere avec luy avec une bonne chambriere, $\& E$ par ce moyen faites - le tourner d'un côté \& d'autre, fanslebeaucoup preffer; ce que vous ferez par plufreurs fois, le careffant lors qu'il obéira, puis quelque temps aprés frappez de voltre chambriere contre terre, \& directement derriere luy, ce qui l'obligera de donner 


\section{i Cheval.}

donner dans les cordes du caveffon : \& ainfi vous le ferez avancer \& reculer tant que lefdites cordes le pourront permettre : \& continuez cette leçon jufques à ce que vous voyez que le cheval baifle un peu les hanches, \& qu'il fe prepare de luy-même. Enfin obligez-le ainfi doucement, \& peu à peu à lever le devant, \& lors qu'il le fera avec docilité \& fans impâtience, vous pourrez faire monter deflus en toute feureté.

Lors qu'un Cheval fera tres. malicicux, rebours \& revêche, fans vouloir avancer fous l'homme pour la chambriere, pour la gaule, ny mêtmc pour les éperons, ne vous opiniâtrez jamais à le penfer gagner en le battant \& preffant des éperons : mais faites mettre pied à terre, puiis fellé \& bridé qu'il fera, \& étriez détroufiez, avec tout ce qui le pourra incommoder, faites-luy metrre la grandcorde, \& le faites trotter autour 
le pillier malgré luy à bons coups de chambriere, \& continucz ce rravail un mois ou plus, fans faire monter perfonne deflus. C'eft par cette methode que vous viendrez à bout du plus méchant $\&$ defefperé de tous les chevaux, \& fans mettre voftre Ecolier en hazard. Si un cheval, comme il s'en rencontre affez fouvent, a de la répugnance plus à une main qu’à l'autre, ne le commencez jamais à quelque forte de manege que co foir, que vous ne conduifiez en avant $\&$ fur une même pifte à l'abord, \& ne l'arreftez auffi jamais que vous ne l'obligiez de porter la tefte, \& de regarder du cofté qu'il aura averfion. Quand vous ferez ccrrain qu'un cheval aura la bouche mauvaife, $8 z$ qu'il forcera toujours la main, ne le pouffez jamais à toute furie, \& vous gardez bien de l'abandonner : au contraire, endormez le au petit galop. leger, \& le foutcnez du gras des 


\section{i Cheval.}

cuiffes, comme fi vous luy vouliez marquer les temps des courbettes.

Si un cheval fe retient, chaffezle en avant ; s'il s'abandonne, foûtenez-le; s'il manie fur les voltes, ne manquez jamais de vigueur, $\&$ faites en forte qu'il marque fes temps à une main comme à l'autre.

Lors que vous changerez de main, ne changez jamais que fur l'un des quatre coins ou angles de la volte, qui fone les bouts des ligncs.

Er chaffez toujours le cheval avant que de chang,r : comme aufie aprés avoir changé, pourvá que ce ne foir pas un cheval qui force la main; \& lors qu'il changera, il faut que ce foir en bien avançant, $\&$ en sarrondiffant.

Lors que le cheval maniera fur les voltes, faites en forte \& le chaffez fi à propos en avant, que la tefte $\&$ les épaules paffent toujours par

$\mathrm{C}$ ij 
les quatre extrémitez de ladice volte.

Si vous eftes affuré qu'un cheval fçache quelque chofe de jufte, ne l'arreftez jamais fans l'affeoir fur les hanches, \& fans luy faire lever le devant à l'arreft, ou au parer.

Et pour conclufion de ce chapitre, il faut que le bon Cavalier foit toujours preft fans fe laiffer furprendre, \& que connoiffant les défaurs de fon cheval, il y remedie auffi-toft par fa fcience, \& $\mathrm{par}$ les preceptes infaillibles \& generaux que je viens de déduire. S'il a trop de fougue, qu'il l'appaife $\&$ adouciffe; s'il n'a pas affez de feu, qu'il l'anime. Enfin il faut qu'il foir roujours en eftat de luy faire faire le contraire de ce qu'il veut faire par malice ou répugnance au bien. 


\section{ChapITRE VII.}

De la difpofition que doit avoir celssy qui veut embrafer l'Art de monter ì cheval.

TL faut en premier lieu, qu'il foit fans aucune incommodicé de fa perfonne, il doit eftre tresnerveux \& fort vigoureux, \& fains aucune appréhenfion, \& que toutes fes qualitez foient gouvernées d'un jugement net \& entier, fans jamais perdre la tramontane en quelque rencontre que ce foit, afin de s'en pouvoir fervir au befoin avec prudence, jugement $\&$ bonne conduite.

Il doit eftre doux, patient, obéillant promptement aux com. mandemens de celuy qui l'enfeigne, \& qu'il aye vraye \& ferme créance que fon Maiftre fçait beaucoup mieux que luy quels chevaux 
il doit travailler pour le rendre fça. vant: \& fur tout, qu'il ne prenne jamais de vanité, quoy qu'il fafie bien. Voila le commencement de l'Ecolier qui veut devenir bon Muntre.

\section{Chapitre VIII.}

ce qu'il faut que fgache le Cavalier, touchant tout l'équipage or harnois de for cheval.

T.L eft tres-julte que celuy qui fait profeffion de monter à cheval, fçache connoiftre l'équipage quiluy elt neceflaire, afin de s'en pouvoir fervir alors qu'il en aura befoin.

Il faut donc fçavoir que le cheval porte felle, bride, cavefion $\&$ licol, \&c.

Ce quife met fur le cheval pour la commodiré de l'homme lors qu'il voyage, fe nomme felle; mais elle 


\section{à Cheval.}

eft compolée, favoir eft d'arçons devant \& derricre, de deux bandes de fer 8 de bois qui tiennent les arçons enfemble: de boucles de fer qui font atrachées aux bandes pour fourenir les érriaires: clle a auffi fes baftes devane $\&$ derriere: elle a des lieges pour tenir l'arçon ferme : il y a le fiege pour s'afieoir dans la felle : elle a des carticrs, un trouflequin, de derriere de la felle, le pommeau: quatre ou fix contre fanglots, des porteftriez, des fangles, un fourfaits, un poitrail, une croupiere, des Eftrivieres, deux panneaux, \& une houffe pour conferver la felle.

$$
\text { De la Bride. }
$$

Tout ce qui fe mer à la refte du cheval pour le guider, fe nomme bride; elle eft compof'ee pour ce qui eft du cuir, fçavoir de reftiere, de porte-mors, de fous-gorge, de foutenans, de frontal, de patellerte $\&$ de rênes.

$$
\text { C iiij }
$$




\section{Le Mors.}

Ce quife met dans la bouche du cheval ent de fer, \& s'appelle mors, il eft compofé d'embouchure, de trenchefille, de branches, de chenetres, d'anneaux, de touretres, de gourmettes $\&$ de crochets pour tenir la gourmette.

Ce qui demeure à la tefte du cheval lors qu'il aefe à l'Ecurie, fe nomme licol : il eft compof'é de tefticre, fous-gorge, 8 deux longes de cuir : à ccux qui fe décoiffent ou délicotent, on y met une feconde fous-gorge.

Il faut fçavoir que les chevaux de manege ont befoin de caveffons: il y en a de plufieurs fortes, mais je n'en parleray que de trois ou quatre : caveffon de corde pour faire panfer les chevaux, \& les mettre entre les pilliers : cavefion rond pour les chevaux d'affez bonne nature: cavefion figuette pour les rouffins: \& cavefion camarre \& mordant pour les gros chevaux 


\section{à Cherval.}

durs de tefte $\&$ de col roide, \& qui forcent la main. Il faut qu'ils foient garnis les uns \& les autres de reftiere, fous-gorge, \& deux longes, avec trois anneaux, un de chaque cofté, pour pouvoir tirer la tefte du cheval, \& l'autre au milieus pour le pouvoir bien faire étendre au tour du pillier.

En outre on fe fert d'un petic fer mordant, que l'on nomme figuette, qui fe place dans la muferolle, qui fert à tous les chevaux qui levent par trop la refte, battent à la main, begayent, \& portent au vent, comme les Caftillons ou Cravates, pour leur affermir $\&$ affurer la tefte. Il y a encore un meilleur moyen que celuy-là, \& qui eft de merveilleux effer; c'elt une platte longeà deux branches, qui s'attache aux deux anneaux du caveffon, 82 paffe entre les jambes du cheval, \&z s'atrache aux fangles.

On fe fert auffi de trouffequeue pour les chevaux de manege; on 
en met aux fauteurs, \& à ceux qui branlent par trop la queuë, \& cela pour trois raifons: ils en paroiffent plus beaux, le trouffequcuë leur aide à fauter, \& les empêche de remuer la queuë.

Il eft aufi neceffaire que les chevaux de manege, \& autres ayent des couvertures ou des capparaffons de toille ou autre telle éroffe que l'on voudra: il faut avoir de bonnes étrilles, de bonnes brofl s. une épouflette de grnffe toille, un bon peigne, une grofl: éponge, un coûteau de chaleur, de bons cifeaux, un brochoir, un bouroir, de bonnes turquoifes d'Allemagne, un fer à tout pied, une ferriere avec quantité de cloux à ferrer. Voila à peu prés les harnois \& l'équipage neceffaire au bon Cavalier. 


\section{Chapitre IX.}

- Ce que c'eft que Maneze.

A Anege en general eft tous les endroits là où on peur faire manier des chevaux, mais à proprement parler, mancge eft un lieu arrefté \& déterminé, pour y faire travailler les Ecoliers, \& y drefler les chevaux.

Il y a deux fortes de maneges, àfça voir le couvert \& le découvert; le couvert eft pour le mauvais temps ir pour la plus grande contrainte. des chevaux.

Et le découvert eft pour le beaus temps, \& pour bien pouvoir égayer $\&$ étendre les chevaux, \& les dreffer pour la guerre, il faut qu'il y air auffi-bien à l'un comme à l'autre des pilliers, à fçavoir deux vis à vis l'un de l'autre, $\&$ de la diftance de deux petirs pas, afin de pouvoir 
faire lever les chevaux, \& un au milieu de la place pour bien faire étendre les chevaux.

Le beau manege doit ente de trente-cinq pieds de large en ouvre, \&z de quatre-vingts pieds pour fa longueur.

Er le découvert auffi grand qu'il fe pourra rencontrer pour bien pouvoir égayer les chevaux pour $l_{2}$ guerre.

\section{Chapitre $\mathrm{X}$.}

Ce que c'eft que Volte.

T Olte ou volter vient des Italiens, ce qui fignifie tourner en rond; auffi fa définition eft une figure ronde, compofée de circonference, diametre \& centre, la circonference eft la pifte ou chemin, par lequel le cheval doit pailer \& repafier, les diametres compofent quatre lignes droites, fur lefquels 


\section{à Cheval.}

ie Cheval doit cheminer en quarré, \& le centre n'eft autre chole que le milieu de la volte, où doit eftre planté un pillier pour bien guider le cheval.

\section{Chotitre XI.}

Ce que c'est que Carricre.

Arriere eft une ćtenduë de chemin, non borné pour bien farre courrir un cheval \&l'étendre avec plaifir, luy faifant employer partie de fa force, en le pouffant $\&$ échappant de la main avec verdeur, pour connoiftre s'il eft libre de partir de la main, s'il fouffre les talons fans faire le retif ou ramingue, ou pour fentir s'il a bons reins, bonne bouche, \& s'il s'affied fur les hanches en parant $\&$ s'arreftant de bonne $\&$ franche volonté.

Mais à propremene parler, carriere ou lice eft un lieu affigné, ar- 
refté \& fair exprés pour courrir la bague, rompre au faquin, \& courir alencontre, ce que l'on appelle rompre en lice.

La belle carriere doit eftre de cent dix pas de longueur, \&z trois perits pas de largeur.

Depuis le parrir, ou le lieu où l'on prend la demy volte, jufques à Ia porence, il y doit avoir quatrevingt-dix pas, \& trente pour le feniteur de la carriere, ou courfe, ce que l'on nomme l'arreft, ou le parer.

\section{ChAPITRE XII.}

Ce que c'est que Pafjade.

D Affade n'eft autre chofe qu'une longueur de chemin pas où il faur que le cheval paff \& repaffe: il y en a de plufieurs f,res, mais je $n^{\prime} \cdot n$ parleray que de quatre, d'autant que je ne juge pas 
propos d'embarrafler la memoire de mon Lceteur : \& que de l'une de ces quarre dépendent toutes les autres, comme je feray voir en fon licu.

Paffides de la main à la main, les demy voltes, ou pafides de quatre temps : les veritables paffades de trois temps; \& les piroüettes, qui font demy tours d'un temps pour gagner la crouppe.

\section{Chapitre XIII.}

\section{Du beau Cheval.}

T E beau cheval doit eftre de lcgere taille, comme auffi de 1. mediocre, c'eft-à-dire, ny colofle, ny auffi bider. Il ne doit pas eftre trop ferré, ny trop ouvere, non plus du devaine que du derriere. Il ne doit pas eftre jartier, ny cagneux, non plus que clamponnier, ou brachicourt, ny pied bot, ny bonté 
non plus que pied de liévre. Il doir eftre fort relevé d'encolure, la refte perice, les yeux affez gros, \& de couleur d'ardoife, la bouche écumante, \& mediocrement fenduë, le front uny, peu de falieres, l'écoille au front, l'encolure longuette \& de bonne grofieur, en fortant des épaules \& amoindriffant toujours, en venant vers la tefte $\&$ tant foit peu en arc ou col de figne. La braye affez ouverte, le canal longuet, \& un peu ouvert, peu de gannache, les barres fines \& déliées, les épaules petites, le bras fort \& nerveux, le canon plat \& large. Le genouill affez gros, le pafturon court \& bas jointé, la corne noire $\&$ liante, les talons forts, le pied creux, la fourchetre petite, la folle feiche \&z bien nourrie, le pied fort, le talon affez haut $\&$ bien ouvert, le corfage beau, les reins forts, la cofte large, la crouppe ronde $\&$ double, les cuiffes bien trouffées, le jaret fec, plat \& large, 


\section{à Cheral.}

la jambe feiche \& platte, les crains longs \& déliez, \& peu chargé de crain, la queuë touffië \& longue, peu de poil aux jambes, le flanc relevé, les nazeaux ouverts \& incarnats au dedans, la verge petite, les genitoires bien retrouffez, \& forr fuperbe en fon marcher.

On dit que le cheval doit avoir entre autres qualitez, trois quiluy font neceflaires.

Il en tire une de la femme, une du lyon, \& la derniere du cerf.

Il doit avoir le devant de la femme, pour eftre agreable en fa rencontre.

Il doit avoir la fierté $\&$ la generofité du lyon, pour le combat, \& pour fervir fon Maiftre à la guerre.

Et la vireffe du cerf, pour porter fon Maiftre avec diligence là où iI defire aller. 


\section{Chapitre XIV.}

connoiffance certaine de l'âge du Chcval, depuis fa naifsince jufques ¿̀ la fin de fa vie.

L eft tres-conftant, que quelque 2 huir ou dix jours aprés que le poulain eft $\mathrm{v}$ nu au monde, il commence de voir le jour, \& quelques jours apés il commence auffi de luy percer quelqus denes, mais lors quill a trois mois, il eft trescerrain qu'il a trence-deux dents en la bouche, fçlvoir vinge derriere \& douze devant : les vingt derriere fe nomment machelieres, $\&$ mâchent \& broyent la nourriture de l'animal cavallin, \& les douze de devane ront neceffaires pour pembeliffement de la bouche sz pour la connoiflance de l'âge, \&z se nomment dents de lait: Nota, quì srois ans \& demy il perce ou 


\section{a Cheval.}

pouffe encore quatre petites efpeces de dents ou os, qui fe nomment crocs ou crochets, qui fervent auffi pour la connoiflance del'âge, defquels je parleray en fon lieu : ce qui fait en tout trente - fix dents, lors que le cheval eft en fa perfection: Nota, aufi qu'il y a beaucoup de chevaux qui ont vingt-quatre dents machelieres.

Les dents machelieres ne tombent 2 ne changent jamais depuis qu'elles font venuës, non plus que les crocs, ou crochets: mais les dents de lait tombent \& changent toutes.

Soyez done tres-certain que depuis que le poula in a pouffé fes premieres dents, jufques à 'ce qu'il aye atteint l'âge de vingt-fept à trente mois, aucune des fufdites dents ne tombent.

Mais à l'âge que j'ay marqué, il en tombe ou change quarre, à ç̧avoir deux deflus, \& deux deffous du milicu de la bouche; \& lors que 
44

vous obferverez cela, dites hardiment que le poulain a bien prés de trente mois. Vous remarquerez icy en paffant, que le vulgaire nomme les dents dont je viens de parler, le mors: \& difent ainfi, ce poulain a trente mois, car il a pouflé 1 mors. Aprés ce temps il refte encore huit dents de lait dans la bouche du poulain, jufques à ce qu'il foir parvenu à l'âge de trois ans, \& trois ou quatre mois; aprés lequel temps il pouffe ou change encore quatre dents, fça voir une de chaque cofté, tant au haut comme en bas, des plus proches de celles que nous avons nommées le mors, ce qui marquera bien prés de quatre années: puis un an aprés tombent ou pouffent les dernieres dents, que le vulgaire nomme les coins, (d'autant que ce font celles des coftez de la bouche, ) 8 lors que le poulain les a pouffées, il perd ce promier nom, a fe nomme jeune cheval, \& a bien prés de cinq ans: 


\section{¿̀ Cherval.}

d'où vient que l'on dit communément, ce cheval eft jeune, car il ne fait que de changer ou pouffer la dent de cinq ans, ou les coins. Nota, que dans cet intervale percent les crocs ou crochets, defquels jay parlé cy-deflus : mais la regle n'en eft pas toujours certaine, car ils percent aux uns plútoft, $\&$ aux autres plus tard, felon qu'ils ont efté bien ou mal nourris, \& $\mathrm{fe}$ lon les pafquages où ils ont efté élêvez. Nota auffi, que pour connoiftre les dents de lait d'entre celles qui ont changé, vous obferverez ponctuellement ce que je vay dire : fçachez donc que les dents de lait font blanches, rondes, longuettes, toutes égales, $8 z$ ne font point creufes, \& n'y a que peu ou point de noir dedans.

Et celles qui ont changé font jaunâtres, larges, courtes, inégales, creufes, \& du noir dedans, \& reftent en cette forte jufques à prés de ecpi ans.

D iij 
$46 \quad$ L'Ari de monter

Voila de ce que jay bien voulu avertir mon Lecteur, pour luy mettre dans l'efpric, \& luy apprendre la veritable connoiflance de l'âge des chevaux.

Maintenant je pourfuivray \& feray mon poffible, afin de luy donner des lumieres pour connoiftre autant qu'il fe pourra faire par les regles generales, ce qui refte del'âge de ce noble animal, jufques à la fin de favie.

Alors, comme j'ay dit, que le jeune cheval a tout - à-fait changé ou pouffé la dene de cinq ans : qui fe nomme auffi les coins avec les crocs ou crochers; en un mor quand il ne luy refte plus aucune dent de lait, il a toutes celles qui ont changé, crcufes \& inégales, avoc le noir à toutes les dents deffus \& deffous, jufques à prés dé fept ans rrois mois, ou pour le plus feprans \& demy, il a toures les dents égales, \& s'appelle razé. Ce qui relte jufques à prés de huit ans, avec 


\section{a Cherual.}

une marque noire fur les dents, que le vulgaire nomme charbon. Mais vers les neuf ou neuf ans \& demy, il fe forme un petit demy cercle dans les dernieres dents du haue de celles qui ont changé, qui marque que le cheval a bien prés de dix ans, puis lors que le même cercle s'érend \& devicnt plus grand, vous pouvez vous affurer que le cheval a bien prés de douze années $\&$ en ce temps les dents commencent de s'allonger, \& blanchir fans aucune marque noire, ce qui continuë jufques à prés de quatorze ans, que les dents font fort longues \& blanches, \& commencent à décharner, mais à quinz: \& feize ans, les crochets font tous émouftez, \& deviennent ronds comme un bouton, ce qui continuë jufques à dixfepe ou dix-huit ans:; auquel temps ie fourcils deviennent blancs, les dents font toutes décharnées, les palieres creufes, les yeux affreux 3 cnfoncez dans la telte, \&z pour 
la fin du pauvre animal, qui eft, comme difent ceux qui en ont faic la remarque plus exacte, pour le plus ordinaire à trente-deux ans, alors les jambes, le flanc, le ventre \& la telte blanchiffent, le carré vieillit, l'encolure eft panchée, à 1a plus grand' part le flanc eft tourà-fait alteré, les jambes \& la force défaillent, \& lors vous connoiffez affez facilement, que le pauvre animal n'eft plus propre à rien.

\section{Chapitre XV.}

Du Cherval faux marqué par artifice: or du naturellement faux marqué, que le vulgaire nomme baigu.

E n'elt pas affez d'avoir faic mon poffible pour faire connointre l'âge des chevaux, par les regles ordinaires \& generales : car il y a des Maréchaux qui les $f_{c ̧ a-}$ 


\section{a Cheval.}

vent faux marquer avee une addrefle fi approchante du naturel, qu'il feroit fort aifé d'y être trompé ; c'eft ce qui m'oblige d'en avertir le Lecteur, az d'effiayer d'y don. ner remede.

Il y en a auffi qui font naturellement faux marquez ou baigus, c'eft à quoy il faut prendre garde: je parleray de l'un \& de l'autre, $\&$ feray en forte que vous les pour. rez tous deux connoître, fi vous obfervez bien ce que je vous vais enfeigner.

Pour le faux marqué par artifice, il n'eft pas tout à fuit impoffible de le connoître, pourvû que l'on y veuille un peu prendre garde de prés : car quelque habile \& experr que puiffe être le Maréchal, fon burin ne peut faire la fauffe marque comme la naturelle: car la naturelle eft faite comme un $5, \&$ la faufle eft quafi ronde; le noir que le Maréchal y ar plique cft beaucoup plus pafle que le nas 
so

\section{L'Art de monter}

turel : de plus, le Maréchal ne faux-marque pas toutes les dents, maisfeulement deux deffus $\&$ deux deffous: de plus, le faux-marqué a les dents plus blanches \& plus longues, parce qu'il eft plus vieux, $\&$ les a auffi moins larges que le jeune cheval, qui les a comme j'ay dir, jaunâtres, larges, courtes \& creufes, \& routes inégales, avec le noir dedans, jufques à prés defepe ans.

Pour le naturellement faux-marqué ou baigu, il eft beaucoup plus facile à connoîre, car il a les dents longues, il eft razé, a les dens rou. tes égales $8 x$ unies, les a blanches 8z moins larges que le jeune cheval, fans que l'on y puife remarquer aucune marque de jeuneffe, gu'une marque noire qui paroît à toutes les dents, que le vulgaire appelle charbon.

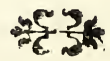




\section{Chapitre XVI.}

Ce qu' il faut confiderer des Chevaux felon le pays ou climat ou ils ont été élevez or nourris.

7 Ous les chevaux generalement parlant, peuvent avoir les mêmes maladies, mais il eft vray qu'ils font moins fujets aux unes quaux autres, felon leur caille, leur temperamment, \& le climat où ils ont été élevez, \& nourris.

Oi afin que chacun puiffe profiter de cet avis, il faut confiderer ce qui fuir.

Si c'eft un gros cheval d'Allemagne, de Flandre, de Frize ou de Hollande, prencz garde à la vûe, au pied comble, au pied gras: aux eaux aux porreaux, aux grappes peignes, crevantes, \& aux fluxions des jambes: cax tous ces che- 
vaux ne fe perdent que par là.

Si c'eft un cheval de Limofin, de Poirou ou des Ifles circonvoifines, prenez garde à la vûë, aux javars, atix malandres, aux foulandres: Si c'elt un Cheval de Bretagne, prenez garde à la groffe tête; à la groffe cncoleure, au pied comble $\&$ ذ̀ la vûee.

Si c'ct un Cheval d'Efpagne, prenez garde aux felmes, aux blefmes, auxcour bes, aux moletres, aux veffigons \& aux Efparvins.

Si c'eft un barbe, prenez garde a la foiblefle du pied, aux fureaux, au talon ferré, à l'encaftelle, \& au peric pied ferré.

Si c'eft un Cheval d'Italie, prenez garde aux infirmitez des deux préceders.

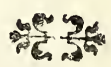




\section{Chapitre XVII.}

L'Equiprge neceffaire à un Manege.

Uanticé de toutes fortes de mors, plufieurs caveffons, un von nombre de filets \& mafticadous, demie douzaine de felles fermes que l'on nomme à piequer, autant de felles razes, beaucoup de teftieres, de refnes, eftrivieres, fangles \& furfaits, quantité de bons eitriez forgez \& bien limez, demie douzaine de platres longues, ou martingalle; autane de plattes longues à deux branches, deux bonnes chambrieres, une douzaine de grandes cordes à boucle, avec le contrefanglot, un martinet, un valer avec l'éguillon, un poinçon, de tres-bonnes gaules, de bons éperons, dont la molletre foir perite, ronde, \& un peu émoucée, un pic, une bonne tran-

E iij 
che, \& un arroufoir.

\section{Chapitre XVIII.}

\section{Des Embouchiuresdes Chevaux.}

E ne me puis icy arrêter à vous déduiro par le menu tout ce gui seroit nectiaire de vous dire touchant les cmbouchcures des Chevaux, il me fautroit trop de temps, \& outrc cela peu de perfonnes me pourroient entendre: De plus, ce n'elt pas mon humeur de rien avancer que je ne prouve, comme auni je ne veux rien promettre que jenedonne: c'eft ce qui m'oblige en ce lieu de vous dire, que le plus court moyen pour bien emboucher un Cheval, \& principalement pour ccux qui n'ont pas cette profonde fcience \& longue experience qui feroit neceffaire pour cet cffet, \& qui n'ont pas les bons Epe ronniers prés de leur maifon, je 


\section{à Cherval.}

leur confeille d'avoir toujours quantité de toues fortes de mors, $\&$ les effayer l'un aprés l'aurre, afin de choifir le plus propre pour s'en fervir : c'elt là l'avis que je vous donne pour promptement réuifir à bien emboucher un Cheval, mais dautant qu'il y a aufi des regles generales, je ne me veux pas contenter de vous avoir enfeigné ce que deffus, je veux encore vous donner trois ou quatre emboucheures, \&c trois branches, avec leurs gourmettes; ce qui pourra vous fervir pour quantiré de Chevaux.

Un canon tout fimple avec une branche droite affez longue, l'œil bas, \& le bas de la branche percé au bour, la gourmette groffe \& ronde, les crochets bien ajuftez, le mors bien forgé , bien limé \& étamé, tant la gourmette que les crochets.

$\mathrm{Ce}$ mors eft abfolument pour rous les jeunes Chevaux qui n'ont

E iiij 
encore é té montez ny travaillez au manege, ny ailleurs.

Si le Cheval a cinq ou fix ans, \& qu'il aye déja été acheminé ou monté, foit par pays, ou au manege; vous luy donnerez un canonà pignatelle, avec une liberté de langue, ou une échafle d'une piece, ou de petites olives avec des annellers des deux côtez, la gourmetre $\&$ les crochets, comme j'ay déja dir.

Pour les Branches à ces fecondes emboucheures; la premiere fera à Ia Connefable, aflez hardie, avec unfaux jarrer, l'oil de mediocre hauteur, le coude relevé, \& la branche percée au bout.

La feconde fera à la Françoife, in peu ftaqué, l'œil fort haut $\&$ un pcu renverfé, \&z percé à côté du bas dela branche.

La troifiéme fera un bas rond, fort hardy \& l'œil bas, \& le bas de la branche percé à côté.

Ces trois forres d'emboucheu- 


\section{à cheval.}

res $\&$ de branches ferviront à tous Chevaux, pourvû qu'ils n'ayent pas la bouche entierement defefperée.

Pour les gros rouffins d'Allema gne chargez de tête, d'encolleures \& d'épaules, de col roide, s'emportant \& forçant la main, vous leur donnerez pour emboucheure une grofle olive à pignatelle, ou des poires renverfees, ou bien un pas d'afne, la branche à bas rond percé à côté, le tout forgé, limé, étamé \& ajufté comme jay dit.

Voila tout ce que je vous puis apprendre touchant les emboucheu. res, le temps, l'experience \& la pratique joints au long exercice, vous rendront fçavant du refte.

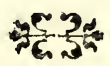




\section{Chapitre XIX.}

Avis au Cavalier diligent qui cherit lexercice de monter à Cheval, ó qui defire réüfir en l'Art de dreffer des Chevaux.

UE fi vous defirez réüfir en l'Art de dreffer des Chevaux, avant que vous inftruire des moyens pour y parvenir; je veux vous donner des preceptes que vous devez avoir prefens à la me. moire, lors que vous voudrez faire travailler des Chevaux pour les dreffer.

En premier lieu, tenez pour confant \& principe affuré, que le Cheval eft un animal fans raifon, qui n'a pour guide qu'un certain inftinat que la Nature luy a donné, \& que tout ce qu'il fait le plus approchant du raifonnable eft par l'habitude, par la coûtume jointe 


\section{à Cheval.}

aux bonnes inftructions que l'Ecuyer leur donne.

En fecond lieu, connoiffez $8 z$ confiderez que vous éres homme, c'eft-à-dire, doüé de fens, d'efprit $\&$ de raifonnement, pour fouffrir avec patience les défaurs que vous connôtrez en tous les Chcvaux, qui proviennent pour l'ordinaire manque de connoifance, \& pour nefçavoir pas deviner ce qu'on leur demande.

En troifiéme lieu, vous devez fçavoir, \& l'experience nous l'apprend, qu'il ne fe fait rien au monde qu'avec le remps, la prudence \& la bonne conduite.

Si vous confiderez bien ce que deffus, il y aura peu de Chevaux defquels vous ne tiriez partie, \& f vous ne les dreffez $\& z$ achevez entierement, du moins vous ferez en forte, \&z les reduirez en tel étar, que vous vous en pourrez défaire, lors qu'ils vous feront à charge. 
60

Toutes les qualizez du gentil Cheval.

Lors qu'il aura bonne bouche, bonne force, fouplefie, gerilleffe, vigueur, agiliré, legereté , qu'il féa ra fans malice, bonne volonté, \& l'éperon excellent, fi vous ne le dreficz $\&$ achevez entierement, dires $\&$ confellez à vous-même que vous n'entendez pas ce mérier, vôtre plus coure chemin eft de recourner à l'Ecole, ou ne vous cn mêlez jamais.

Les mediocres qualitez du Cheval.

S'il a grande force, mauvaife volonté \&zmauvaife bouche, grande impatience, peu de foupleffe, sz que parmy tous ces défauts vous con. noifiez qu'il aye l'éperon friand, fin \& delicat, vous le devez auffi dreffer; fi vous entendez bien vôtre métier, quoyque ce foit avec beau. coup de peine \& de travail, join 
\& vec la methode $\&$ la patience, 82 lorfque vous y obferverez ponctuellement toutes les regles que j’ay déja dites \& que je diray encore en la fuite de ce difcours.

\section{Duméchant Cheval qui ne Sepeut drefer.}

Lors que le Cheval fera fans force, fans bouche, beaucoup de malice, point de volonté, nulle foupleffe, point d'agilité, aucune vigueur, \& que pour comble de tous ces défauts, il n'aura point d'eperon, dites hardiment que c'eft une rofle, \& affurez qu'il n'y a point d'are, qu'il n'y a plus d'Ecuyer, de me hode, d'experience, ny aucune fcience, \& que le meilleur homme de cheval du monde eft au bout de fon rouler.

Remarquez encore bien cecy, de tous les Chevaux que vous cntreprendrez de dreffer en toute voftre vie, vous n'en acheverez peut-être jamais un feul qui ne le démente, 
62

dédie ou rebute par plufieurs fois, premier qu'il foir dreffé, \& lors que vous le croirez bien libre à une main, il vous refufera tout d'un coup, fans que vous en puiffiez deviner la caufe ; \& ainfi changeant d'humeur, ou pour tourner, ou pour manier fur les voltes, il vous fera fouvent de pareilles équipées, $\&$ vous refufera tout net, \& parti. culierement lors que ce fera un fau. teur de quelque air que ce foit: mais que tout cela ne vous defefpere $\&$ ne vous inquiete feulement pas, revenez à vos principes, quelque folie, efcapade ou malice qu'il vous puiffe faire, fouvenez - vous qu'il eft befte, \& qu'il faut que vôtre fcience, prudence $\&$ jugement fiffe connoifte en ce rencontre la belle methode \& la longue parience de voftre art fi à propos, que voltre raifon le rameine à fon d voir ; étant tres-vray que ce qui fait ainfi manquer les chevaux, s'opi.iâtrer \& fe dédire, provient de 


\section{à Cheral.}

l'incertitude qu'ils ont s'ils font bien oumal; ce qu'il leur faut faire connoître autant que leur inftinct $\&$ voftre fcience le pourra permettre. Remarquez \&z pratiquez ces preceptes, \& croyez que fi vous les mettez bien en ufage, vous réüflrez fans doute en l'art de dreffer les chevaux.

\section{Chapitre $\mathrm{X} X$.}

Le moyen de connoitre à peu prés le naturel des Chevaux.

L ne peut y avoir que decing for1 res de natures de chevaux:Je fuis tres-certain que ceux qui liront ma propofition dans les premiers mots de ce Chapitre, ferone auffi furpris qu'étonnez, puifque tous ceux qui ont traité cette matiere, affurent qu'ils n'ont jamais renconrré deux chevaux de femblable nature, c'eft ce qui m'oblige de prier 
64 L'Art de monrer

mon Leeteur de neme pas condamner fans entendre mes raifons: $\&$ je croy que lors que je me feray expliqué, que beaucoup de perfonnes feront perfuadées de mon même fentiment, ou du moins on ne pourra m'accufer d'ignorance, \& voicy comme jefpere le prouver.

Je dis donc que bien que les naturels des chevaux nous femblent tous differens, $j$ 'cfpere faire voir qu'ils fe peuvent reduire à cinq principanx, ce que jay promis de prouver.

Puis qu'il eft vray de dire que le cheval, comme tous les autres animaux, ont en cecy le même avantage que l'homme, puis qu'ils participent comme luy des quatre élemens, defquels ils tirent leur eernperamment, fçavoir, du chaud, du froid, du fec \& de l'humide: Ce que les Medecins appellent la bile, le flegme, la melancolie \& la colere. Il me femble que je puis dire \&s affurer avec affez de vray- 


\section{à Cheval.}

Semblance, que de ces quatre qualitez il s'en peut former un cinquiéme, qui fait la derniere humeur ou naturel du cheval.

Qu'il ne foit ainfi, n'eft-il pas vray que le cheval fera tout à fait de bonne nature, ou qu'il fera entierement de mauvaife nature, ou bien qu'il fera de la mediocre, c'eftà-dire, pas tout à faitbon, ny aufi pascout à fait mauvais, ou bien qu'il inclinera plus fur la bonne que fur la mauvaife, ou qu'il participera plus de la mauvaife que de la bonne.

Cela fuppor'e, il n'eft pas impoffible de connoître le naturel d'un ou plufieurs chevanx, puis qu'ils fe peuvent racourcir à cinq, qui eft ma propofition prouvée.

Mais afin que chacun puiffe réuiffir en cette connoiffance, quelque cheval qui vous tombe entre les mains, foit jeune ou vieux, fi vous defirezle drefler \& connoître fon naturel, je vous confeille de le faire 
66 L'Art de monter

feller \& $<$ brider, de le faire conduire au manege, fans que perfonne foit deflus, puis vous luy ferez mertre le caveffon \& la grande corde; \& le ferez trotter au tour du pillier avec le plus de douceur qu'il vous fera poifible, ce que vous fcrez pour trois raifons. La premiere, vous luy conferverez par ce moyen le bouche \& les jambes. Secondement, vous ne metrrez point celuy qui feroit deffus en hazard. Et en troifiéme lieu, cefera le vray fecret pour apprendre en peu de temps la nature descinq cy-deffus, de laquelle il participera le plus, ce que vous ferez toujours de voltre travail, jufqu'à ce que le cheval vous fuffe connoître s'il eft de bor. ne ou mauvaife nature : ce que vous connoîtrezainfi, $f$ au bout de quelque temps vous obfervez qu'il fuye bien la chambricre, qu'il a. vance fans beaucoup de repugnance, \&z que de luy - même il s'achemine au tour du pillier, fi-tố 


\section{à Cheval.}

qu'il vous verra en pofture de luy en donner, ou que vous frapperez contre terre derriere luy; vous pourrez dire que c'eft un bon figne, \& qu'il n'eft pas entierement rebours ny méchant; cela fuppolé, \& qu'il continuë de vous obéir avec foupleffe \& prefteffe \& fans s'opiniâtrer. En un mot, lors qu'il fera toujours preft à partir lors que vous le defirerez, vous luy donnerez un peu plus de feu qu'à l'ordinaire, $\&$ I'obligerez de prendre le petit galot leger, que s'il galope facilement, il y a bonne efperance, \& vous le continuërez en cette bonne humeur, le flattant \& carreffant, afin de le rendre auffi certain $\&$ obéiffant de galop, comme nous avons dit de pas $\&$ de trot.

Aprés cela, vous effayerezàle faire changer de main, ce que vous ferez en cetre maniere. Lors que vous le connoîtrez obéifliant, \& qu'il fe difpofera à vous obéir, vous luy montrerez la chambriere de- 
vant luy, puis tout en même temps vous la changerez du côté contraire à ccluy que vous voudrez qu'il tourne ou change. Puis lors qu'il fera changé, vous le ferez continuer fon chemin en avant. Et ferez ainfi de temps en temps d'ane main à l'autre, jufques à ce qu'il foit tres-libre à vous obéir, $\&$ tors que vous ferez parvenu à ce point, vous aurez beaucoup gaigné Gar voltre cheval: Et vous n'aurez plus que deux chofes à obtenir, fçavoir de luy faire fuyr la chambriere d'uncôté \& d'autre, comme s'il fuyoir les talons. Er en fecond lieu, dele metre entre les deux pilliers; ron pour le faire fauter, mais bien pour le faire donner dans lescordes, tant que la longueur d'icelles vous le pourront permetre, tant en avançant, qu'en recu lant, afin finalement de l'obliger (1e metre fur les hanches, \& a lexer le devant fans malice, fans rougre \& fans précipicarion. En 


\section{à Cheval.}

un mot, toutes fes leçons ne terdent que pour luy donner la vraye obéiflance. Et lors que vous luy aurez affez long-temps fait pratiquer toutes ees leçons en fuire l'une de l'autre, vous viendrez affurément à raifon de tous les plus méchans \& vicieux chevaux qui fe pourront rencontrer. Vous fçaurez auffi pour conclure ce Chapitre, que je ne vous ay donné cét avis que pour les méchans chevaux ou. pour ceux qui n'ont été domtez:

Car lors que vous connoîtrez bien un cheval, \& que vous ferez affuré de fa bouche, de fon obéiffance $\&$ de fa foupleffe, il ne fera pas befoin de toutes ces précautions; $\&$ vous pourrez faire monter vôtre Ecolier deffus dés le premier jour. 


\section{Chapitie XXI.}

Les chofes qu'il faut abfolument que Sgache le bon Cavalier.

Durarrêter un cheval, on ufe de l'un de cestermes, felon la volonté ou habitude de celuy qui fait travailler ; le Maiftre profere l'un de ces mots, à l'un defquels il faut auffi-toft obéir, hola, parez, arrêtez, ou c'eft affez; en outre il faut fçavoir les quatre effets de la main, qui fe font du poignet feulement, fans que le coude, la tête ny les bras, non plus que le corps, y contribuënt.

On dit en bon terme de Cavalerie, échapper un cheval de la main, pouffer vertement un cheval, ou partir un cheval de la main, \& c'elt le premier effet de la main en baiffant le poignet $\&$ les ongles, ferrant le gras des cuiffes, \&z mettant 


\section{à cheval.}

un peu le corps en arriere, fans avancer le bras ny la main vers les oreilles du cheval.

On dit auffi, pour fe bien fervir des termes de l'Art, arrêter ou parer un cheval fur les hanches, qui eft le fecond cffet de la main, mettant les ongles en haut, pefant un peu fur les écriers, le corps ferme \& un peu en arriere.

Le troifiéme effet de la main, eft pour faire tourner un cheval à main droite, ce qui fe fait en tournant le poignet \& les ongles vers le côté droit, fans remuer le bras ny le coude.

Le quatriéme effer de la main, eft pour aider à tourner le cheval à gauche en tournant le poignet $\&$ les ongles vers le côté gauche, fans aufi remuer rien que le poignet.

Comme il y a quatre effers de la main, il y a auffi quatre effets de la gaule : la gaule croifée fur le col ou épaule du cheval, \& la pointe 
d'icelle en bas, ce quiaide à tournes àdroit.

Secondement la gaule au bout du nez $\&$ du côré droì, pour aider à tourner à gauche.

Troifiémement, la gaule par deffus les chauffes, pour jetter la crouppe hors la volte , \& enfin la gaule lelong des itancs $8 z$ derriere la botre, pour tenir les hanches du cheval fujettes.

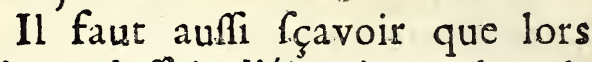
qu'on a deffein d'élargir un cheval, $\&$ le conduire large lors qu'il s'étreffiit de luy-même, il faut avoir la gaule dedans.

Comme auffi s'il s'elargit par trop, 22 qu'on le veuille érreflir, il faut porter la gaule dehors.

Il faut aufi fçavoir qu'il ne faut jamais ôter la gaule aprés avoir changé, ny porrer du côté du dehors, que lors que le cheval a bien repris fa pifte, quil ne chemine affez large, \&z quil ne foir fur le bon pied. 


\section{à Cheval.}

II faut auffi encendre, que lors que l'on parle de la main quand on eit a cheval, que cela s'entend la main gauche; $\&$ quand on dit, cet homme a la main bonne, c'eft ì dire la main gauche.

Il faut auffi $f_{\text {ça voir }}$ que lors que le cheval manie, trotte ou galoppe à main droite, que la jambe du dedans eft la jambe droite, \& lors qu'il manie à gauche, la jambe gauche eft celle qu'on appelle l'aide du de. dans.

Lors que l'on fe fert de la gauche dedans pour élargir un cheval, il faut aufí approcher l'eperon comme la gaule, \& du même colté, \& faire le même de l'éperon, \& de la gaule contraire, lors qu'on le veut étreflir. 


\section{Chapitre XXII.}

Ies chátimens \& les aides que l'on donne aux chevaux, or leur difference.

Es éperons, de la gaule, de la voix, des deux cordes du caveffon, du gras des cuiffes \& de la chambriere.

Les aides fe donnent de la langue $\&$ de la gaule, du mouvement des cuifies, des jambes, de l'éguillon, du poinfon, \& 2 du talon fort délicat.

Et la difference qu'il y a entre les aides \& les châtimens, c'eft que les châtimens font affez rudes, \&z les aides tres-délicates. 


\section{Chapitre XXIII.}

\section{Pour cennoiftre fa un cherual eft. drefsé.}

TL faut le chaffer en avant, le tirer en arriere, puis le chaffer derechef en avant, l'arrefter fur les hanches, \& en l'arreftant effayer de luy faire marquer deux ou trois pofades, le repartir encore une fois ou deux, \& voir s'il pourroir faire deux ou trois courbettes à l'arreft; aprés il luy faudra faire fuir l'un \& l'autre talon, comme auffi la volte renverf'ee, le porter d'un cafté \& d'autre fur deux lignes paralelles, le porter de cofté la tefte contre une muraille, puis luy faire fuir le talon en avançant, comme aufli le même en reculant; s'il obéit bien à ce que deflus, fans malice, précipitation ny. inquiétude, il doir eftre dreffé, ou bien acheminé. 
Si l'on vous demande ce que c'eft: qu'un cheval dreffé \& achevé, répondez hardiment, c'eft un cheval qui eft tres-bien dans la main, \& dans les talons, \& qui ne fçair ce que c'eft que de refufer la main, non plus que le talon.

\section{C hatitre XXIV.}

C'e qu'il faut qu'wa Cavalier fgache pour pouvoir fe dire bon homme de cheval, or'en bien fervir.

I un homme fe veut vanter d'eftre bra homme de cheval, \& qu'ille veuille dire fans vanité $\&$ fans fe fluter, il faut qu'il poffede les qualicez qui s'enfuivent.

En premier lieu, il faue quil le fçache échapper vertement de la main, \& qu'il le fçache juftement arrefter.fans le forcer ny incommoder les hanches à fon parcir ou arreft, qu'il le f̧ache lever de ferme à 


\section{à Cheral.}

ferme, qu'il fçache la difference qu'il faut faire entre le lever à pofades ou à courbettes, qu'il entende à le bien \& délicatement guider d'un talon fur l'autre, foit en avançant comme en reculant.

Outre cela il doit le fçavoir faire trotter \& galopper bien rondement, \& connoiftre quand il galoppe faux, ou s'il ent bien enfemble, \& bien uny.

Il faut encore qu'il le fçache galopper fur les quarre lignes de la volte, ce que l'on appelle rravailler en quarré, \& qu'il le fçache bien chaffer en avant; finalement, il doit avoir l'adrefle de le bien tourner de la main fur chacun des quatre coins ou angles de la volte, qui eft, pour tout dire, fçavoir bien guider $\& z$ conduire d'une main à l'autre.

Pour bien entendre ce que je viens de dire, il faur de neceflité fçavoir, que s'il fe pouvoit faire, pour ainfi parler, que le cheval pût eltre reparé en deux également,

G iij 
tout ce qui feroit depuis la premiere cofte jufques au bout de l'oreille fe doit appeller, \& eft abfolument dir \& nommé de la main en avant, \& c c'eft la main feulement qui guide certe partie, ce qui refte depuis ladite colte jufques au bout de la queuë, eft dir ou s'appelle de la main en arriere, $8 x$ c'eft abfolument le talon qui guide $3 x$ conduit cette derniere partie ; c'eft pourquoy on dit, pour parler en bon terme, ce cheval ert beau de la main en avant; comme on dit auffi lors que le cheval a la crouppe belle avec les parries du derriere : Voila un beau cheval de la main en arriere.

Cela fuppofé, comme il eft vray, il eft facile de faire manier un cheval de quelque air ou manege que ce foit, \& le conduire de la maniere que l'on voudra, pourvú qu'il foir dreflé, \&z que le Cavalier fçache bien accorder la main avec le talon, fçavoir que la main commence toujours le premier effer, \& que le 


\section{a Cheral.}

talon fuive immediatement aprés, eftant tres-neceffaire que la tefte \& les épaules cheminent toujours les premieres, \& les hanches fuiven tout auffi-toft aprés, qui eft le vray effet $\&$ la concordance de la main $\&$ du talon.

Sil'on veut que le cheval manie droir, il le faut chafler en avane, \& pour cet effet on doir avoir la main. tres-ferme \& fort égale, les talons auffi bien égaux \& affez proches du cheval, afin qu'il ne traverfe pas, fi on le tire arriere, il faut qu'il recule auffi droit qu'il a avancé.

Et lors que vous le porterez d'un talon fur l'autre, il faudra en ufer de la même maniere, conduifant la tếte \& les épaules avec la main, \& les hanches avec les talons, avec plus ou moins de vigueur que le cheval obéira aifément.

Voila le plus briévement que j'ay peu traiter de ce que le Cavalier a befoin de fçavoir pour fe pouvoir dire homme de cheval, je viens prea

G iiij 
fentement aux plus courts $\&$ affurez moyens done il faudra ufer pour dreffer des chevaux.

Je ne parleray point de tous les airs ou maneges relevez \& chevaux fauteurs, pour en traitter à fonds ne l'ayant pas jugé neceffaire; ce petic abregé n'etant fimplement qu'un manege de guerre, je vous les nommeray pourtant tous à la fin de ce petit cuvre, je vous les feray connoiltre chacun par leur propre nom que je leur donneray, \& leur définition.

\section{Chapitre XXV.}

Ie moyen de dreffer les Chevaux.

T. Ors que vous aurez bien confideré \& f çu tout ce que je viens de déduire cy-deffus, vous ferez conduire au manege voltre cheval, \& ferez monter quelqu'un deffus, \& aprés luy avoir mis le cavefon, \&z attacher la grande cor- 
Page 80

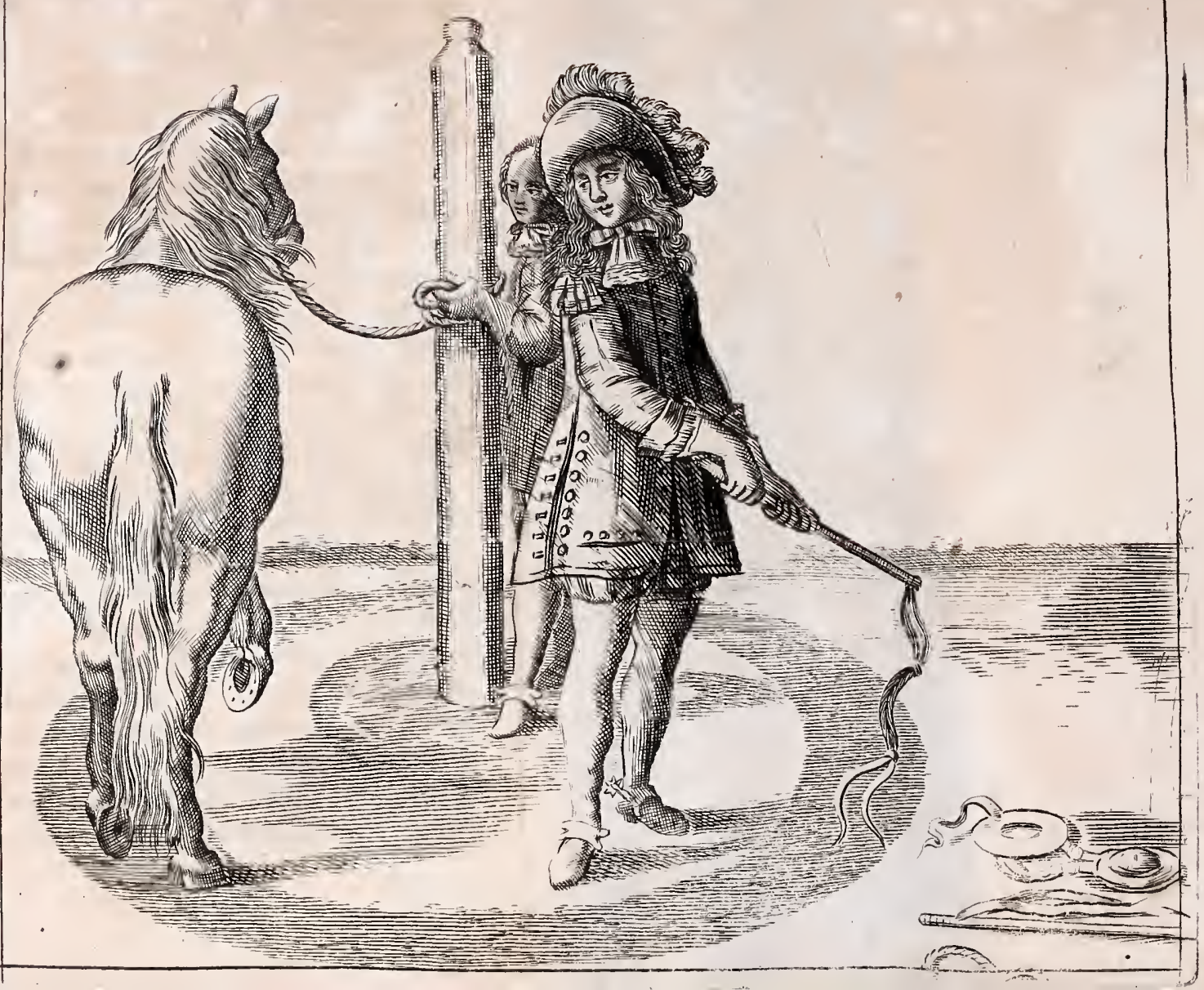




\section{a Cheral.}

de, vous le ferez trotter autour du pillier, avec autant d'étenduë que l'efpace vous le pourra permettre, $\&$ le travaillerez fi à propos, qu'il chemine fur les quatre lignes de la volte, \& non pas en rond, \& la tête dedans la volte, qu'il foit droit, qu'il regarde fon chemin, \& qu'il. chemine toujours en avant, $\&$ vous fouvenez que-ces premieres leçons font la baze \& le fondemene de tout le métier; qu'il regarde donc du coßé qu'il ira, foit à droit ou à gauche, quil porte la telte droite \& ferme, \& lors qu'il fera capable de galopper, qu'il ne galoppe jamais faux ou fur le mauvais pied, que l'on appelle fe defunir ou trầner les hanches, que s'il galoppoit faux vous vous fervirez de l'un de ces moyens poury remedier; vous le remetrez au trot fans l'arrefter, puis vous luy laifferez derechef prendre le petit galop, julques à ce qu'il fe remetre fur le bon pied, \& qu'il s'uniffe tant d'epaules que de 
82

\section{L'Art de monter}

hanches, ce qu'on appelle cheminer fur le bon pied.

Mais fi c'étoit un cheval qui connût les talons, voicy le remede. Par exemple, fi galoppant à main droite, il fe defuniffoir, changeaft de pied ou galoppoir faux, vous luy ferez appuyer le talon gaiche affez vertement une ou deux fois, jufques à ce qu'il s'uniffe: $\&$ fi galoppane à main gauche, il commettoit la même faute, vous luy feriez donner du talon droit, tant qu'il fe remit en ordre. Souvenez-vous auffi de n'avancer jamais voltre cheval, \& ne l'embarraffez point de quantité de differentes leçons, qu'il ne porre la tefte droite, qu'il ne galoppe fans changer le pied, qu'il ne foit un peu dans la main, qu'il n'entende en quelque façon, \& ne fouffre les talons, \& qu'il n'obéifle aucunement au poing de la bride, \& pour dernier avis, ne luy demandez rien de jufte, que vous ne l'en connoiffiez capable. 
C'eft à quoy vous parviendrez facilement, fi vous le trottez, \& galoppez avec patience \& douceul'efpace de trois mois, avec les précautions dont je vous ay averty, plus ou moins, felon fa bonne ou mauvaife volonté, \& fa memoire, \& fur tout felon voftre jugement, car s'il vous obéiffoit bien au bout d'un mois ou fix femaines, il ne feroit pas befoin de le tenir plus long-temps à cette leçon.

\section{Chapitre XXVi.}

Uand vous verrez que voftre cheval trottera ou galoppera bien uny, qu'il regardera fon chemin à droit comme à gauche, qu'il ne fera point la volte couchée, \& qu'il ne fe panchera point en galoppant, alors vous pourrez effayer de le changer de main, ce que vous ne ferez que de pas à l'abord, \& fur l'un des quatre coins de la volee, 


\section{4 \\ L'Art de monter}

craine qu'il ne fe couche en changeant de main.

Prenez aufi garde de piés de le guider \& $z$ conduire en avant, fans le laiffer acculer, ce que vous ferez aumi fans le trop preffer ny inquicter, afin que la patience dont vous uferez, luy faffe comprendre ce que vous defirerez de luy, \& auffi qu'il vous obéiffe de bonne volonté, \& fans contrainte; \& cette leçon fera continuée filong-temps qu'il la faffe certainement de pas, de trop \& de galop.

Cela fait, \& le chéval en étant bien afluré, \& fur tout qu'il porte la tefte en beau lieu, fans faire le col roide, ny autre vilaine ou mauvaife pofture, vous luy pourrez ôter la corde, \&z le laiflant fur la foy de celuy qui fera defius, vous le ferez promener par le droit, \& luy donnerez un peu plus de liberté \& de terrain que devant, s'il vous obéii à la bonne heure, vous le carrefferez forr, \& luy ferez donner du pain ou 


\section{à Cheral.}

del'herbe, \& s'il continuë de bien faire encore une fois ou deux, puis vous le renvoyerez à l'Ecurie, aprés l'avoir fort carreflé.

Mais fi au premier jour de vôtre travail il luy prenoit fantaifie de vous defobéir, ne fçachant pas encore bien ce que vous luy demandez, vous ne le châtirez pas pour cela, mais vous luy ferez remettre la grande corde, \& retournerez ì vos principes, $\& 2$ ainfi peu à peu avec grande patience \& jugement, vous le fercz parvenir à ce que vous defirercz.

Au bout de trois ou quatre jours, \& fuppofé qu'il vous aye bien obéi fans corde $\&$ fans aucune répugnance, ny malice, tout de même au galop comme au tror, vous le ferez, conduire dans une plus grande efpace, là où vous le trotterez \& galopperez par le droit, felon voftre prudence, autant que fa bonne vo. lonté \& $\mathrm{fa}$ force le pourront permetere; ce que vous continuërez 
par plufieurs matins, jufques à ce qu'il n'y manque plus, \& lors qu'i] le fera avec facilité, vous effayerez en l'arreftant de le preparer à s'affeoir fur les hanches, afin de fermer fon arreft, que s'il s'y prepare, que ce foir le plus droit que vous pour rez, fans fouffrir qu'il fe traverfe à l'arreit, ny qu'il s'impatiente, ce que vous continuërez par plufieurs jours, tant qu'il fe mette en devoir de baiffer les hanches, fi-toft qu'il fentira que l'on mettra le corps en arriere, \& qu'en effer il s'arreftera avec quelque certitude \& facilité de bouche, fans branler ny remuer la tefte, ny forcer la main, lors vous le ferez conduire en un lieu un peu panchant, ou calade, afin de luy donner plus de facilité $\&$ d'airance de s'affeoir fur les hanches, \& continuer quelque temps cette leçon, afin de luy accoûtumer \& luy apprendre à lever le devant fans impatience, afin qu'il puiffe marquer quelques trois ou quatre pofades 


\section{à Cheval.}

au parer ou à fon arreft, \& lors qu'il vous obéira à voltre plaifir, vous efrayerez de le faire reculer, le tirant arriere de 12 maniere que je vous vay enfeigner. Et fi voltre cheval ne vouloir pas vous obéir, alors vous mettrez pied à terre, \& ferez monter quelqu'un deffus, \&z luy donnerez plufieurs coups de caveffon; \& s'il ne vouloit vous obéir pour cela, vous prendriez un bâton, \& luy en donneriez deffus le nez.

Premierement avec l'aide des deux longes du caveffon, puis au bout de quelque temps avec le caveffon \& la bride enfemble, puis lors que le cheval en fera capable, avec la bride feule.

Mais j'entens que tout ce que je viens de dire fe faffe avec la plus grande douceur $\&$ le jugement le plus net, qu'à aucune leçon que je vous ay enfeignée, y donnant toute la patience \& le temps qui fera neceffaire pour cette belle methode, 8. fur tout en executant cette leçon, 
prenez bien garde d'incommoder la bouche, les barres, ny le barbochet \& fous-barre du cheval.

Remarquez encore cecy, \& l'apprenez bien, içachez que le caveffon eft donné aux chevaux pour plufieurs raifons, mais on s'en fert pour rois principales. La premiere, pour leur plier la tefte, le col, \& les épaules. La feconde, pour leur conferyer la bouche. Et la troifiéme, pour leur faire aimer $\&$ fouffrir la bride.

Que donc le cavefion leur faffe mal ou non, il n'importe, voir même il eft plus à propos qu'il les fafle pâtir, pourvâ que ce ne foir avec trop de violence, afin que la douleur que leur fera le cavefion par le dehors, leur donne à connoiftre que le mors ne les incommode $\&$ ne les blefte pas dans la bouche, \& fe fervant ainfi à propos du caveffon, cetre petice douleur exterieure caufée parledic cavefion, leur fera non feulement fouffrir la bride, mais il la Leur fera rant aimer, qu'ils pren- 


\section{à Cbeval.}

lront goût à mâcher le mors, ce qui eur rendra la bouche fraîche, gailarde ,écumante \& plaifante.

\section{Chapitre XXViI.}

Ors que le cheval fera tout-ìfait au point que vous venez ícurendre, il faudra le conduire lans un lieu fpacieux, où le trotant \& galoppant par le droit quelque cent ou fix-vinge pas, vous efayerez de le changer de main, fans acculer en le changeant.

Prenez aufi un foin tout parti- ulier de luy donner affez d'efpace oour tourner, faices auffi en forte, que chaque pas qu'il fera foit bien en avançant $\& z$ s'arondiffant; \&c pour dernicr avis, travaillez fir-bien que lors qư il aura fait fon tour, qu'il e tourne fur la ligne par laquelle 1 étoir venu, puis qu'il continuë on chemin le plus droit que faire e pourra, afin d'aller prendre fon 
autre tour à main gauche de la même methode que j'ay enfeignée à droit.

Je vous avertis que vous ne fe. rez cette leçon que de pas $\&$ de trot, jufques à ce que voltre cheval y foit tres-certain, \& qu'il change de pas \& de trot avec liberté de refte, de bouche \& d'épaules, \& lors qu'il fera en cet eftat, vous lo pourrez obliger a prendre le petit galop leger, \& le changer au bour des lignes à droit \& à gauche de la methode que je vous ay enfeignée de pas \& de trot: mais lors qu'il aura bien obéi $8 z$ changé avec juIteffe, en marchant en avant \& $\mathrm{en}$ s'arondiffane, arreftez-le, \& le carreffez fort, \&z luy faires donner de lherbe, afin de luy faire connoifte quil vous a contenté, puis fans l'inquieter ny furprendre, vous effayerez de lo faire reculer quatre ou cinq pas, \&z continuërez par trois ou quatre fois, \& autane de fois quall vous obéira, vous le carrefie- 
rez fort, \& luy ferez donner du pain, finalement vous le conduirez au petit galop; jufques au bout de la ligne, puis vous le changerez à gauche, comme jay. enfeigné à droit, s'il vous obéit, arreftez-le, $\&$ le tirez en arriere comme devant, puis luy donnez halcine, afin qu'il ne fe rebute point, puis le renvoyez à l'Ecurie; \& je vous donne pour toutes ces leçons autant de temps que voftre prudence $\&$ voftre fcience le jugera neceffaire pour y bien accoûtumer le cheval, afin qu'il le faffe agreablement avec facilité \& $\mathrm{plaifir}$; à quoy étant parvenu, vous pourrez au premier jour de voftre exercice le galopper legerement, \& le changer de main jufques à trois ou quatre fois; s'il vous obéir, carreffez-le, afin de. l'obliger à prendre plaifir une autrefois, \& ainfi qu'il demeure en eftat de vous contenter lors que vous Ie defirerez: Et afin qu'il demeure toujours en eftat \& en vo= 
92

lonté de vous fatisfaire, donnez-luy du pain, \& aprés l'avoir fait reculer $\&$ avancer par plufieurs fois, vous luy donnerez grande halcine, faites-luy réiterer cetre leçon par deux ou trois reprifes, puis l'ayant beaucoup flacté \& carreflé, vous l'envoyerez à l'Ecurie.

Si au premier jour de voltre exercice il ne vous obéiffoit pas, foit par fantaifie, ou par caprice, ne vous fầchez point, \& ne le mettez poine en colere, au contraire, traitrcz-le doucement, \& revenez à vos premieres leçons avec grande patience, faites fi-bien qu'il rentre dans fon devoir, \& conrinuez ainfi jufques à ce qu'il fafle toutes ces leçons, \& qu'elles foient bicn imprimécs dans fa memoire; \& lors qu'il fera bien obéiflant, vous ferez au premier jour de voltre travail ce que je-vous vay enfeigner : vous luy ferez mettre la grande corde, puis le ferez conduire au pillier, \&z buy metrrez la tefte vis-à-vis d'ice 


\section{à Cheval.}

luy, \&z eflayerez de luy faire fuir les talons, ou entendre les talons, ou connoiftre les aides des jambes: tous ces termes ne fignifient qu'une même chofe, vous luy ferez donc fuir les talons avec le plus de douceur $\&$ de patience que vous pourrez, luy donnant à connoiftre ce que vous defirez de luy, tournant le poignet à droir, \& approchans aufí le même talon, \& ferez en forte que la tefte demeure toujours vis-à-vis du pillier, que s'il vous obéit peu, ne le preffez pas pour en tirer davantage, \& vous gardez bien de le mettre en colere, au contraire, carreffez le foudain, puis quelque remps aprés réiterez ce que deflus, jufques à trois ou quatre fois, avec la même patience, \& s'il vous defobéit, n'y eftant pas accoûtumé, ne l'opiniâtrez pas, mais ôtez adroitement le talon, \& le tirez un pas ou deux en arriere, $8 \tau$ concinuez jufques à ce qu'il vous obéifle, afin que par cetre patience 
94

\section{L'Art de monter}

\& douecur, vous luy puifficz apprendre à fuir tant foit peu les talons. Enfin s'il vous obéii renvoyezIe à l'Ecurie, aprés l'avoir carrefl'e, faites-luy donner quelque forte de plaifir , \& apprenez que cette maniere de faire ainfi travailler les chevaux fe fait pour deux raifons : la premiere eft, pour bien leur apprendre à connoiftre les talons: 82 la feconde, pour leur placer la tefte, le col, \& les épaules.

Sçachez auffi de plus, que cette façon de guider les chevaux fe nomme la volte renverfée, d'aurant que les épaules font le petit rour, \& les hanches \& la crouppe font le grand, qui eft le contraire, ou le revers de la veritable volte.

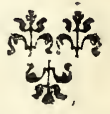




\section{Chapitre XXVIII.}

7 Ous ferez tant par voltre travail, \& employerez fi - bien le temps \&z le foin quil y faudra pour le rendre bien certain à fuir l'un \& l'autre talon par le moyen \& la methode que je vous ay enfeignée, fans qu'il faffe le col roide, fans branler la tefte, fansfe précipiter ny inquieter, que vous ne pourrez plus douter de fon obéiffance ; En un mot lors qu'il le fera fans aucune répugnance, avec foupleffe \& facilite, alors vous luy apprendrez à fuir les talons par une autre methode.

Vous choifirez une muraille propre à voftre deffein, de la longueur de vingt-cinq ou trente pas, puis vous luy mettrez la tefte vis - à - vis d'icelle, lors tournane un peu le poignet à droit, vous approcherez le talon gauche, le guidant de la 
main $\&$ du talon, jufques à l'excrémité de ladite muraille, \& lors que vous y ferez arrivé, aprés a voir carreffé le cheval, \& refté quelque remps aprés en cet eftat, vous tournerez le poignet à gauche, \&z approcherez le talon droit afin de conduire voltre cheval, is le remettre au licu même d'où il étoit parcy lors que vous avez commencé voltre premiere leçon.

Ce que vous continuërez fil longtemps, qu'il le faffe avec facilité \& plaifir, fi-toft qu'il fentira que le Cavalier tournera la main, \& approchera le talon, \& lors qu'il aura bien obéi , vous le carreffercz fore, \& luy ferez donner de l'herbe tout autant de fois qu'il aura bien fair, au contraire, s'il luy prenoir fantaifie de vous defobéir , $8 z$ s'il fe précipitoit fur le talon conEraire, vous aurez recours à voltre premiere leçon, luy faifant mettre la grande corde, \& la tefte vis-à-vis le pillier, comme jay déja enfeigné.

Enfin 


\section{à Cheval.}

Enfin, pour dernier avis decetre leçon, \& afin que vous en puiffiez tirer la derniere obéiffance, fuppofé que vous l'ayez porté ou conduit lelong de la muraille, du talon droit fur le gauche, lors que vous l'aurez conduir jufques au bout, il le faudra renfermer en cette maniere, fçavoir, en tournant fi bien la main \& le poignet à droit, \& approchant fi à propos le talon droit, que le cheval fe trouve renfermé dans l'angle qui doir être finireur de la muraille, puis lors qu'il aura été quelque tcmps en cetre pofture, vous luy remetrez derechef la tête vis à vis de la muraille, par le moyen du ralon gauche, rournant aufí le poignet $\& z$ les ongles à gauche, afin de le mertre èn érat de fuyr le talon gauche de la même forte quel'on luy avoit fait fuyr le droir; aprés vous le conduirez jufques à l'exrremiré de la muraille, où écant arrivé, vous le renfermerez avec le talon 
98 L'Art de monter

gauche, de la même merhode que je vous ay donnée du talon droit, \& c'eft à cette leçon qu'il faut rendre voltre cheval bien certain, bien fouple $\&$ bien obéiffant, dautant qu'elle fe pratique quafi à tous momens, foir en le portant de côté, foit en fermant une paffade, ou pour le tenir fujet entre les talons, ou bien pour le porter d'un talon fur l'autre, fur deux lignes paralelles, ou finalement pour le bien mener fur les voltes. C'eft ce qui me fait confeiller au Cavalier de la bien imprimer dans la memoire du cheval,afin qu'il y foit bien certain, libre, obéiflant \& fouple.

\section{Chapitre XXIX.}

E que deffus bien imprimé dans la memoire du cheval, \& luppofé qu'il n'y manque point, vous le ferez conduire dansle licu demanege, où prenant affez d'ef- 


\section{ì Cheral.}

pace, vous le ferez trotter $\&$ galopper fort legerement fur les hanches, comme aufie fur les quarre lignes quarrées, la tête ferme, bien dans la main \&z fur le bon pied, \& en empêchant qu'il ne fe panche ou faffe la volte couchée, puis vous l'arrêterez de temps en temps fur les hanches, en luy levant le de. vant, \& luy faifant marquer deux ou trois pofades au parer, ce que vous concinuërcz jufques à trois ou quatre fois, faifant toujours comme je viens de dire, \& luy faifant grande carefie, \&zlors qu’il obéira bien, \& luy donner auffi beaucoup d'haleine entre les reprifes, \& le renvoyerez à l'Ecurie : Mais au premier jour de voftre travail, vous le galopperez fur les quatre lignes droizes, \& l'arrêterez fur les hanches, au bout de chacunes d'icelles vous luy leverez le devant au parer, puis vous le ferez reculer Erois ou quatre pas, \& vous continuërez ce rravail cing ou fix jours 
durant, afin de preparer voltre cheval à ce que j'ay dit,qui eft de changer de main fur l'une des quatre angles de la volte ou extremité de l'u. ne des lignes.

Aprés donc que vous l'aurez rendu tres-certain à tout ce que deffus, vous effayerez de le faire changer fur l'extrernité de l'une des lignes, comme j'ay dit, ce qui s'appelle travailler en quarré, ou de quart en quart, \& conduire ou guider un cheval d'une main à l'autre, ce qui fera continué jufquesà trois ou quatre reprifes par chaque jour, l'arrêrant de fois à autre pour luy donner plaifir, le carcfiant auffi toutes les fois qu'il obéira bien, vous ne manquerez pas aufi de le lever, \& le faire reculer \& avancer à tous les arrefts, \& le faire reculer \& avancer affez fouvent ; comme vous n'oublierez pas aufli de luy faire fuyr les talons, afin qu'il refte roujours dans la veritable obéiffance : \& fur tout, prenez bien 


\section{à Cheval.}

garde que tout ce qu'il fera foit en demeurant fort droit, fans fe traverfer \& pancher, ny s'éloigner d'un cofté ny d'aurre, $\&$ je vous donneray pour toutes ces leçons un mois ou fix femaines, ce que vous réirererez par cinq ou fix reprifes chaque jour de voltre trayail, fans oublier de le chaffer en avant, le tirer en arriere, \&z luy faire bien fuyr les talons, le lever devant, \& luy faire marquer les pofades; le tout avec grande douceur \& patience.

\section{Chapitre $\mathrm{X} X \mathrm{X}$.}

T Ors que vous aurez gagné tout ce que deffus, \& bien mis dans la memoire de voltre cheval, il fera fort avancé \& bien en état de vous fervir pour la guerre $\$ 2$ pour le combat particulier : mais jedefire qu'il faffe quelque chofe de plus, comme les paffades de trois temps.

I iij 
C'eft ce Manege que l'on doir weritablement nommer jufte : car route l'adreffe du Cavalier, \& toute la juftefle du cheval jointe avec leur vigueur \& foupleffe, fe font évidemment connoître \& ad. mirer en cette forte de Manege : Je veux vous enfeigner le moyen de les pouvoir apprendre au Cheval, \& la methode de les faire pratiquer au Cavalier.

En premier lieu, vous conduirez voltre cheval le long d'une ligne droite, bornée ou non bornéc; comme par exemple, le long d'une muraille ou chemin, de l'étenduë de trente ou quarance pas, où étant arrivé vous le conduirez de pasle long d'icelle, auffi loin que vous aurez deffe in que voltre paffadefoit longue: \& lors que vous fercz dans le deffein de luy faire former la paffade, vous metrrez le corps en arricre, peferez un peu fur les étriers, ce quil'obligera de s'affeoirfur les hanches, \& lors que 


\section{à Cheval.}

vous fentirez qu'il commencera de les baiffer, vous rournerez adroitement le poignet vers la main droite, ce qui luy conduira la têre, \& les épaules, puis vous approcherezle talon gauche immediatement aprés qu'il fera fuivre les hanches four former le premier temps. En fecond lieu, vous tournerez encore le poignet comme devant, \& conduirez aufli la croupe du même talon gauche, afin de former le fecond temps. En troifiéme lieu, vous tournerez encore le poignet à gauche, \& accorderez fi bien le même talon gauche, que vous fermerez \& accomplirez la paffade, en forte qu'il fe trouvera la tête où il avoit 1 croupe lors que vous aurez commencé vôtre leçon, ce qui s'appelle paffade jutte de trois temps: Manege, comme jay dit, beau, julte \& tres-difficile, car il eft requis qu'il fe fafle de tel jugement, que le Cheval marchant \& s'arrondiffant felon la conduite de la

I iiij 
104

main \& des talons du Cavalier ; de telle addrefle qu'il fe puiffe juftement trouver fur la même ligne fur laquclle il étoit premierement party, autrement la paffade ne fe pourroit pas nommer julte. Enfin aprés avoir fermé \& accomply vôtre paffade comme vous venez d'entendre, il faudra preparer le cheval à former la paffade à gauche comme à droit, pour à quoy parvenirvous travaillerez en cetre maniere: Vous carcfferez voltre cheval, le tirerez en arriere, le chafierez en avant, le leverez devane, puis enfin le conduirez de pas jufques au bout de la ligne, \& lors que vous y ferez parvenu, vous luy ferez former la paffade à main gauche de la même methode que j'ay démontrée à droir, \&z y obferverez tous les mêmes aides, finon que pour le tour à gauche vous tournerez le poignet à gauche, \&z approcherez la jambe droite ou le talon droit, \& continuërez cette leçon quinze 


\section{à Cherval.}

jours, faifant faire trois ou quatre reprifes chaque jour avec grande patience $\&$ douceur , $\&$ de pas feulement, jufques à ce qu'il y foir trescertain, fans s'impatienter ny precipicer, ny faire aucune mauvaife action.

Mais lors que vous ferez tresaffuré de fon obéiflance, vous le pourrez partir de la main jufques au bout de la ligne, où vous liarrêterez fur les hanches, puis vous le tirercz en arriere \& l'échapperez ainfi deux ou trois fois d'un bout de la ligne à l'autre, afin dele bien affurer.

Finalement, en vous fervant bien à propos des preceptes que je vous ay enfeignez, vous le laifferez partir, \& luy ferez faire deux paffades de chaque main, qui feront fi vigoureufes \& fi juftement foûtenuës, qu'il ne dẹmeure pas, \& qu'il ne force pas auffi la main. En un mot il le faudra conduire de tel jugement, qu'il relte toujours 
en bonne école \& jufteffe; ce qui fera continué chaque jour de voftre travail, fi long-temps que vous connoiffiez qu'il fera toujours preft de vous fatisfaire lors que vous le defirerez, $\& z$ qu'il le fafle fansaucune faure ou defordre, ce quife fera auffi avec la même methode, jugement \& patience dont j'ay fouvent parlé.

Vous affurant que fi vous executez bien cette leçon, foyez trescertain que vous viendrez à bour de toutes les autres : car elle eft la plus belle, la plus jufte $8 z$ la plus difficile de toures. Et vous vous fouviendrez que de cette forte de paffade dépendent toutes les autres, comme la baze \& le fondement de tout ce quil y a de parfait $\&<$ de jufte dans l'Art de monter à cheval : car il faut que le cheval le fcache, qu'il aye affez de force, de vigueur, de volonté $\&$ de foupleffe pour y fournir; car s'il y avoit aucun défaut, on 


\section{à Cheval.}

ne la pourroir pas nommer paffade jufte de trois temps, puis que fa vraye définition eft celle qui paffe \& repaffe fur la même ligne fans s'égarer du chemin ou pifte, marchant en avant \& s'arondiffant fi juftement en faifant fon tour, qu'il fe trouve aprés avoir marqué ces trois temps \& fermé \& accomply fa paffade fur la même ligne par laquelle il étoit venu en cette façon, fçavoir, les épaules oppofées aux hanches, \& les hanches aux épaules, \& qu'elle foit commencée \& achevée de la même force, cadance, vigucur, \& ćgalicé de temps \& de terrain, 8 facilité de bouche, en marquant tous lestemps égaux \& de même hauceur, \& quil accompagne fon manege de deux ou trois courbettes, \& fon arreft: Et cela ne fuffir pas encore, mais il eft auffi abfolument neceffaire que le Cavalier poffede afiez de talent en fon métier, \&z qu'il aye aflez de feience, de jugement \& de jultefle 
pour le pouvoir faire executer au cheval. C'eft ce qui m'oblige de vous avertir de tres-bien étudier cette leçon, \& la faire fouvent pratiquer \& comprendre aux chevaux defquels vous aurez deffein de vous fervir pour la guerre ou pour le combat particulier, afin de vous en pouvoir fervir au befoin.

\section{Chapitre XXXI.}

TL y a une autre paffade ou maLiere de fire rourner les chevalix, que l'on nomme demie volte, ou tour de quatre temps, que j'ay jugé devoir apprendre au $\mathrm{Ca}$ valier, quoy qu'elle ne foit pas fore nec flaire à la gucre, non plus qu'au combat particulier: mais je trouve certe maniere excellente pour faciliter le moyen aux chevaux de pouvoir apprendre les parfades jultes de trois temps, dautant que les chevaux fe fentans in. 


\section{à Cheval.}

commodez en ne marquane que trois temps, ont impatience p.r la douleur qu'ils fouffrent aux hanches, \& par cette crainie, n'y étans pas accoútumez fi bien que ceux qui connoiffent ce défaut en leurs chevaux, qui provient manque de force, d'agilité, foupleffe, ou habitude ; je leur confeille de leur laiffer prendre jufques à quatre ou cinq temps, en les tournant, a fin de les accoûtumer, "crainte qu'ils ne fe rebutent, \& qu'ils ne refufent le poing de la bride, \& ne defobéiffent à la main, pourvû pourtant qu'ils ferment leurs paffades, ou plûtoft demie-volte, \& que la croupe n'échappe pas, retournant toujours fur leur même ligne, comme i’ay dit aux paffades de trois temps, afin qu'ils foient en état de repartir fur la même ligne, poue tourner a uffi bien juftement au bout d'icelle, comme jay enfeigné cy-deffus : \& ainfi changeant d'une main \& d'autre, en donnant faci- 
lité par le moyen du terrain $2 x$ de l'efpace que l'on leur donnera, ils s'accoûtument à bien tourner $\& 0$ béir au poing de la bride, pour enfin parvenir aux paffades juftes.

\section{Chapitre XXXII.}

\section{Des Pafsades de la main a la main.}

I fait bien le plus fait bien 2 le moins, c'cft ce qui ma obligé de mettre \& traitter de cette maniere de paffade de la penultiéme, quoy qu'elle foit la plus facile à executer, elle eft neanmoins tres-neceffaire pour la guerre, \& tres-utile pour bien égayer les chevaux à la campagne, \& pour les tenir autant en école, comme pour leur continuer l'exercice \& I'haleine, leur faifant pratiquer la belle galoppade.

On la nomme paffade de la main à la main, dautant qu'il n'y a que la 


\section{à cheval.}

main qui doive contribuer à cette forte de Manege : Il faut feulemene prendre garde que le cheval foit bien enfemble, s'uniffe, \& qu'it refte toujours fur le bon pied, ayant feulement une hanche dedans, afin qu'il ne foit point en danger de s'abattre lors que le Cavalier voudra changer de main, \& faire caracolle ; c'eft ainfi que l'on dit les Chevaux tourner de bouche \& d'éperon, fans avoir jamais été inftruits au Manege, c'eft feulement de leur bonne volonté, fans fe fervir d'autre aide que de la main, \& les virevouftans à la fantaifie de celuy qui eft deffus. Elle eft encore appellée paffade de la main à la main, dautant quele cheval eft toujours conduit $\&$ guidé d'une main à la main, foit en tournant ou en ferpageant.

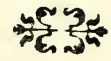


Chapitre XXXIII.

\section{Des Piroüettes.}

Es Pirouiettes ou demy d'un diemps, eft un air ou manege de grande prefteffe, agiliré \& foupleffe, où l'habitude y eft auffi tresneceffaire, joint avec l'addreffe de l'Ecuyer, qui fair voir par certe forte de manege fa belle methode, aufi-bien que fa fcience. Er il faur outre tour ce que je viens de dire, que le cheval aye bonne bouche, grande volonté , beaucoup d'agilité, \& une legereté accompagnée de fouplefie.

En un mot, ce font demy tours d'un temps pour gaigner la croupe; ce mot de piroüerte vient de pivot: auffi lors que le cheval tourne de cetre maniere; on croiroit que tout fon derriere feroir un vericable pivor, fur lequel il roule avec une telle 


\section{à Cheval.}

telle prefteffe \& $\mathrm{fi}$ peu de terrain, qu'il n'ct quafi pas croyable. Il y a de deux fortes de pirouiettes, l'une fe fair de la tête sz des épaules, de la tête à la queuë, \& les hanches dehors : mais la belle \& la veritable piroüette eft celle qui tourne d'un temps, \& la croupe refte toujours dedans les épaules, faifant un mediocre tour, \& les hanches fuivant au tour d'un petit point. Ce Manege eft beau \& excellent, mais il fe trouve peu de chevaux quile faffent bien, à caufe des qualitez qui ne fe rencontrent pas que bien rarement.

Ils font tres-propres à ceux qui ne fe fient pas en leur addrefle, peuvent attendre leur adverfe partie fans bouger de leur place, \& lors qu'ils fe voyent preffez, ils peuvent tourner leur cheval pour gagner la croupe de leur ennemy. Voila ce que je m'étois propolé de démon: trer touchant les paffades. 


\section{Chapitre $\mathrm{XXX}$ X}

Le moyen de mettre un Cheval fur les Voltes.

7 Efte maintenant d'enfeigner au Cavalier la methode avec laquelle il faut agir pour metrre $\$ 2$ dreffer un cheval fur les voltes, ce que l'on nomme de deux piftes, \& la croupe dedans. Er bien que mon deffein n'étoit au commencement que de vous donner des precepres pour la guerre, le cheval eftant déja fi avancé; je veux que Ie Cavalier luy puiffe apprendre à pratiquer le moyen de luy pouvoir faire couler quelques volres. Premierement vous ferez conduire voltre cheval au lieu ordinaire du manege, ou vous le promenerez d'une pirte, fans luy donner fou. gue ny inquieruda, ny même fans. fare aucun femblant de le vouloi: 
page.115

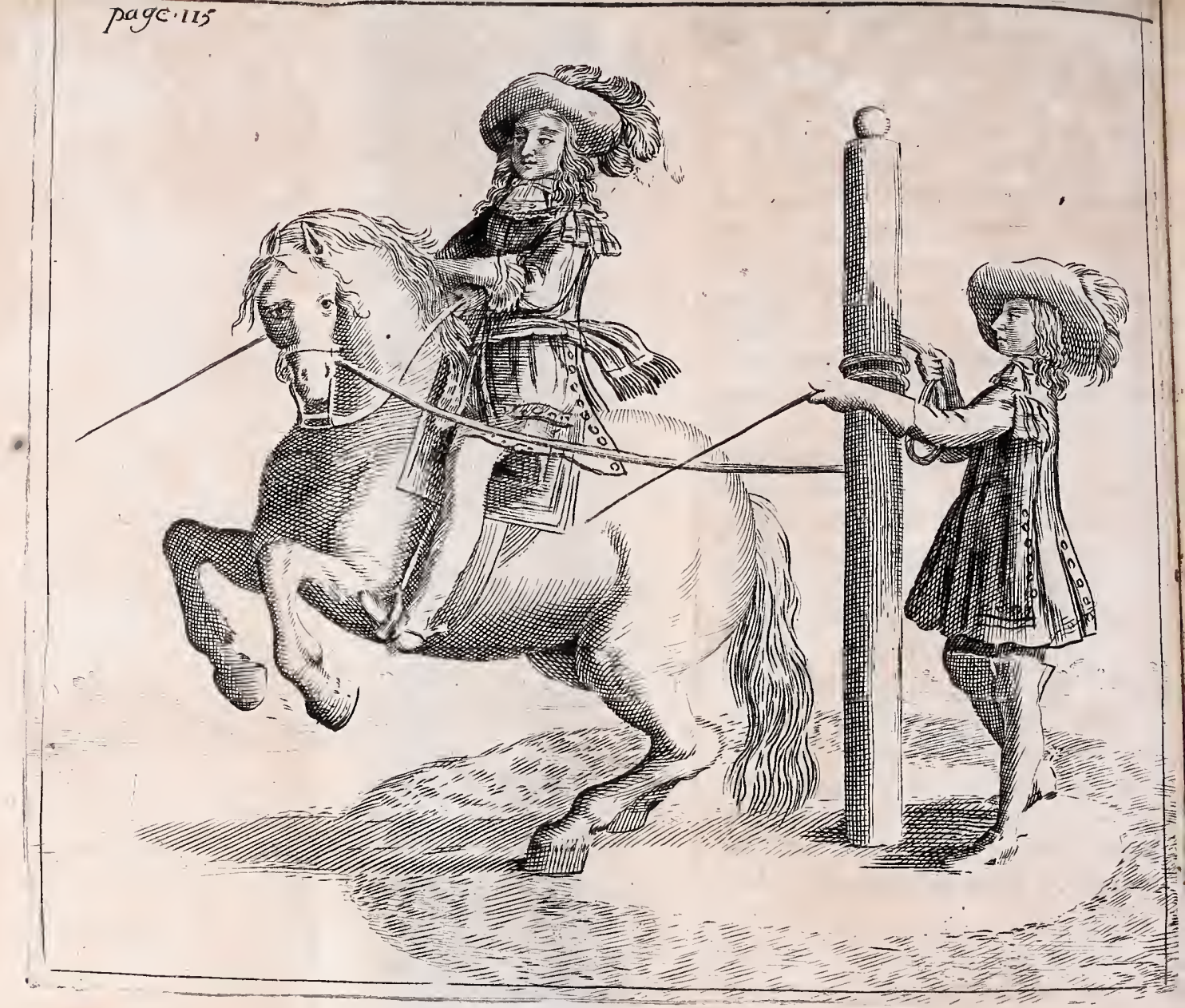




\section{à Cheval.}

faire manier, puis l'ayant ainfi promené quelque temps, vous.luy mettrez la tefte au pillier, \& luy ferez fuyr les talons l'un aprés l'autre, luy faifant faire la volte renverfée par plufieurs fois. Aprés cela vous le porterezde cofté \&z d'autre fur les quatre lignes de la volte, la tête dedans; ce que vous continuërez autant de temps qu'il en faudra pour y rendre le cheval bien certain, le promenant un jour fur une pifte; un autre vous luy ferez faire la volte renverfée, \& une autre fois vous luy ferez fuyr les talons le long des quatre lignes ou angles de la volte, jufques à ce qu'il foit tout-àfait obéiffant.

\section{Chapitre XXXV.}

Trs que le cheval fera fouple \& bien déliberé à ceque deffus, fe promenant fur la même pifte avec plaifir, \& bien uny, \& qu'il

$\mathrm{K} \mathrm{ij}$ 
fera tres-libre àfuyr les talons, tant l'un que l'autre, auffi bien la tefte au pillier que le long des quatre lignes de la volte, vous le ferez attacher entre les deux pilliers, avec le cavefion de corde, où érant vous ferez voltre devoir pour luy faire lever le devant par plufieurs fois, $S E$ s'ilvousobéit avec facilité $\&$ fans inquietude, vous ferez monter quelqu'un deffus, qui le conduira par diverfes fois d'un talon fur l'autre, fans le trop prefler. Aprés ccla vous le ferez fort careffer , \& luy donnerez de l'herbe, \& un moment aprés vous le ferez tirer en arriere, \& chafferez en avant, tout autant que les cordes du caveffon vous le pourront permetre; ce que vous réirerercz cing ou fix fois avec grande douceur \& delicarefle de main, \& jufteffe des deux gras des cuiffes, jufques à ce qu'il le fafte $\&$ y obéiffe avec plaifir $\&$ facilité : cela fuppor'é, vous le carefierez \&z l'en voyerezàl'Ecurie avec quelque for. ecde fatisfaction. 


\section{à Cheval.}

Mais au premier jour de voltre travail vous ferez voltre poffible, lors qu'il fera entre les pilliers, de luy faire un peu accompagner des hanches; que s'ilfe prepare \& qu'il donne trois ou quatre courbettes, faites-luy grande careffe, \& luy donnez du pain \& beaucoup d'haleine , \& luy faites connoiftre qu'il vous a contenté, \& le laiffez en cet. te bonne humeur; cependant que vous apprendrez que ces premieres Ieçons ne tendent à autre fin, finon pour l'accoûtumer \& luy apprendre à bien donner facilement dans les cordes du caveffon, \& y bien obéir fans impatience ny inquietude, faifant ainfi chaque jour de voftre travail, jufques à ce qu'il vous donne autant de courbettes que vous en defirerez. Apprenez encore en fecond lieu, que toute cette maniere d'agir n'eft que pour le rendre obéiffant, fouple \& deliberé, pour pouvoir prendre facilement le temps des voltes.

$\mathrm{K}$ iij 


\section{Chapitie XXXVI.}

Uand vous aurez obtenu ce $\perp$ que deffus de la bonne volonré $8 x$ memoire de voftre cheval, dans autane de temps qu'il en faudra pour vous donner la certitude de fa fcience en toutes ces leçons, vous le tirerez des pilliers, \& luy ferez mettre le petir caveffon rond, le conduifant au lieu du Manege, là où vous le promenerez long-temps $\$ x$ d'une pifte comme j’ay déja dir, \& à chaque coin ou angle de la volte vous luy ferez delicatement lever le devant, comme j'ay enfeigné entre les pilliers : s'il vous obéï careffez-le fort, $8 z$ un moment aprés, continuez voftre chemin, aprés l'avoir tité deux ou trois pas en arriere, puis le conduifez jufques à l'endroit de l'autre angle ous coin de la volte, où vous ferez le même que deffus, \&z continuërez 


\section{à Cheval.}

ecte leçon, jufques à ce que vous ayez paflé les quarre coins ou angles de la volte; \& continuez ces leçons les unes aprés les autres, tantoft à droit, \& tantolt à gauclie, changeant ainfi de main, le tirant en arriere, puis le portant en avant, $\&$ le faifant inceffam. ment lever à chaque bout \& extre mité des lignes, tant qu'il le fafie bien facilement. Lors quele cheval fera réduir au point que vous venez d'entendre, vous aurez bien avancé de la befogne, il le faudra fort carreffer, luy donnant du pain, \& aprés beaucoup d'haleine, il le faudra renvoyer à l'Ecurie.

Au premier jour de voltre exercice, aprés l'avoir long-temps promené fur les quatre lignes de la volte, lors que vous fentirez qu'il y prendra gouf \& plaifir, rendezvous un peu plus nerveux qu'à l'or: dinaire, \& vous affermifiant \& pefant fur les étriers, vous tournerez tout doucement le poignet vers $l_{2}$ 
main droite, cheminant fur la ligne qui fair le chemin du cofté droit, puis vous approcherez delicatement le talon gauche; fi bien que la main fera cheminer la têre $\&$ les épaules, \& avec le talon vous conduirez les hanches jufques à la fin de la ligne, au bout de laquelle vous tournerez la main pour mettre le cheval droir fur la feconde, puis vous approcherez encore le taIon gauche pour le porter de côté jufques à l'excremité de la troifiéme ligne, où étant arrivé, vous ferez cette troifiéme fois commej'ay dit aux precedentes: $\&$ ainfi vous acheverez de la même methode, jufques à ce que vous ayez fait tout le tour, ce qui s'appelle paffager un Cheval fur les quarre lignes de la volte, la tefte dehors \& la croupe dedans; ce que vous ferez fi fouvent, tant à droit qu'à gauche, qu'il le faffe avec plaifir \&x certitude, guidant toûjours la telte par le moyen de la main, \& les 


\section{a Cheral.}

les hanches avec l'aide du talon; que fi par cas fortuit le cheval vous defobéiffoit, n'y eftant encore accoûtumé, ne vous fâchez point pour cela, \& ne le reburtez pas en le châtiant ou battant a vec trop de violence, eflayez plûtolt de le remettre avec douceur, \& le ramener à fon devoir : \& fa a prés y a voir fait voltre devoir par la patience felon l'Art, \& qu'au licu de vous obéir il fe vouloit précipiter \& fe jetcer fur le talon contraire, \& qu'il fe défendit par grande malice, vous l'arrefterez tout court, \& luy fercz faire une ou pluficurs pirouistes du colté qu'il vous aura refufé : \& fi aprés toute cetre patience il fe rendoit revêche \& ne vouloit pas obéir, vous reviendrez à vos principes, c'elt à dire la tefte au pillicr, luy faifane faire la volte renverfée, puis le mener de colté la refte à la muraille: \& ainfi peu à peu avec voltre methode, douceur \& parience, vous le ramene. 
122

rez dans l'obéiffance, le promenant derechef d'une pifte, puis luy faifant faire des piroiiettes, le tout avec beaucoup de patience, \& fans le battre, jufques à ce qu'il foit cout-à-fait obéiflant aux leçons cydeffus.

Chapitre XXXVII.

Ors que vous aurez fi heureufement travaillé, que le cheval fe fera rendu parfaitement obéiffant, fe promenant \& paffageant avec facilité fur les quatre lignes de la volte avec jufteffe de ielte, d'épaules \& de crouppe, vous commencerez de l'arrondir, c'eft à dire, que vous ferez en rond ce que vous aviez fait peu devant en quarré : mais en faifant certe leçon commencez à main droite, \& de pas, comme jay dit, \& d'unc même pilte; puis l'ayant acheminé de certe maniere par cinq 


\section{à Cleval.}

ou fix fois, lors que vous fentirez qu'il fera enfemble $\&$ bien uny, la refte ferme $\&$ droite, \& les hanches bien placées; alors vous rendant un peu plus nerveux, tournez la main \& le poignet droit, preparez voftre talon gauche à le fecourir ; en un mot, accordez in adroitement la main \&z le talon, qu'il en reçoive le foulagement neceffaire pour commencer de le bien conduire en le chaffane bien avant, faifant cheminer la main pour conduire la tefte $\&$ les épaules, \& que le talon gauche fuive tout aumitolt aprés, par la vigueur de vos aides, en forte qu'il ne s'accule ou entable, qui feroit une faute tres-grande : car outre qu'il feroit en tres-mauvaife pofture, vous le rendricz retif ou ravaingue, \& ne voudroit plus obéir, à caufe de la doulcur que vous luy feriez fouffir en l'acculant ou entablant.

Je vous averris auffi que lors que vous le pafiagerez, de prendre bien

$$
\text { L ij }
$$


garde que la refte $\&$ les épaules paffent inceffamment par les quatre coins ou angles de la volte, en les effleurant en paftant, ce qui s'appelle bien embrafler toure la volie, fans permetre qu'elle foit ovale on berlongue, \& qu'il fuive ainfi toute la circonference : 85 pour dernier avis de cette leçon, le cheval doit cheminer en cette forte, il doir avoir la tefte \& les épaules autour de la circonference, \&z la crouppe vers le centre, c'eft à dire, que les épaules doivene eftre oppofees aux hanches, \&zles hanches aux épaules.

Chapitre XXXVIII.

Four achever un Cheval.

Prés que le cheval, par les A methodes que je vous ay enfeignées, vous aura tout-à-fait rendi certain de fa liberté \& obéiff 


\section{à Cheral.}

fance, telle que vous le pourrez fouhaicer, vous conrinuërez ainfi voftre travail par chaque jour de voftre exercice, jufques à ce que vous connoiffiez qu'il n'y a plus à craindre qu'il vous puile $f_{\text {aire }}$ aucune efquipée ou cfcappade': alors vous le pafiagerez avec un peu plus de nerf $\&$ de vigueur que de coûtume, \& luy donnerez aulfi un peu plus de fougue que devant, \&z ainfi vons l'obligerez infenfiblement à fe lever, afin qu'il fe prepare à marquer quelque temps ou cadance de volte : Que s'il vous en donne, ou en marque deux ou trois, arreftez-le foudainement, \& luy faites grandes carrefles, \& luy faites donner de l'herbe, afin qu'il puiffe connoiftre qu'il vous a contenté : puis continuant voftre paffage de pas, fi vous connoiffez qu it fe prepare \& s'anime de luy-même, en baiffant les hanches, laifez - luy faire encore quatre ou cinq courbettes ou cadences de voltes, puis 
l'arreftez comme devant, le carseflane fort, en continuane toujours le pafiage de pas, puis luy donnez haleine, \& du pain, ou de l'herbe, afin de le tenir tonjours en bonne humeur, puis le renvoyez à l'Ecurie avec plaifir.

Puis au premier jour de voltre exercice vous recommencerez cetre leçon jufques à ce que vous fentiez qu'il fe prepare de luy-même de maniere, fi - toft que vous luy rémoignercz par la vigueur de vos aides ce que vous fouhaitez de luy, puis quelque temps aprés l'ayant bien promené de pas, \& 1 a crouppe dedans, vous eflayerez de le changer de main, auffi de pas feulement, \& fur l'un des quatre coins ou angles de la volte, prenant bien garde de l'acculer, \& lors qu'il aura changé, vous le paffagerez la crouppe dedans, \& fercz toutes les mêmes chofes à gauche, que je vous ay enfeignécs 2 droit : \& pour cer effer, vous $\mathrm{cm}$ - 


\section{à Cheval.}

ployerez tout le temps que voltre prudence \& voltre fçavoir vous le feront juger neceflaire pour y rendre le cheval bien affuré, \& que vous connoifficz qu'il y prenna gouft \& plaifir, le faifant avec aifance \& facilité, fans tourefois le trop ennuyer ou rebutter en tout ce que vous luy demanderez.

Mais lors qu'il y aura affez de remps que vous l'aurez tenu cn cctie école, auffi-bien à droit comme à gauche, \& fur les quatre lignes de la volie, \& en la bien embraffant, \& que vous connoiftez qu'il fe preparera fi-tolt que vous ferrerez !es cuifles, \& qu'il vous connoiftra en polture de le vouloir faire manier. En un mot, lors qu'il connoiftra affez ce que vous defirez de luy, vous l'animerez, \& l'o. bligerez de faire ou marquer autant de temps ou cadance qu'il en faudra pour accomplir la volte, ou cinq ou fix davantage, fi vous luy fentez aflez de force ou de vigueur

L iiij 
pour y fournir, \& prenez bien garde que tout ce qu'il en fera, foit en bien embraffant toute la volte.

Que tous les temps, s'il fe peut, foient égaux, c'eft-à-dire, de même force, de même vigueur, \& de même cadance, fans que l'un foit plus relevé, ou plus terre à terre que l'autre.

Qu'il foit bien aftis fur les hanches, bien fermé de tefte, fans fe pancher ny coucher plus d'un cófté que d'autre, fans auffi metre ou porter la tefte hors la volte. Et pour dernier avis \& conclufion de ce perit Abregé, il faut que les épatiles paniont incenamment par les quatre coins ou angles de la voite; chaffant toujours le cheval en avane, \& qu'il marque fes temps ou cadances de même air à une main comme à l'autre, \& lors qu'il maniera à droir, qu'il aye la refte $\grave{a}$ droit, \& qu'il regarde à droit, faifant auffi cout le même à gauche, qu'il ne fe panche aufi, \& ne fe 


\section{à Cheval.}

eouche en maniant de quelle main qu'il manie, \& qu'il ne porte point la tefte hors la volte, ce que vous continuërez avec la même methode \& patience que je vous ay enfeignée, autant qu'il en faudra pour luy apprendre à couler autant de voltes, que le Cavalier prudent en pourra raifonnablement fouhaiter, foit à droit ou à gauche, felon fa force, fon agilité, $f a$ difpofition $\&$ fa bonne volonté , \& lors qu'il fera confirmé a ce que deffus, vous le pourrez dire cheval achevé.

Voila ce que je m'érois promis de vous donner en ce petit Abregé, gui paftera, sil vous plaift, pour un Manege de guerre le plus racourcy qu'il m'a efté poffible; bien au contraire d'avoir voulu écrire un gros volume, \& m'eftre rendu long \& ennuyeux. Je fçay bien que je me pouvois étendre plus au long touchant cette matiere : mais comme ce n'étoit pas mon deffein de faire de vaines redites; je me fuis 
contenté de me fi bien exprimer, \& faire entendre en fi peu de paroles, que file Cavalier a tant foit peu d'amour pour cer exercice, \& qu'il veuille le cherir avec le moindre foin, il le pourra en peu de temps apprendre par cceur. En un mor, je n'ay pas jugé efte neceffaire d'embarraffer la memoire de mes Lecteurs d'une fuire infinie de leçons, qui auroient fans doute efté de peu de fruit, manque de la grande methode \& pratique qu'il faut avoir en cet exercice pour le bien comprendre. Maintenant je vais traitter le plus briévement que je pourray des airs ice levez, je commenceray par vous les nommer tous par leur propre nom, \& en faire la defeription \& la veritable définition, afin que vous en puifliez parler, auffi-bien que les diftinguer les uns d'avec les autres, par leur propre nom, lors que vous en verrez dans les celebres Academics, \&zentre toutes 



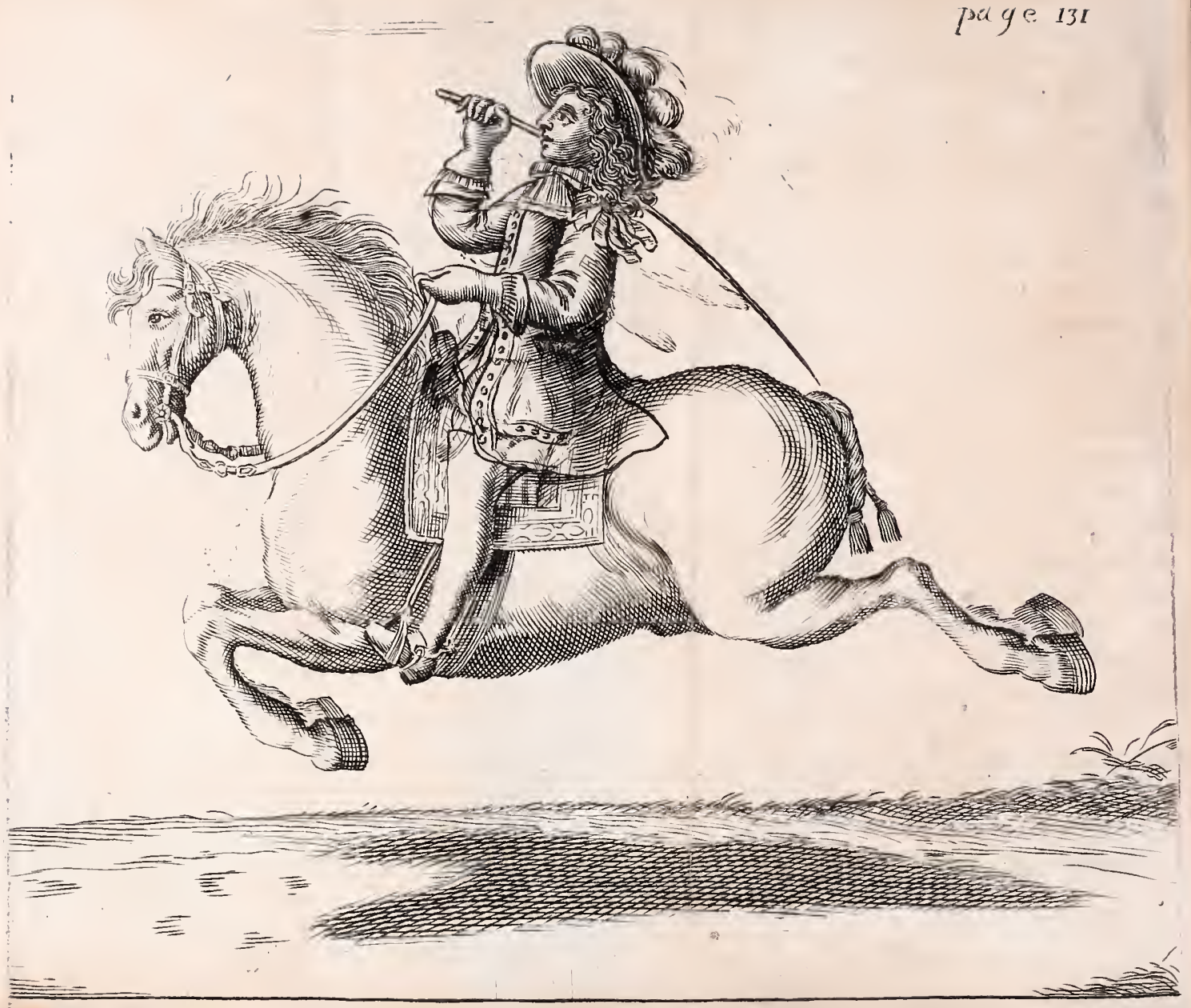


à Cheval.

celles de l'Europe, dans la fameufe Ville de Paris.

Chapitre XXXix.

Le nom de tous les Airs \& Maneges

$$
\text { releviz. }
$$

E plus relevé que terre à terre.

Le mes-Air ou moitié Air.

Les veritables Courbettes.

Les Croupades.

Les Balotades.

Les hautes Croupades.

Les Capriolles.

Les Sauts ou Maneges d'un

\section{temps.}

Le Manege ou l'Air de deux temps, eft un Sault.

Le plus relcvé que terre à terre, eft celuy qui fans marquer les Courbettes, paroift plus gay \& plus relevé que le terre à terre.

Le mes-Air ou moitié Air, eft 
celuy qui tient des Courbettes , \& du terre à terre: mais qui ne les marque pas fi juftement.

Les veritables Courbettes, eft un air tres-égal du devant \& du derriere, où il faut que le devane s'avance de plus de quatre doirgs à cháque remps, \& que le derriere accompagne $\&$ fuive de même cadance pour gagner le même rerrain. Manege beau \& affez difficile: car il faut que le cheval le fçache, \& que le Cavalier aye affez d'adrefle pour le pouvoir execurer.

Les Croupades, eft un air plus relevé que les Courbettes, où il faut que le devane \& le derriere s'élevent de même hauteur, cadance \& égalité de terrain devant $\&$ derriere, \& que le cheval pliane \& troufiant les pafturons derriere, ne fafle pas voir fon fer extericure. ment, fans ruer ou efparer

Les Balotades eft le même air: finon qu'il me femble un peu plus 


\section{à Cherval.}

trerveux, \& au contraire, que les Croupades, tiennent le fer cachó fous le cheval.

Les Balotades le font voir exrerieurement, fans tourefois ruer ny efparer, non plus que les Croupades.

Les hautes Croupades eft un air de force $\&$ de vigueur, \& bien approchant des Caprioles, mais lors que le cheval ne ruë \& n'efpare point, le Manege fe nomme haute Croupade.

Les Caprioles font les fauts de grande hauteur, \& d'une force toute particuliere, \& lors que le cheval eft dans la plus haute élevation, il rué \& efpare de toute fa force, comme s'il fembloit fe vouloir feparer de luy-même, à le voir ruer de telle imperuofité.

Pour dire un cheval bien achevé à caprioles, il doit fauter entre les pilliers de ferme à ferme, le long d'une carriere par le droit allant \& venant, en rond, ce que 
l'on nomme fur les voltes: \& finalement en arricre, en avant, $\&$ des deux côiez, ce qui s'appelle faire la croix à caprioles, \& tant que tout ce que deffus s'accompliffe fans fougue, fans malice, fans defefpoir $\&$ fans fe précipiter, ou fe jetter fur la main, ny furles talons.

$S^{\prime}$ il fe rencontroit un tel cheval, on le pourroit dire parfait \& achevé.

Les Sauts ou Maneges d'un temps, eft un air tout particulier, $\&$ beau de force $\&$ de vigueur, $\& 2$ tres-égal devant $\&$ derriere.

Le cheval fe doit élever en pliant les quatre jambes, \& retomber les quatre fers enfemble, avec telle égalité \& juftefle, que l'on n'enrende qu'un feul coup, lors qu'il tombe, puis il fe doit auffi-toft élever de la même cadance, \& marquer autant de temps que fa force $\&$ vigueur luy pourra permettre. Ce Manege eft le plus difficile de tous les airs par haur, comme aufi le 


\section{ì Cheval.}

plus rare, \& y a peu de chevaux qui continuënt dans cet air : pour moy je n'en ay jamais vû que deux depuis ving $t$-cinq ans que $j e$ fuis dans la profeffion.

Celuy à mon avis le plus facile de tous, fe nomme diverfement, les uns l'appellent le pas, le fault; les autres difent deux pas, le fault: aucuns veulent dire un pas, une courbette, \& un fault; pour moy, je ne croy pas me tromper en le nommant l'air de deux temps, \& un fault, puis qu'il faur de necefficé que cetre cadance ou mefure y foit obfervée, les chevaux demeurent volontiers en cet air, d'autant que le temps qu'ils ont ne les inquiere \& ne les molefte que fort peu, ce qui leur donne plaifir. Voila ce que jay bien voulu vous apprendre touchant les airs relevez, je ferois ravy de vous avoir donné quelque conrentement. 
136 De l'excellesce de l'Art

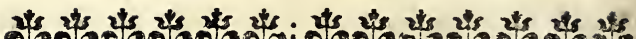
ก.84

\section{DE LA COURSE}

DE BAGUE,

ROMPRE EN LICE,

ET ROMPRE AU FAQUIN.

D fair une remarque affez confiderable pour n'eftre pas oubliée, c'eft pourquoy j'av voulu -ommencer ce premier Chapitre par cette reflexion.

Il fe trouve, dit-on, quelques hommes, qui en ce rencontre avoient une inclination naturelle à l'exercice de monter à cheval, \&z qui fans avoir appris, promettene dés le premier jour quelque chofe d'agreable en la polture, $8 \tau$ même en la fermeté : on en dit de même des Armes \& de la Danfe, \& des autres exercices du corps; mais

pour 
pour la courfe de la Bague, nous ne voyons perfonne, generalemene parlant, qui témoigne, ny adreffe, ny liberté, ny jufteffe en cer exercice, s'il n'a efté bien montré , \& s'il ne l'a praciqué quelque remps, bien qu'il eft vray de dire, que c'eft celuy de tous qui fait davantage paroiftre le Cavalier, eftane une des plus belles actions \& des plus agreables à la vúië, \& qui doit eltre la plus polie en fa pratique.

Pour moy je latiens la plus difficile : car d'autant qu'elle fe faic en public, on defire y paroiftre , 82 cette émulation ou envie de bien faire, engendre bien fouvent un contraire effet: En forte que l'efprit eft emporté à cetre cupidité de metrre dedans, fans fe fouvenir de ce qui eft requis à une belle courfe.

Outre cela, cer exercice fe fais le plus fouvent pour donner plaifir aux Dames, comme il eft aufi 
${ }_{3}{ }^{3}$ Le l'excellence de L'Ars

le feul pour lequel elles donnene le prix, \& ainfi pour leur plaire un chacun fe fent emporté de gloire afin de les contenter, $\&$ on tâche de fe rendre parfait en general , \& aimable pour quelques-unes en particulier.

Ainf l'ambition de remporter ce prix nous aiguillonne d'une $\mathrm{fi}$ preffante chaleur, que toure certe envie emportant les mouvemens de noftre efprir, nous fait le plus fouvent perdre la bonne pofure, ce qui caufe des manquemens $\& Z$ mauvaife grace en certe belle atzion, qui doit efre jufte en tout.

Si bien que je confeille au Cavalier de s'y rendre bien parfait, afin de joüir du contentement que jo viens de dire, outre cela, je conSeille à tous les galans hommes ne fe porter jamais fur la carriere, \& de ne pratiquer jamais cet exercice en public, qu'ils ne foient bien afrurez en particulier.

Damint, comme j'ay dit, que 


\section{de monter à Cherual.}

cet exercice qui fe pratique d'ordinaire à la vûë des Dames, \& qu'elles femblent avoir plus de loy $\&$ de liberté de fe gauffer des maladroirs. Je confeille au Cavalier prudent, de ne fe metrre pas en ce hazard, crainte de quelque notable préjudice à leur réputation, qui pourroit leur engendrer des querelles.

De l'Infitut de courre la Bague.

TL eft tres - conftant qu'anciennement, \& dans les premiers ordres de la guerre on avoir accoûtumé de metrre deux rangs de Lanciers à la tefte des Efcadrons, \& les Bataillons rangez eftoient en cet ordre avec des Lances qui faifoient tefte par rout, felon quils eftoicne commandez: Et cela afin que les Baraillons euffent plus de moyen de foúrenir le choc, \& n'eftre pas is facilement rompus ny renverfez.

$$
\mathrm{Mij}
$$


$M i$ is comme nous voyons que les ordres changene felon le vouloir \& l'experience des Gencraux \& des excellens Capitaines, il y euft des confiderations qui firent changer cer ordre, pour établir un meilleur moyen d'artaquer \& de combattre; \&. ainfi cet ordre de Lanciers fur ofé: Miis dautant que quelques foldats, ou aurres illultres Perfonnes, s'eftoient rendus fort adroits au manicment de cefdites Lances. Er de plus, que les Maneges juntes \& relevez n'éroient pas encore en - ufage de ce temps - là , comme its Cont aujourdhuy: Ces perfonnes dont jay parlé cy - deffus, s'avif- rent pour s'égayer cux \& lcurs cho. valux, de faire une certaine joûte ou efpece de combat courrans l'un contre l'autre, \& effayoient de rompre leurs bois avec adreffe $\& i$ juftele; \&z cetre maniere de combatere fut trouvé fi agréable, que ies plusfrequens exercices des Rois a des Princes, eltoit de rompre des 
Lances en lice les uns contre les autres.

Er cet exercice fe rendit fi familier, que les Capitaines \& les foldats ne faifoient autre meftier dans leurs garnifons, afin d'y rendre eux \& leurs chevaux adroits \& bien ajuftez.

Mais enfin comme cet exercice eftoir aufi penible que perilleux, \& nommément lors que l'on cour- roit en camp ouvert.

A joûtez à cela l'extrême malheur qu'il en arriva à Henry II. l'un de nos Rois, il fut comme aboly.

C'eft aprés ce temps que l'on s'avifa de prendre une lance plus legere, \& imitant encore un peu la coûtume de courre à l'encontre, on plaça la figure de la moitié d'un homme, lì où on s'exerçoir, pour luy donner du bout de la lance au milieu du front.

Ce qui concinua encore quelque temps. 
I4.2 De l'excellence de l'Art

Mais enfin nos Modernes trouverent l'invention de mettre un anneau de la hauteur d'un homme à cheval, \& le placer du cofté que pouvoir venir leur ennemy, qui eft le gauche, $\&$ ainfi peu à peu ils s'accoûtumcrent eux \& leurs chevaux à courre jufte, \&z cela les rendit fi adroits, \& s'ajuftoient auffibien que s'ils eufient courru l'un contre l'autre, tant il eft vray qu'il n'y a rien qui ajufte tant le Gendarme, que les frequentes courfes do Bague.

Ce que jav dit en ce petit difcours, ne refulte autre chofe que pour faire voir, que comme l'exercicc de la Bague, outre ce qu'il eft agreable à voir, eft beaucoup necefTaire à ceux qui $f_{c}$ veulent fervir de la Lance, \&z pour apprendre qu'elle doit eftre un peu panchée, \& la pointe vers l'oreille gawche du cheval. 


\section{Pour infruire le Cavalier à la courfe de Bague.}

A Vant que de fairc courre un Ecolier, il faut qu'il foit ferme de refte, de main, de corps, $8 z$ s.ans branler les jambes, \& que confervant cette bonne grace, il s'accoútume à courre deux ou trois jours ou plus fans Lance, ayant feulement une gaule à la main: \& qu'il s'ajufte fi-bien, qu'il ne luy puiffe arriver de defordre, lors qu'il aura la Lance à la main.

Ec lors qu'il fera capable de la porter, il faut qu'il chemine vers le commencoment de la carriere, ayant Ia Lance placée fur la cuiffe droite, \& un peu panchée vers l'oreille gauche du cheval, où eftane arrivé, il doit y relter jurfques à ce que la Bague foit ajuftée à fon point, puis il doit lever fa Lance deffus ra cuifle, fi peu pourtant que 
144 De l'excellence de l'Art

l'on ne s'en apperçoive quali pas; $\&$ incontinane aprés doic laiffer ă l'inftant prendre la demy volte terre à terre à fon cheval à main droite en entrant dans la carriere, puis faifant l'une des levées, dont je parleray cy-aprés, conrinuëra la courfe de bonne grace, jufques à l'arreft ou au parer, accompagné de deux ou trois courbettes.

Remarquez icy en paffant, qu'il y a trois chofes tres-neceffaires à celuy qui veut acquerir la qualité de beau \& bon Gendarme.

La premiere, la grace \&z l'air avec lequel il faut porter fa Lance au partir.

La feconde, la defcente douce \& ferme tout le long de la courfe, \& la fermeré \& jultelle du corps à l'arreft.

Ec la troifiéme, la fermeté de $f_{2}$ main, de fa tefte, de fon corps $\&$ de fes jambes.

Pour la hauteur de la Bague, elle
doir 


\section{ile monter à Cheval.}

doit être ajuftée bien peu au deffus du fourcil gauche, dautant que les bons Chevaux de bague fe baiffent toujours un peu en courant.

Le bon Gendarme doit empêcher de courre fon Cheval de route fa force au partir, pour deux raifons.

La premiere eft, que le Che. val, quelque bon qu'il foit, ne peue fournir jufquau bout dans cette violence, \& s'arrête ordinairement à l'endroit de la bague, ce qui empêche le Cavalier de prendre la bague, comme aufi ce défaur rend la courfe de mauvaife grace.

L'autre eft, que les Chevaux de bague, eftans prefque cous impatiens par la fougue que leur donne la courfe, ou ils changent de pied, ou ils fe jettent contre la muraille, ou hors la carriere, fi bien que pour éviter ces défauts, le bon Gendarme doit aprés avoir pris fa demie volte, retenir fon cheval le plus qu'il pourra jufqu'au milieu 

dela carriere, puis baiflant adroitement la main, fon cheval fournira fa courfe agreablement.

On peut faire quantité de levées qui peuvent estre toutes pafables, pour. vî que la pointe riéchappe pas. Mais à vray dire on fe doit contenter de trois.

7 A premiere fe pratique en cetre maniere : Le Cavalier ayant pris fa demie volte en la pofure que j’ay déja dite, lors qu'il s'achemine vers le commencement de la courfe, il doir lever la Lance dés le premier mouvement quele Cheval fait pour encrer dans la carriere, du même endroir qu'elle eft, puis tout d'un coup avec vigueur \& fore haut, fans remuer alutre chofe que le bras, il doie porter fa main jufques vis - à-vis fon oreille droite, prenant bien garde d'écarter trop le poing, 
se monter à Chcual.

orainte que la Lance fe trouvấ trop éloignée du vifage, puis la Lance bien placée commej'ay dit, fans ferrer ny trop hauffer le coude, laiffer la Lance en cét endroie quelque dix ou douze pas dans la carriere, avant que commencer la baiffer, puis la laiffer defcendre tout doucement, en forte que le poing revienne en fa place, en s'a. juftant à la bague, làquelle eftane paffee, il faut lever la pointe droite en l'air, \& tourefois fi juftement que la pointe n'échappe pas, puis remetre la Lance fur la cuiffe, au mème érat qu'elle eftoit au commencement de la courfe.

Du fecond Partir, ou Levée.

- E fecond Partir ef prefque femblable au premier, il y a feulement cetce difference, quefe trouvant ajuftee comme j'ay dit, au bout de la carriere, au liets de lever la Lance rout droir de 12

$\mathrm{Nij}$ 
il 48 De l'excelience de l'Art pofition où elle eftoit, il la faut laif fer tomber en bas, tant que vôtre bras le peut permettre fans defordre, puis faifant un bien petic demy cercle, vous levez la Lance affez haut, puis eftant entré douze ou quinze pas dans la carriere, vous continucz voltre courfe, \& l'achevez comme je vous ay déja enfeigné: Ec cette feconde courfe eft fort utile pour ceux qui ne font pas fort adroits, \& qui ne courent pas fouvent, comme auffi pour ceux qui veulent prendrela bague avec plus de facilité.

Le troifiéme Partir, ou Levée.

1. E troifiéme partir elt d'au1. tant plus difficile à execurer, qu'il cht auffi infiniment plus beau, $m$ is aufi eftane bien fair, il donne une merveilleufe grace au Cavalior ; mais pour vous le donner bien à entendre \& en peu de mors, je vous diray qu'il faut toujours 
que la Lance foir placée au lieu accoûtumé pour bien partir, puis lors que le Cheval eft preparé a' prendre fa demie volte à main droite, \& la Lance levée bien peu, comme j'ay déja dic, le Cheval ayant pris un quart de volte, $\&$ montrant le cofté droit dans la carriere, il faur laiffer romber le poing le long de la cuiffe, \& la Lance en fon contre-poids dans la main, aufi bas que le bras le pourra permettre, fans faire mauvaife action ou grimace. La poince de la Lance toujours fur l'oreille gauche du Cheval, \& fi-toft qu'il met la tête dans la carriere, faut adroitement élargir le poing de la Eance, en montant \& élargifiant en même temps à bras étendu, afin de former un demy cercle, \& placer juftement la main proche l'oreille droite, comme jay enfeigné au premier partir, fans que pour ces mouvemens la Lancelorte en quelque maniere que ce foit de la.ju

$\mathrm{N}$ iij 
30 De l'excellence de 'Art

te ligne, qui doit tomber directement à l'oreille gauche du cheyal; pour le refte de la courfe elle s'acheve comme la premiere, $8 z$ l'arreft femblablement, aprés avoir levé la Lance \& l'avoir remife en fa place, \& il faut bien fe garder de baifler le poing, comme font aucuns negligens, qui femblent pluftoft tirer l'eftocade que former un bel arreft:-outre que s'il avenoit qu'ils cuffent fait un dedans. fi la bague tomboit outre ce, qu'ils. apprêreroient beaucoup à rire, leur dedansferoit nul.

Ce que le Caualier doit confiderer. lor.fqu'il court la bague.

L ne fuffit pas que le Cavalie: 1 ait entendu mes inftructions rouchant les differentes levées, ny. même la polture que jay dite de la juftelle de cout fon corps; mais il fiut qu'il le mette fi bien en pratigue, que l'envie de gagner le prix: 


\section{de nonter à Cheval.}

ne luy faffe perdre la belle pofture du corps $\&$ des jambes, \& qu'il marque bien cecy : il ne doic jamais a voir l'épaule droite en arriere, ny le vifage de travers, ny ouvrir la bouclie, ny faire grimace des yeux, comme s'il voúloit vifer à la bague, ny branler, ou baiffer la tête lors qu'il pafte fous la bague, ny ferrer le coude, ne battre point ou bien rarement fon Cheval lors qu'il court, ny branler les jambes, ny tirer l'eftocade en paffant pour prendre la bague.

En un mor, il doit avoir la main ferme, le poignet droit \& proche le pommeau de la felle, $8 E$ les jambes fermes $\&$ affez proches du Cheval, enfin il doic eftre droir, jufte, libre $\&$ fans affectation.

Je ne parleray point de l'exereice de rompre en lice, dautane qu'il n'eft plus du tout en ufage dans ce fiecle, je diray feulement qu'il a efté autrefois fort ufité \& pratiqué par les Rois \& les Prin.

$N$ iiij 
\$2 De l'excellence de l'Art

ces, mais le grand hazard qu'it $y$ avoir pour les hommes \& les chevaux qui eftoient fouvent ef tropiez dans le choc, on a tout à fair délaifié cette maniere de joû́te ou combat.

I4. maniere de rompre an Faguin, cul courre la Quintaine.

O m m e l'on s'eft enfin laffé de ccurre à l'encontre, ou rompre enlice, \& qu'il eft tout à fait aboly, comme je viens de dire, à caufe de la peine $s$ du mal qui s'y rencontre bien fouvent:

Pour la courfe de bague, on y prend aufi beaucoup de plaifir, $\& 2$ on s'en laffe fort peu, mais il y en 2 qui n'eftiment pas cet exercice affez martial; c'ent pourquoy les plus inventifs ont trouvé un milieu, qui cft une figure d'homme, que l’on place au même endroit que fiJ'on vouloir courre en lice, \& 
de la même hauteur, \& lesarmes, ou fans armes, ils rompent leurs lances, s'ajuftans contre cette fi. gure, qu'ils nomment Quintan, comme fi c'eltoit contre un homme naturel; c'eft ainfi qu'ils rencontrent un milieu, entre la furie de rompre les uns contre les autres, \& la gentillefle de courre la bague.

L'endroit pour rompre eft dans la tefte, les meilleurs coups fons au deffus des yeux, dans le front, $\&$ les tout à fait jultes font marquez de la grandeur d'un bien pe. tit cercle que je nomme le petit Ecu, ou Ecufion ; les moindres font au deflous : Et fi le mauvais Gendarme donnoit dans un Ecu que le quintan porte au bras gauche, ledit quintan ou faquin tourne fur un pivot, \& frappe juftement celuy qui s'eft fi mal adtoitement fervy de fa Lance, \& s'il court en partie, il en eft mis dehors pour avoir commis une fil lourde faute, 
354 De l'excellence de l'Art

\& pert fes courfes en punition de fa mauvaife action.

On peutà cet exercice fairel'une des levées que j’ay enfeignée la plus libre \& plus accoûtumée au Cava. lier, comme s'il courroit la bague, dautant que les Lances defquelles l'on fe fert contre le quintan, fone foibles \& fe rompent facilement, fans qu'il foit befoin d'aucun arreft, \& même le plus fouvent on s'y exerce en pourpoint.

Voila ce que jay jugé de plus neceffaire de vous enfeigner pour la. courfe de bague, ce que jay dit de rompre en lice, \& même du quintan, n'eftant qu'en paffant, \& afin que ceux qui ne l'auront pas vû pratiquer en puiffent du moins parler \& f f̧avoir ce que c'eft.

La figure precedente vous fera voir $\&$ comprendre la courfe de bague, le rompre en lice.

Er la courfe contre le quintan. 
Des Airs ou Manezes relevez, avee la définition du.mot, Air.

N dreffe les Chevaux pour trois raifons, qui ne refultent principalement que pour l'une d'icelle.

On le dreffe pour le plaifir. pour l'urilité \& pour fervir fon Roy, \& cette derniere eft la plus. confiderable; il y a de plufieurs fortes d'Airs, comme j'ay déja dit 82 nommez, les uns plus bas, \& les autres plus hauts : on appelle cette façon de Manege Air, dautant que le Cheval s'éleve en l'air, \& celuy qui s'éleve le plus haut, doir felon ma croyance eftre dic le plus. beau.

Tous les Chevaux ne font pas capables de ces Maneges ou Airs relevez : c'eft pourquoy je confeiledeux chofes au Cavalier.

La premiere eft, de commencer 
I56. De l'excellence de l'Art

roujours, tel Cheval que ce foir, par les regles ordinaires de pas, de trop \& de galop; \& pour n'eftre paslong à vous déduire le refte, ne commencez jamais à luy demander des fauts, qu'ils ne foit libre fans fe défendre, \& qu'il n'obéifle au poing de la bride, \& qu'il ne fouffre en quelque façon les châ. timens.

Secondement, il faut que le $\mathrm{Ca}$ valier ait ce jugement de fuivre l'inclination du Cheval:

Par exemple, s'il le vouloir leve à courbette, \& que le Cheval voulut s'élever plus haut, il ne Je fau. droit pas châtier, pourvấ qu'il le. fit de gayeté \& en avant, \& ainf s'il s'élevoit a balottades, croup. pades, \& même jufqu'à caprioles, il Ie faudroic laifler égayer, car s'il avoit affez de force pour continuer l'un de ces airs, il en feroit. beaucoup plus beau, \& auffi s'il: avoit feulement quelque legeseté de peu de durée, il fe ra-. 


\section{de monter à Cheval.}

baifferoit affez à courbettes, ou à mes-air.

En fuivant donc mon avis, le bon Cavalier entretiendra fon cheval en l'air qu'il voudra prendre, \& fuivant fon inclination, il l'affurera en la julteffe de fa cadence, foit croupades, balottades, ou caprioles, daurant quil eft abfolument vray que les airs font d'inclinarion, \& donnez au Cheval par la nature. Er il faut que le bon homme de Cheval farte fon poffible à luy donner à entendre, autant que fon inftinct luy pourra permetre, la démonftration de celuy qu'il jugera luy eftre plus propre, \& auquel il inclinera le plus: car ce fera fans doute celuy auquel il aura meilleure grace, \& qu'il fera avec plus de plaifir.

Si bien que javertis le Cavalier de fegarder bien de battre le Cheval, quelque cadence ou air qu'il veuille prendre, foit de bonne voLonté ou par malice, \& combien 
I5: De l'excellence de l'Art mêtme que ce ne fût pas celle qu'il defire; car quelque faut qu'il fafle, il faut luy entretenir, \& $\&$ sil a force, l'obliger $\&$ le forcer même à fauter; car s'il a affez de force, comme j’ay déja dit, il continuëra, finon il fe rabaiffera affez toft, \& au lieu des caprioles prendra les balotades, \& enfin fe rabaifiera jufques aux courbettes: Que fi le Cavalier en ufe autrement, outre ce qu'il ne viendra pas à bout de fon entreprife, le Cheval vigoureux \& plein de feu pourroir faire des defordres qui le retarderoient beaucoup, \& \& qui pourroient encore bleffer celuy qui feroit deffus. Je te donne encore cet avis \& en rete bien affuré, qu'il y a peu ou point de Chevaux fauteurs quine foient extrémement coleres; c'eft au Cavalier prudent à faire fon profit de mes averriffemens. 


\section{de monter a Cheval.}

Pour mettre \& commencer wn Cheval a Caprioles.

TL y a peu de Chevaux qui foient lipropres à ce Manege; car il faut qu'ils foient premierement de grande force , bien legers, nerveux, \& quils ayent de bonnes jambes: dautant que les efforts qu'ils font leur ufe beaucoup les jambes, $\& 2$ on peut dire que fans une methode toute particuliere, il y auroit peu de Chevaux qui continuaffent cet air: dautant qu'il s'en trouve peu qui ayent affez de difpofition $\&$ de force, ou s'ils ont ces qualitez, ils font d'ordinaire impatiens, malicieux, \& fe défendent avec beaucoup de violence.

Jugez de là, \& confiderez que fi tels Chevaux font difficiles à réduire de pas, de trot \& de gallop fans la bonne methode, quel. les équippées ils feront lors que l'on 
160 De lexcellence de l"Art

leur voudra demander des fauts, \& s'ils fe font défendus de pas, de.rror \& de galop, ce que la furie \& le defefpoir leur fera faire, lors qu'il les faudra lever, voyez donc d'y apporter la bonne \& vràye mechode que je vais vous enfeigner, autrement les jambes du Cheval fe trouveroient en peu de temps ruinées, fa force abattuë, \& fa gentilleffe perduë, fans rien pouvoir faire de bonne grace.

C'ert ce qui m'oblige de confeiller à ceux qui auront deflein de mertre des Chevaux à capriolles, de fe fournir d'un bon Eco. lier pour affilter le Maifre, puis guider le Cheval à l'entour le pillier fans perfonne deflus, \& faire comme cy-devant, lors que jay enfeigné le moyen de connoifte le maturel du Cheval, comme pour éviter les accidens qui pourroient arriver à ciluy qui feroir defius, puis lors qu'il obéira de pas, de wrot \& de galop, on l'artachera

entre 
entre les pilliers pour luy faire fuyr la Chambriere d'un cofté $\&$ d'autre; que s'il obệit bien, on fera monter un bon Ecolier deffus, qui luy fera faire ce que je viens de dire, \& continuant ainfi à le déliberer, \& luy donner l'obéiffance d'aller en avant, \& donner dans: les cordes du caveffon, avant que de luy demander quelque chofe de plus jufte.

Et lors que l'on le jugera tout à fait fage à cette Leçon, il le faudra lever devant, \& continuer tane qu'il y réponde, \& qu'il la faffe facilement, \& qu'il leve le devant le plus haut qu'il fe pourra, enr l'obligeant doucement à plier les jambes avec l'aide de la gaule: car fi le Cheval tient les jambes roides à quelque air que ce foir, il ne le peut faire que de mauvaife grace. 
162 De l'excellence de I"Ar"

Seconde Legon pour les Caprioles:

E que je viens de dire bien conçú par le Cheval, on l'ô. terả des pilliers, \& le bon Ecolier eftant deffus, on le conduira au. rour le pillier, ou on le commencera par le trot ou le petit galop leger, \& bien dans la main fans qu'il fe defuniffe, \& à tous les arrefts on luy levera le devant le plus liaut que l'on pourra, que s'il luy échappe quelques fauts, il fe faudra bien garder de le châtier, principalement fi l'on connoift qu'il les. faffe de gayeté, puis que c'eft le but ol l'on a deffein d'arriver : mais $s^{\prime}$ il les faifoir de malice en fe traverfant \& defuniffant, il faudroit le faire pouffer vertement, cans lay permertre de s'amufer ou rerenir, puis le lever toujours au: Parer, comme jay dit.

Er à la fin de fa Leçon, le finir coujours cntre les pilliers, \& 


\section{- dé monter à Cheval.}

fuy faire bien lever le devant, s'il obéir bien, il faudra le carefler $\&$ faire defcendre l'homme, puis luy aidant delicatement de la gaule fur la croupe, faudra eflayer de le faire efparer ou ruer, que s'il $f_{e}$ défend contre la gaule par malice, \& qu'il ne voulût obéire, il faudra avoir un poinçon au bout d'un bâton affez long, \& luy picquer doucement la feffe, afin de l'obliger a ruer, que s'il ruë une fois feulement, il le faudra fort careffer puis le renvoyer à l'Ecurie.

Troifiéme Leçon pour les Caprioles.

T Ors que le Cheval commen. cera d'obéir au poinçon, on le remetrra autour du pillier, ou on continuëra de le trotter \& gaJopper, \& voir s'il voudra donner deux ou trois courbettes, deux ou trois fois feulement, pour le tenir roujours en obéiffance \& bonne Ecole, le levant toujours devane.

O ij: 
I64: De l'excellence de l'Ari pour le rendte dautant pluslegers: ce qui eft le plus neceffaire aux Chevaux fauteurs, puis retournans entre les pilliers l'ayder. derechef du poinçon, aprés luy avoir levê le devant, faifant comme jay enfeigné cy-devant, s'il obéit \& ruë fans difficulté, il le faudra fort carefler, puis paffer de l'autre côté, \& luy aider, comme dit eft, du poinçon à l'autre felle, s'il obéit, il lc faudra beaucoup careffer, pruis réiterer quatre ou cing fois de chaque cofté, \& le renvoyer ì l'Ecurie.

Quatriéme Leçon pour les Capriobes.

Ors que le Cheval, aprés * avoir doucement fuivy cette merhode, répondra entre les pilliers, levant avec certitude le devant fans s'impatienter, ny fans faire aucune force contre les cordes, pliant bien les jambes, \& qu'il marquera fes paulades. axce faci 


\section{ac monter à Cheval.}

lité , \& qu'il répondra au poinçon des deux coftez, avec la même pa = tience $\&$ liberté que j'ay dit prefentement, \& que le Cavalier con. noiffe qu'il n'y a aucun danger de mettre le bon Ecolier deflus.

On commencera encore autour. le pillier, de la même façon \& ordre que j'ay déja dit, \& aprés liavoir levé aux arrefts, on le conduira entre les pilliers fans le defcendre, où y écant attaché on le: careffera fort, fans fe fervir du poinçon, avant que luy avoir levé le devant par plufieurs fois, comme auffi fans luy avoir fait fuyr. les talons par plufieurs fois de cô. té \& d'autre, \&z le faire auffi tenir droit entre les deux pilliers de fois à autre, le careffer aufi entre tous, ces temps, afin de l'accoûtumer à l'obéiffance, à la patien. ce, \& à la jufteffe.

Cela eftant bien concerté, l'Ecuyer qui fera à piéd s'approchera doucement à cofté du Cheval,

$O$ iij. 
I66 De l'excellence de l'Art

cependant que celuy qui fera deffus levera delicatement le devane avec la gaule par deux ou trois fois, alors l'Ecuyer s'accordant avec fon Ecolier, \& voyant le Cheval en état, il appuyera delicatement le poinçon, pour voir fi à cette ayde le Cheval voudra faire quelque faut ou' capriole entiere, ou bien une demie, car quand pour le commencement le Cheval n'efpareroit, ou ne rueroie pas tout à fait, n'importe, pourvû qu'il témoigne vouloir pren. dre quelque cadence, \& aprés l'avoir careffé \& donné haleine, il faut réiterer cette Leçon, l'Ecuyer fe tournant d'un colté 82 . d'autre, \& fi on travaille de ce jugement, le Cheval donnera en peu de temps une bonne capriole. 
cinquiéme Leçon pour les Caprioles.

I le Cavalier obferve, que $S$ fon Cheval commence à connoiftre ce que c'eft que caprioles, \& qu'aprés qu'il en aura fourny une, qu'il fe prepare d'en donner deux : En un mot, qu'il réponde à l'aide de la gaule \& da: poinçon, auff facilement devant que derriere, il faudra commencer à le foûtenir un peu de la main, \& luy faire connoiftre que l'on ne veut pas quil s'abandon-. ne, ou tire fur les cordes du ca-veffon, \& ce afin qu'il puife faire ces fauts agreablement, \& fans forcer la main, fans toutefois le preffer ou battre, ne penfant pas. obtenir cette jufteffe en une Le. ģon, ny peut-eftre en vingt, ce lera felon ta prudence $\&$ la dif: pofition que tu connoiftras en tor Cheval, \& te fouviens qu'il n'y a point de plus grande faute en: 
168

De l'excellence de l'Art

cette forte de Manége, que celle qui oblige le Cheval de s'ennuyer, ou pour luy en trop demander, ou le battre avec violence $\&$ à contretemps.

sixiéme'Lecon pour les Caprioles.

I le Cavalier au bout de $\$$ quelque temps que ce foit, connoift que fon Cheval obéifle à la main, fans la forcer, je luy confeille de le commencer à courbettes, \& continuer cette Leçon deux ou trois jours, afin de connoiftre s'il aura affez de force \& de gayeté pour continuer les Caprioles, eftant tres certain qu'il eft impoffible que l'on puife faire fauter un Cheval quand il eft outré d'haleine, fi bien que luy en donnant fouvent, felon ce que je viens de dire, fi fon naturel eft de faucer, on le connoiftra bientoft:car le Cheval difpos \& repolé, 


\section{de monter à Cheval.}

\& qui entendra ce que nous avons déja dit cy-deffus., s'élévera de luy - même, \& prendra plaifir à fauter, voyant qu'on ne luy force, $\&$ que l'on ne luy contraint pas, \& ainfi connoiflant que cela part de la feule volonté, il obéira avec facilité \& bonne grace; c'ent pourquoy vous vous fouviendrez de travailler à l'air des caprioles, avec beaucoup plus de jugement, prudence \& fagefle qu'à tout autre air que ce foit, recherchant foigneufement toures fortes de moyens pour luy faire concevoir ce qu'on luy demande, tantoft entre les pilliers, púis la tefte à la muraille, tantoft dans un coin, quelquefois le long d'une carriere, \& $a$ ainfi fe fervans de tous les divers moyens \&. mouvemens de la main, de la bride, du caveffon, du contrepoids du corps, des aides, des cuiffes, des jambes, des talons, \&z du poinçon:

En un mor faifans toutes ces actions avec jugement \&z à propos, 
170 Del'exccllence de l'Art

vous parviendrez à un commencement de faurs, qui le conduiront par le refte qui fuivra à une entiere perfection.

Septiéme avis pour les Caprioles.

- E Cheval eftant affez fçavant pour bien execurer ce que vous avez oüy au Chapitre précedent, le Cavalier commencera fa leçon autour le pillier, premierement à courbettes, puis l'Ecuyer s'approchera avec l'aiguillon en main, \& l'Ecolier levant toujours à courbettes, l'Ecuyer aidera avec l'aiguillon, s'il en marque ou en fait une ou deux, on le çarreffera beaucoup, \& apriés luy avoir donné du pain ou de l'herbe, \& quelque peu d'haleine, l'Ecolipr prendra un petit poinçon, \&z aprés avoir fait un tour au perit galop leger, il aidera délicarement du poinçon, en foûtenant un peu le CheVal, afin de le fentir dans la main, 


\section{de monter à Cheval.}

que s'il donne deux ou trois cáprioles, il le faudra arrefter, luy levant le devant fort haut, \& le beaucoup carreffer, puis continuant de pas environ la moitié de la volte, il faudra le lever derechef à courbettes, puis luy aides comme la premiere fois; \& s'il continuë à bien obéir, vous ne manquerez de le bien carreffer, prenant bien garde de l'ennuyer: Et fi pour finir cette fepriéme Leçon, vous en pouvez tirer quatre ou cinq avec juftefe \& de bonne cadance, vous le renvoyerez à l'Ecurie avec quelque forte de fatisfaction.

\section{Huitiéme avis pour les Caprioles.}

T E Cheval eftant affuré entre les pilliers \& fur les volres, conme j'ay dit au Chapitre prec dent, vous continuërez ces Lecons autant de temps qu'il en faudra, avec la mêmz douccur \& patience 
772 De l'excellence de l'Art

dont je vous ay avertis, pour y rendre le Cheval certain, tant en l'o. béiflance de la gaule devant, comme du poinçon derriere, jufques à ce qu'il faffe fept ou huitcaprioles bien rcglées \& bien juftes, fans s'impatienter \& fe traverfer, ny forcer la main, \& fuppol'e qu'il falle auffi une volte entiere, ou une volte sz demie autour le pillier, avec la même obéiffance que j'ay marquée entre les pilliers.

Alors vous le pourrez conduire. le long d'une carriere ou muraille, où l'ayant quelque temps promené de cofté \& d'aurre, vous luy laifferez prendre le petit galop leger, le conduifant d'un bout à l'autre, \& 'e parerez fur les hanches à chacun des extrémitez, \& luy ferez lever le devant, luy faifant marquer des courbettes.

Et tout cela, afin de connoiftre Ii le Cheval eft libre au partir, s'il court dans la main, s'il a le vray appuy, s'il ne fe traverfe point : En 
un mot, pour fentir s'il a affez d'obéiffance \& de jufteffe pour. fauter par le droit, vous en uferez a vec l'ordie que je diray au Chapitre fuivant.

Newviéme avis pour mettre un Chevab Jur les Caprioles.

T Ors que le Cheval fera bien inturé, fe promenant le long de la carriere fans ardeur, \& qu'il obéit au petit galop leger, paranc $\&$ arreltant fur les hanches.

L'Ecolier luy pourra donner l'aide du poinçon, en foûtenant affez, pource qu'll ne s'enfuye rrop en avant, \& qu'il ne force pas la main en fautant.

Que s'il donne deux ou trois caprioles juftes il le faudra foudain arrefter, le faire reculer, luy lever le devant, \& le beaucoup carreffer, luy donnant du pain ou de l'herbe, puis au bout de quelque temps fuivre fon chemin de pas,

P iij. 
174 De l'excellense de l'Ar

puis luy laifrane derechef prendre le perir galop, le conduire jufques au bout de la carriere, où l'ayant arrefté fur les hanches s levé le devant, il le faudra cirer arriere, $\&$ aprés l'avoir Adité, le tourner à min droite, sc reprendre le chemin pour aller à l'autre extrémité.

Où ayant pris le petit galop, vous aiderez le Cheval, comme $j$ 'ay dit, \& l'obligerez à faucer en laidant jufte \& bien à propos, fans luy donner de faulles aides ou conrre-temps, en vous gardant bien de l'incommoder, vous accommodant à fon air, \& 2 prenant ces temps. avec la plus grande juftefie qu'il fera poffible.

Ce que vaus continuërez de la même methode fil long-temps, que le Cheval faute ou fournifle des caprioles juttes, bien reglées de même temps \& cadance, fans s'abandonner ny forcer la main jufgues au bour de la carricre, \& qu'il 
cantinuë cet air en allant $\&$ retournant.

Et pour cela y donner le temps \& la parience pour y parvenir, au bout duquel temps vous laifferez repofer voftre Cheval, \& ne le mettrez pas à tous les jours, vous affurant que fi vous rencontrez un Cheval qui en vienne jufques à ce point, qu'il n'aura gueres de compagnons.

C'elt pourquoy lors qu'il s'en rencontre quelques-uns, on les doit cherir comme ils l'étoient anciennement des Rois \& des Empereurs.

Dautant que dans les triomphes $\&$ dans les magnificences, aux entrées, $\&$ en tous les endroits, où on entreprend quelque chofe de beau \& de rare: il n'y a rien qui donne tant d'admiration aux regardans, $\&$ qui fafle aufli tant paroiftre le Cavalier, que lors que julte, droir \& ferme, il fait bien manier un Cheval à caprioles, étant le plus 
I7.6' De l'excellence de l'Art

beau de tous les airs, en ce qu'il doit s'élever davantage en haur, oì il fait voir qu'il participe plus de la qualiré de l'air, qui eft la définition que je luy ay donnée.

En outre, la perfection du $\mathrm{Ca}$ valier fe connoift plus à drefler les Chevaux en cet air qu'en nul autre, étant certainement le plus beau, \& le plus difficile.

De l'Air de deux temps, of un faut.

T'Ay déja parlé de cet air en ma. I premiere Edition, \& n'avois pas pouflé à bout tout ce que je diray prefentement, n'eltant pour lors mon deffein de traitter des airs relevez, \& Chevaux fauteurs.

Vous avez fans doute bien remarqué, que jay dit, comme je l'aflure encore, que l'on nomme cet air diverfement, fans repeter ceque j'en ay déja dit, je vous en- 


\section{de monter à Cheval.}

feigneray d'y parvenir ; il n'importe point du nom, pourvû que l'on fafle voir la verité, \& donner la. methode de ce que l'on veut faire entendre par paroles, \& executer en effer; quoy qu'il en foir, il eft vray de dire qu'il eft comporé d'une capriole, d'une courbette fort baffe, avec un mediocre temps ou pas; \& comme j'ay dit en paffant, pourvû que le Cheval foit tant foit peu difpos. Il aime $\&$ fournit affez aiférnent à ce Manege; pource qu'en faifant cette petite courbette $\&$ ce mediocre temps, il a le temps de prendre fa force, fi-bien qu'il peut commodément \&zlong-temps continuer ce Manege : Si-bien que le Cheval étant déja dreffé à caprioles, prend bien fouvent cet air de luy-même, ou fi cela n'arrive, il eft bien plus aifé au Cavalier de luy faire comprendre, l'ayant levé devant, fait faire des courbettes, fait fuyr les talons, \& le refte: que vous avez entendu. 
Suivant donc ce que je viens de dire, il faudra luy faire metre le caveffon, puis le promener de pas à l'entour le pillier \& le carreffer, afin de luy donner à connoiftre que lon ne le veut pas gourmander, quoy que l'on luy aye donné ledit cavefion.

Puis ayant cheminé de pas un tour ou deux, on le doit lever à courbettes, \& $s^{\prime}$ il obéit il le faut carreffer, puis s'aidant un peu des talons, foutenant la main aflez ferme, il luy faudra faire faire une capriole, puis lâchant la. main \& le chaffant en avant, effayer de le faire former un pas, puis aprés retenant la main, marquer le petit temps dont je vous ay parlé, \& finalement l'animant de la voix \& du poinçon, luy faire faire encore une capriole, \& ainfi faifant fuivre les aides a vec fermeté \& jufteffe jufques à deux ou trois fois, le carreffer le tirant arriere, puis le conduire derechef 


\section{de monter à cheval.}

au pas, \&. continuer de la même methode, puis le renvoyer à l'Ecurie.

Mais fi au premier jour de ton travail il ne vouloit pas t'obéir.

Il faudroit le mener au perit galop une volte ou deux, puis faire pofter un homme derriere luy, avec un aiguillon, afin de fecourir tant l'homme que le cheval, \& s'il répond, à la bonne heure, finon $\&$ qu'au lieu d'obéir il fe tranfportât, fe traverfant avec beaucoup de defobéiffance, on y apportera les. remedes que je vous wais enfeigner en la Leçon fuivante.

Deuxiéme Leçon pour l'air de deux temps or un faut.

I le cheval continuoit à fe dé$\$$ fendre par les efcapades que jay nagueres dites, il faudra avoir recours aux pilliers, auquel luy étant attaché vous le leverez 
180 De l'excellence de l'Art

courbettes, s'il obéit vous le car refierez, puis continuant vous le ferez aider avec le poinçon, le fai-s fant foûtenir par l'homme qui fera deflus, auffi-bien de la main comme du talon, \& luy ferez faire un faut, \& ferez cecy pour cette raifon: car le cheval étant attaché, ne fe pourra tranfporter en avant: fi-bien qu'urant de cette methode $\&$ douceur, \& fans le molefter ny l'ennuyer, on luy pourra bien-toft faire concevoir ce que l'on defire de luy, ainf il reprendra cette cadance que fa fougue luy avoit fait perdre, faute diavoir bien connu ce que l'on defiroir, où eftant affuré, reftant dans la main \& les talons, il fe laiffera facilement conduire fur les voltes, ou par le droit felon la volonté de fon Miltre, eftant déja dreflé à caprioles, comme j'ay dit cy-devant.

Mais fi c'eftoit un cheval qui n'euft point efté drefl'e, \& que l'on connut quelque difpoficion natu - 


\section{de monter à Cheval.}

relle en luy, pour cette forte d'air ou Manege.

Il faudroit en ufer de la même maniere que j’ay enfeignée pour les.caprioles, à la referve de cecy, fçavoir eft, que lors que vous voudrez le faire fauter, il faudra donner les deux premiers temps avec lenteur \& adrefle, le chaffant en 2vant, afin qu'il aye le temps de s'accommoder, puis qu'il fourniffe fon faut de même vigueur que les caprioles , \& de la mếme liaureur, s'il fe peut.

De l'Air des Balotades.

'Ay déja dit en ma premiere Edi$\int$ tion, que les Balotades eft un air bien approchant des caprioles, \& n'en differe, comme j'ay fair voir, qu'en ce que le cheval de caprioles étant en l'air, ruë \& efpare de toute $f_{2}$ force, $\&$ aux Balotades, quoy que le cheval s'élevấ 
182 Del'excellence de l'Art

aufi haut que les caprioles, il ne ruë qu'à demy, pour le temps il eft d'egale cadance avec les caprioles \& les aides pareilles, comme auffi la methode $\&$ le chemin pour y parvenir y eft tour femblable.

Mais il faut que le cheval prenne naturellement cet air, qui aurrement feroit tres-difficile de luy obliger ou apprendre.

De l'air des Croupades.

TL m'eft fâchcux de repeter î 1 fouvent la même chofe, mais je fuis neceflité de dire encore cette fois, que les.Croupades, êt le même air \& la même chofe que les balotades, n'y ayant difference aucune en la hauteur, mefure ny cadance, $\&$ fi on y en peut remarquer quelqu'une, c'eft qu'aux balorades le cheval efpare à demy, faifant voir ces fers exterieu- 
rement , \& aux Croupades le che$\checkmark a l$ trouffe les jambes, plie les pafturons derriere fous luy, comme s'il fembloir les vouloir tirer jufques au ventre, \& retombe, prefque les quatre pieds enfemble ayant le temps tant foit peu plus court que celuy des balorades: c'eft pourquoy on les confond fouvenr l'un avec l'autre.

Voila ce que je puis dire pour l'inftuction de ceux qui aiment l'exercice des chevaux fauteurs; refte d'avertir le Cavalier, que lors que le cheval fera obéiffane en ce point, il eft tres-afluré qu'il en fera tout ce qu'il luy plaira pour tous les autres Maneges, pourvû. qu'il travaille avec les précautions, le jugement \& la parience dont je lay averty; Je luy diray encore, qu'il faut que le Cavalier fuive les aides \& les mouvemens du cheval, $\&$ que le cheval les reçoive pareillement de luy, autrement ny l'un ny l'autre ne pourroient rien faire qui vaille. 
Je diray aufili, que le bel ä bon homme de cheval ne fçauroit fai- re rrop peu d'actions du corps ny des jambes : c'eft pourquoy il doic continuellement travailler à cacher tant les aides que les châcimens, \& les faire les moins apparens qu'il pourra : car à veritablement parler, il n'y a rien qui choque plus la vúë des regardans, que ces vilaines aides \& ce branlement de corps $\&$ de jambes, c'eft ce qui me fait prier ceux qui auront cette mauvaife grace, de faire leur polfible pour s'en corriger.

En un mot, fi le cheval pouvoir manier de la feule vigueur de l'homme, fans que l'on s'apperçût d'aucune aide ou châtiment, il auroit trouvé la vraye pierre Philophale, \& le dernier fecree en l'Art de monter à cheval.

J'acheve \& prie le Lecteur de confiderer, que fi javois voulu rédiger par écrit, \& parricularifer 
de monter ä Cheval.

par le menu toutes les Leçons dont il eft befoin de fe fervir en routes rencontres, il me feroit du tout impoffible, étant tres-vray que nôtre maniere de travailler n'étant. conduite que felon les occaffions n'y ayant point de regle certaine en noftre Art, il me feroit tresdifficile de l'exprimer fur le papier, d'autant plus que les actions de l'entendement font beaucoup difficiles à exprimer par écrit, puis qu'il eft tres-conftant, que la belle methode confifte au jugement, \& ì: faire, comme l'on dit, la guerre a: l'œil, changer de moment en moment d'action \& de conduite, felon que la neceffité le requiert, \& travailler plûtoft la cervelle du cheval, que ruiner fes jambes.

C'eft pourquoy vous m'excuícrez fi je ne m'exprime fi-bien par le difcours, que je pourrois faire en travaillant devant ceux qui s'y connoiffent, je leur ferois admirer ce. que mes écrits ne peuvent démon-trer.

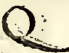




\section{De l'excellence de l'Art}

Ceux qui voudront prendre la peine de voir ce peu que j'en ay écit, verront la franchife \& la bonne volonté avec laquelle j'ay agy , \& mis rous mes foins pour fatisfaire le public : fi je ne fuis affez fçavant ny aflez éloquent pour avoir répondu à leur envie \& loüable curioficé, je feray mes efforts pour me rendre plus capable $\& z$ micux difant, en la derniere Edirion que je pretends faire bienroft voir au jour, avec rour le luftre \& l'éclat dont je me pourray avirer.

Les parties du Cheval les pius ne. ceffaires de fcavoir au bois Cavalier.

Uoy quill fe trouve beaucoup de perfonnes, qui ay ene quelque connoifunce des parties du cheval, neanmoins il y en a auff ba plípart qui ne les ont pas re- 


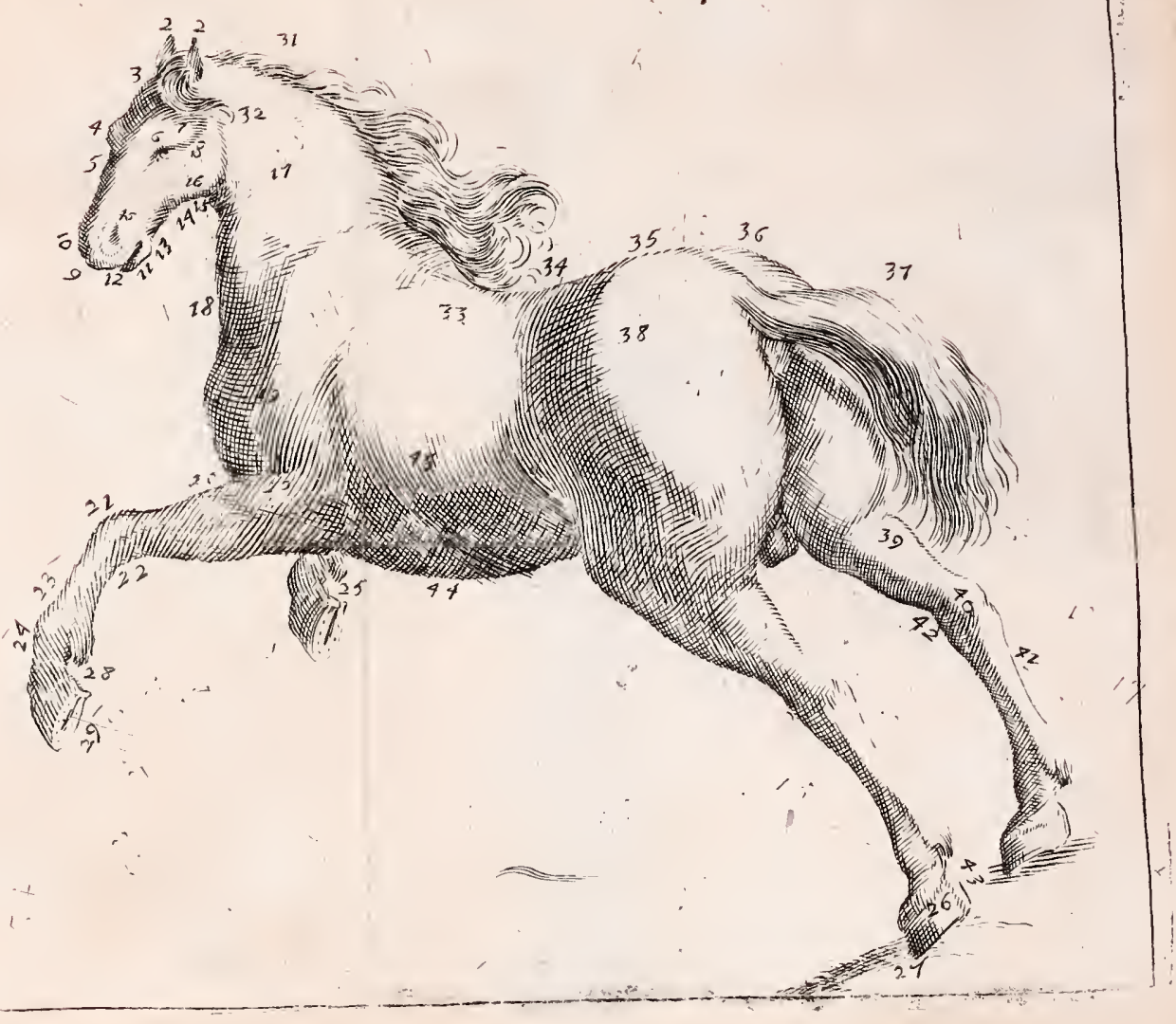




\section{de monter a Cheval.}

marquées, \& principalement les Etrangers, ce qui m'oblige de vous en nommer celles qui font neceffaires, n'eftant pas mon deffein de faire l'anatomie du Cheval, aprés que tant d'autres ont fi dignement traité de cetre matiere : je nommeray feulement les principales, \& celles qu'il faut \& eft befoin que le Cavalier connoiffe, par les chiffres fuivans.

1. La tefte, 2. l'œil, 3. les oreilles, 4 . le front, 5 . le chanfrin, 6 . les fourcils, 7 . les falieres, 8. les narrines, 9. les lévres deffus \& deffous, ro. la place de la belle marque, ou étoille, Ir. la bouche, 12. les barres, r3. le palais, I4. les replis, ou crans du palais, où on donne les coups de corne, is. la fous-barbe, 16. le canal, 17. la gannache, is. la braye, 19. les machoires, 20. le tuper, ou le bouquer, 2r. les crains, 22. l'encolure, 23. le poitrail, 24. les épaules, 25 . le bras, 26. Ie genoüil, 27 . Ie canon, 28. le

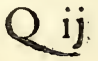


r88 De lexcellence de l'Art

bouliet, 29. le pafturon, 30: le fabot; la corne; ou la couronne, 3 . les talons, 32: la folle, 33. la fourchetre, 34. la pince du pied, 35. le petitpicd, ou le vif qui eft enfermé dans Ia couronne, $\&$ deffous la folle, 36. le garrot, 37. la place de Ia felle; 38. le deffus du nombril, 39. les reins, 40. la crouppe, $4 \mathrm{r}$. les hanches 42. les cuiffes, 43: le jarree, 44 . la jambe, 45 . le boullet derriere, 46: le paturon derriere, 47 . le pied de derriere, fabot, corne, our couronne, idem. Pour les autres parties dir pied de derriere, elles fe nomment comme celuy du devant; 48. les coltes, 49. le ventre, 5o. les genicoires, 5i. le fourreau, \& la. vicrge, 52: les Hancs. 
Les endroits oì viennent ordinaire ment les maux of fluxions. aux.Cheraux.

A Prés vous avoir dunné la conAnoiffance des principales parries du cheval par leurs noms propres, je defire encore vous nommer par les chiffres fuivans, \& vous marquer les endroits où viennent ordinairement les maux \& les: fluxions aux chevaux, afin que les connoiffans, vous y puiffiez donner remede $8 z$ les guerir, avec la methode que je vous donne dans. les remedes quifont à la fin de ce Livre.

La gorme fe connoift dans Ia braye lors qu'elle eft pleine, \& mêlée de petits durillons, au chif: fre $I$.

La morve fe connoift, lors que le cheval jette abondamment par les, nazeaux une vilaine humeur:

Q iij. 
jaunâtre, mêlée de fang $\&$ puante dans les nazeaux, au chiffre 2. La poux fe connoift au flanc, au chiffre 3. lors que le cheval fouffle, \& en bat extraordinairement: la bouche échauffee fe connoift, lors que le cheval a les barres $\&$ la bouche pâle, \& le poil du tronc de la queuë heriffé, au chiffre 4 . la bleffure eft fort dangereufe fur le garrot, au chiffre 5 . comme auffi audeffus du nombril, au chiffre 6. les fureaux fe connoiffent $\&$ paroiffent ordinairement au milieu du canon, montant vers le genouil, au chiffre 7 .

Les malandres viennent à la jointure du genouill par le dedans, au chiffre 8 .

Les foulandres fe font voir au dedans du jarret, au chiffre 9. La blême fe connoift deffus la folle, au chiffre ro.

La fême vient comme une petite fente, dont il fort du fang à colté de la couronne, au chiffre Ir. 
Lancaftelle ou pied ferré, fe connoift lors que les talons s'approchent fi prés l'un de l'autre, qu'il foulent le petit pied, au chiffre I2.

La mulle traverfe, la crevaffe, \& les javars, paroiffent aux pafturons derriere ou devane, au chiffre 13 .

Les mollettes fe connoiffent un peu plus haur que le boulet, foir derriere ou devant, au chiffre I 4 .

Les enflures des jambes font ordinairement au boulet, lors qu'elles viennent par le travail, au chiffre 15.

Le mal du gros tendon paroift le long du bras \& du canon par le dedans, jufques vers le boulet, au chiffre 16.

Le nerf ferru ou foule, fe connoift a la groffeur de la jambe, \& tors que le cheval butte \& bronche fouvent auffi, au chiffre 17 .

La galle paroift ordinairement au garrot, $\&$ le long de l'encolure, au chiffre I8. 
192

De l'excellence de. l'Art

Le farcin paroift en toutes les parties du corps du Cheval, par des boutons \& perites cordes, dures \& longuettes.

Les courbes paroiffent aux jarrers dehors \& dedans, au chiffre I9:

Les efpervins paroiffent au-deffus $\&$ à cofté du jarret, au chiffre 20.

Les arreftes paroiffent depuis le jarrer jufques au bouler; par dehors aux jambes de derriere, au chiffre. $2 \pi$.

Les porreaux paroiffent principalement au derrjere, au chiffre 22.

Les peignes paroiffent autour la couronne $\&$ au-deffus, avec une. petire humidité, $\&$ le poil heriffé au chiffre 23:

Les grappes paroiffent aux jambes de derriere, au chiffre 24 .

Enfin toutes les fluxions viensent ou peuvent paroifte aux quatre jambes, mais ils viennent plus, 


\section{de monter à Cheval.}

plus ordinairement au derriere, qu'au devant.

Et au contraire, les Chevaux s'ufent ou foule pluftolt les jambes devant que derriere.

Des divers poils des Chevaux, Go des bonnes of mawvaifes marques.

TL eft affez probable que l'humeur, le temperament du Cheval, comme fa qualicé dépend àes quatre Elemens, \& fe conforme plus avec celuy duquel il participe davantage; par exemple, s'il tient de la terre plus que des autres, il fera morne, pefant, melancholique , \& de peu de cœur , \& pour l'ordinaire.

Il eft de poil noir, mal teint, fans aucun feu.

Ou poil de Cerf, ce quion appelle fauve, ou de poil de fouris, gris falle, ou aurres couleurs mêlées. 
194 De l'excellence de l'Art

S'il parcicipe de l'eau, il fers phlegmatique, tardif, lent, $\mathrm{mol}$, \& peu d'éperon, il eft d'ordinaire blanc.

S'il tient plus de l'air, il fera fanguin, prompt gaillard, \& agile en fes mouvemens, \& fera pour l'ordinaire bay, duquel que ce foit.

S'il tient plus du feu, il fera colere, legere, ardent \& fauteur, fans toutefois avoir beaucoup de force \& de nerf, \& $\&$ doit eftre le plus ordinairement d'un Alzan, reffemblane à la tlame, ou à un charbon ardent.

Mais lors qu'avec la deuë proportion il parcicipera de rous les quatre Elemens enfemble.

Alors il approchera autant qu'il fe peut de la perfection, \& doit eftre bay caltin, ou gris pommelé, roüan nommé telte de more, ou alzan obfcur, ou alzan brûlé, qui font de tous les poils les plus enimez, \& fone fans doute de 


\section{de monter à Cheval.}

plus forte, robufte \& gentille nature.

Aprés ceux que vous venez d'entendre, ceux qui font plus eftimables fone ccux qui en approchent le plus.

Comme le bay doré \& rouge en couleur, ou le vericable bay ob?cur, pouvâ qu'il n'aye pas le rour des yeux, le mula, ny les flancs lavez.

Le roux ou abzan rubican, le blanc mouchecté de noir, ou de fcu, les gris argentez, avec les cxtremitez noires.

Vous obfervorez aufi que de tous les mauvais poils, rous ceur qui aurone les extremitez noirs, \& une raye noire, depuis le haut de La queuë, tour le long de l'échine, jufgues au garot, feront les meilleurs.

Mais il faur aumi vous avertir, que de quelque bon poil que puife eftre le Cheval, fut-il du bay excellent quejay marqué, ou du gris 
$\$ 96$ De l'cxcellence de li,Art pommelé, ne fera pas ordinaire. ment tour parfait, s'il n'a quelque partie de aduftion aux parries baffes, ou du moins doivent entre noires.

Er bien que de tous poils il fe rencontre de bons Chevaux, je vous ay bien voulu donner cet avis, tiré de l'experience qui s'apprend rous les jours dans l'exercice $\&$ la pratique de leur complexion.

Vous noterez auffi que les Cheyux qui ont par trop de blanc, font naturellement foibles, comme les auberes, les pyes mal marquez, les gris fales, \& leurs femblables.

Voila ce que j’ay jugé à propos de vous dire touchant les divers poils des Chevaux, je vous diray maintenant un petic mot touchant les plus confiderables marques.

En premier lieu, le Cheval bien marqué doir avoir les mare 


\section{de monter à cheval.}

ques blanches des pieds, qui ne foient pas trop hautes en montant le long de la jambe, \& moins elles montent fur les jointures des pafturons, \& plus elles font à eftimer , \& encore qu'il y ait bien fouvent de l'abus en tous les fignes, \& qu'on en voit des effets contraires, je veux vous enfeigner quels font les meilleurs, \&z quels font les pires.

Celuy, qui a la marque blanche du conté de la Lance, fera fouple \& maniane, mais il eft eftimé malheureux, le blanc du cofté de la main de la bride, n'eft pas à eftimer, le blanc du pied droit s'appel Arzel, on le tient fort mal. heureux en combat ou rencontre, quelque droit qu'il puiffe eftre, car il eft d'ordinaire vicieux \& infortuné.

Celuy qui a du blanc du côté du montoir, eft beaucoup oftimé : il eft de bon coeur \& grand coureur. 
Celuy qui a du blanc aux dcux pieds de devant, fera mal-heureux.

Celuy qui a du blanc à deux pieds fcul mant, eft bien marqué, lors quavec cola il a la marque ronde \& blanche au front, que l'on appelle l'é oille.

Le Marqué de blanc aux quaare picds fra de bonne nature, doux \& paifible, mais il a peu de force.

Le blanc de la lance du pied: droit s'appelle travé, \& eft dangercux.

Le blanc de la main de la bride dupied droir s'appelle entre-travé, il elt de femblable nature, de l'ar$z e l, 8 z$ encore pire.

Le blanc de la main de la lance \& du pied du monroir, s'appelle auffi entre-travé, eft de la même nature, mais il eft moins dangereux, \& 8 on le tient de grand coeur \& valeur.

On remarque aufili, que tane le travé que l'entre-travé, s'en- 


\section{de monter à Cheval.}

gendre en certe forte au ventre de la mere; fibien qu'il fe mer les. pieds enfemble, \& elt en danger de tomber.

Le Cheval qui n"a aucune marque blanche, eft fouvent ramingue \& rebours, \& pourtant lors qu'il eft reduit, il doit eftre tresbon.

Si le Cheval a l'épy feul, ou accompagné avec l'épée Romaine fur le col long des crains, il fera heureux, \& d'autant plus qu'il paffera d'un cofté \& d'autre.

Er fera encore meilleur, lors qu'il l'aura fur le front, de plus, cela fait connoiftre le Cheval franc \& loyal, \& heureux en guerre, \& principalement lors qu'il les aura fur les dcux hanches du colté du trone de la queuë, comme auffi là où il ne fe peut regarder, $\&$ combien qu'il cû́t les marques blanches \& mauvaifes, neanmoins ayant les efpits cy-deffus marquez, il fera non-feulement en partie,

$R$ iiij 
20o De l'excellence de l'Art

mais auffi tout à fait retiré de ces mauvaifes influences.

Mais lors qu'il a les efpits ou remoulin à l'endroir de l'épaule, ou deffus le cour, ou en aurre lieu où il le puifle voir : on tient ce figne malheureux, \& fera pire, dautant qu'il fe trouvera prés du cour.

Vous. fçaurez auffi pour le dernier avis de ce petit moyen, de connoiftre les bons \& mauvais poils, comme les bonnes ou mauvaifes marques. Il ne faut pas croire que le Cheval, quoy qu'il fût accomply de toutes les perfections, en poil \& avantageufes marques, $\&$ du refte proportionné \& organifé de tous les dons de la natu. re, qu'il puiffe de foy-même bien faire, \& qu'il peut bien manier fans l'are \& belle merhode du bon Ecuyer. C'ent ce qui feroit impoffible, comme je feray voir en fon licu. 


\section{de monter à Cheral.}

2u'il ne faut pas fe fervir d'un Cheval, depuis que l'on l'a deftivé au Manege.

Omme les Chevaux de chafle, les Chevaux de voyage, $8 z$ ceux qui fervent d'ordinaire, ne fe trouvent que rarement propres air Manege: Je dis par la même raifon que ceux que l'on deftine au $\mathrm{Manege}_{r}$ doivent eftre peu ou point montez de qui que ce foit , $\&$ principalement de ceux qui n'entendent pas le métier.

Et dautant que je fçay bien l'impatience en laquellefont d'ordinaire ceux qui or t des chevaux à l'Academie ; J'ay fait ce Chapitre exprés en forme d'avis \& de confeil irrevocable, afin que cette confideration leur ofte cette envie, qui leur eftant tres-inutile, empêche leurs chevaux de profiter, \& s'ils les montoient, les rebuteroit-on du Manege, pour beaucoup de raifons. 
202 De l'excellence de l'Art

La premiere eft, qu'il faut que le cheval foit toujours frais \& gaillard lors qu'il fera monté ; car s'il eft las ou fatigué, il fera pareffeux, \& n'obéïra qu'à coup d'eperon.

La feconde, que fi le cheval ne fe plaift à fa befogne, c'eft en vain que le Cavalier travaille, cftant tresconftant , que foit homme, foit bêre, s'il ne prend plaifir à fon travail, il n'y réüfira jamais.

Il arrive en troifiéme lieu encore pis: fil homme qui travaille un cheval, \& n'y encende que fort peu, il Gâtera pluftoft le cheval qu'il ne l'avancera : c'eft pourquoy on dit qu'il. eft fort exquis.d'eftre bon Medecin, mais qu'il eft tres-dangereux d'eftre demy Medecin.

La même chofe fe peut dire d'un. homme quife croit bon homme de cheval, \& ne l'eft pas à demy, fi bien que fi tels gens fe veulent mêler de drefler des chevaux un peu commencez, ils les retardent de plus de deux mois, ou les mettent 


\section{de monter à Cheval.}

peut-eftre en état de n'eftre jamais. achevez juftes, à caufe de la mauvaife habitude qu'ils leur donnent.

En quarriéme licu, le cheval eft un Animal quelquefois, \& le plus fouvent colere \& impatient, $\&$ lors qu'un ignorant le veut rechercher de quelque chofe jufte, $\&$ que c'eft hors de temps \& mefure, le cheval ne connost pas ce que ce pauvre habitant de la terreluy demande, \&z ainfi ils fe rendent auff irraifonnables l'un que l'aurre, fans qu'il y aye aucune concordance entr'cux.

En cinquiéme lieu, le cheval qui a bien commencé, \& qui ou-. tre cela eft encore doüé de bonne memoire, fereflouvenant des bonnes leçons du bon Ecuyer, lors qu'il vient à connoiftre $\&$ fentir des aydes toutes contraires à ceux que la bonne habitude luy a donné, il fe met en defordre, perd patience, \& ne fçait plus ce qu'il doit faire. 
204 De l'excellence de l'Art

C'eft ainfi que la moralité de la Fable de Phaëton nous enfeigne le defordre qu'il luy arriva, eftant précipité dans la mer, \& fes chevaux à vauderoute, qui penferent embrafer le monde, manque de la bonne conduire qu'il faut pour guider \& conduire ces fuperbes courciers du Soleil.

En un mor, je donne unavis $\$ 2$ un confeil irrevocable, à ceux qui voudront avoir un cheval bien achevé, de ne le faire monter à perfonne, \& lors que l'on le conduira au Manege ou ailleurs, que l'on le meine en main jufqu'à ce qu'il foit achevé, ce qui s'appelle eftre bien dans la main \& dans les talons.

Mon Leateur, je croy qu'il ne fera pas inutile de vous avercir du. foin que j’ay pris d'augmenter \& de corriger cer cuvre de l'Art de. monter à Cheval; Et cncore plus particulierement, de vous dire, comme j'ay jugé à propos, d'y a jou- 
cer une fcconde parric, pour les remedes des maladies \& infirmitez des chevaux, où j'ay voulu prendre un foin particulicr, que jay fait mon pouvoir pour me refouvenir des remedes les plus exquis, dont je me fuis fervy, les ayant tous éprouvez par plufieurs \& diverfes fois, tant pour moy que pour mes amis, \& en tous les pays \& rencontres où je me fuis trouvé. Je fçay bien que beaucoup de perfonnes en ont écrit, \& que tous les livres en font remplis, je fçay bien auffi qu'il en eft comme des autres chofes qui concernent la Medecine, \& qu'il y a quantité de gens qui font Medecins fans a voir jamais étudié, ny faic profeffion de la Medecine, \& qui donnent des remedes à tour le monde felon leur caprice \& fans aucune connoif. fance. Il en elt tout de même de beaucoup de gens qui en ufent de la fembable forte pour les chevaux, luer ordonnans des remedes felon 
leur fcience \& à leur mode. Pour moy je m'eronne comment tels ignorans ofent feulensent s'émanciper d'ouvrir la bouche pour donner des ordonnances fans fondement, fans fcience, fans pratique, ny fans aucun ordre ny methode. Erla cho. fe la plus abrurde \& ridicule que l'on doit remarquer en ces fortes de gens, eft que la plufpart fone du menu peuple, fortis de la lie dumonde, 8\% pourtant ils ne fe contentent pas de vouloir paroifte fçavans, mais ils voudroient encore ôter, s'ils pouvoient, la réputation à ceux qui fon veritablement fçavans, en experience, en prarique \&z en fcience. Voila, mon Lecteur, ce qui empêche que les remedes de tous ces genslà ne réuffiffent pas, \&z bien au contraire ces diverficez de remedes mal entendus \& mal appliquez, fans la connoiffance du mal, font un contraire effet, \& nuifent beaucoup plus qu'ils ne proficent. Ce qui me fait conclure qu'il n'ent 


\section{de monter à Cheval.}

que de s'addreffer aux fçavans, fi fon veur bien réüfir à quoy que ce foit, tant pour dreficr les Chevaux que pour les guerir de leurs maladies: ce n'eft pas mon deffein de m'arrêter en ce lieu à déduire tout ce que je pourrois avancer fur ce fujer. Je ne veux blâmer perfonne, $\&$ veux croire que chacun fait tour pour le mieux, je me contenteray d'avertir mon Lecteur \& tous ceux que je defire fatisfaire, aufi-bien dans mon avis que dans mes remedes. Du refte, je puis affurer le public que je travaille pour fon utilité , \& qu'il n'y a point d'autre morif qui m'oblige, que le deflein que jay toujours eu, en mettant tous mes foins, mes labeurs \& mes peines pour contenter les curieux $\&$ les honneftes gens. Recevez donc, s'il vous plaint, ma bonne volon ré, $\&$ me faires la grace de croire, que tous mes foins, mes veilles \& mes pcines, ne feront jamais voüez qu' l'utilité publique. 
208 Del'excellencedel'Art

Avant que de parler des maladies des Chevaux, je defire vous donner la connoiflance des poids de la Medecine, comme la vertu des huilles, unguents, emplaftres, eaux, graiffes $\&$ abfonges propres pour guerir les Chevaux, ce qui eft tres-neceffaire au Cavalier.

Fin de la premiere Partie.

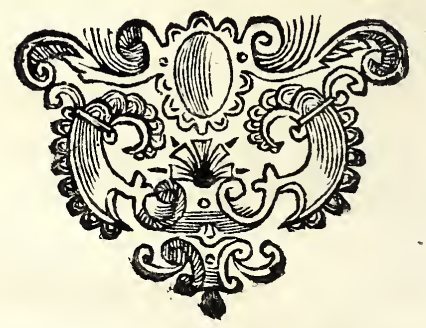



